Issued iny Sandia National Laboratories, operated for the United States Department of Energy by Sandia Corporation.

NOTICE: This report was prepared as an account of work sponsored by an agency of the United States Government. Neither the United States Government nor any agency thereof, nor any of their employees, nor any of their contractors, subcontractors, or their employees, makes any warranty, express or implied, or assumes any legal liability or responsibility for the accuracy, completeness, or usefulness of any information, apparatus, product, or process disclosed, or represents that its use would not infringe privately owned rights. Reference herein to any specific commercial product, process, or service by trade name, trademark, manufacturer, or otherwise, does not necessarily constitute or imply its endorsement, recommendation, or favoring by the United States Covernment, any agency thereof or any of their contractors or subcontractors. The views and opinions expressed herein do not necessarily state or reflect those of the United States Government, any agency thereof or any of their contractors.

Printed in the United States of America. 'This report has been reproduced directly from the best available copy.

Available to DOE and DOE contractors from

Office of Scientific and Technical Information

PO Box 62

Oak Ridge, TN 37831

Prices available from (615) 576-8401, FTS 626-8401

Available to the public from

National Technical Information Service

US Department of Commerce

5285 Port Royal Rd

Springfield, VA 22161

NTIS price codes

Printed copy: A15

Microfiche copy: A01 


\author{
SAND90-2804 \\ Unlimited Release \\ Printed November 1990
}

\title{
RENEWABLE ENERGY PLAN OF ACTION FOR AMERICAN SAMOA
}

\author{
John W. Shupe \\ U.S. Department of Energy \\ San Francisco Operations Office \\ Pacific Site Office \\ Honolulu, Hawaii 96850
}

\author{
John W. Stevens \\ Design Assistance Center \\ Committee on Renewable Energy Commerce and Trade \\ Sandia National Laboratories \\ Albuquerque, New Mexico 87185
}

\begin{abstract}
American Samoa has no indigenous fossil fuels and is almost totally dependent for energy on seaborne petroleum. However, the seven Pacific Islands located at 14 degrees south latitude that constitute American Samoa have a wide variety of renewable resources with the potential for substituting for imported oil. Included as possible renewable energy conversion technologies are solar thermal, photovoltaics, wind, geothermal, ocean thermal, and waste-to-energy recovery. This report evaluates the potential of each of these renewable energy alternatives and establishes recommended priorities for their development in American Samoa. Rough cost estimates are also included. Although renewable energy plaxnning is highly site specific, information in this report should find some general application to other tropical insular areas.
\end{abstract}




\section{RENEWABLE ENERGY PLAN OF ACTION FOR AMERICAN SAMOA}

\section{PREFACE}

The current energy requirements of the Pacific Islands are met almost totally by imported oil. Continued dependence on this finite resource, with its uncertain availability and cost, jeopardizes both the economic and political stability of these isiand ierritories.

In recognition of the critical energy needs of the U.S. territories in both the Caribbean and the Pacific, Congress established Section 604 in P.L. 96-597 (the Omnibus Territorial Act; December 1980), which called for the development of comprehensive energy plans that would lead to the reduction of imported petroleum. Congressional intent was that this reduction would be accomplishea primarily through the replacement of oil imports by indigenous renewable energy resources.

Although no funds were appropriated to implement this authorization, the U.S. Department of Energy (DOE) conducted a comprehensive two-year study of the Caribbean and Pacific territories, resulting in the Territorial Energy Assessment Final Report, completed in December 1982. This report provided an excellent overview of geographic, socioeconomic, and energy-related statistics and issues--as well as a general inventory developed tor each of the eight U.S. territories of those renewable energy alternatives that showed potential as substitutes for imported oil.

In the intervening eight years, there was little change in the near-total dependence of the island territories on imported oil. This resulted from 1) the drastic reciuction in the cost of oil from around $\$ 30$ to $\$ 12$ a barrel in $1983 ; 2$ ) the relatively slow market penetration of renewable energy at the national and global levels; and 3) the limited amount of Federal funding allocated for the installation of renewable

ॠConsistent with the terminology of the Omnibus Territorial Act, the generic term "territories" will apply both to territories and commonwealths, as well as to former and current entities of the Trust Territory of the Pacific Islands. 
energy projects in the Pacific territories. The insular economic development that has taken place during the past decade has been accomplished primarily with energyintensive industry--tourism, shipping, light manufacturing, and aquaculture--so that the territorial demand for oil has grown significantly.

Today, with the price of oil near $\$ 40$ a barrel because of the current Middle East situation; with the concerns on global warming; and with marked improvements in the liie-cycie economics and reliability of many of the renewable technologies, it is appropriate to look anew at this issue. Ultimately, these island territories must relinquish their dependence on imported oil, and the timing may be right to initiate this transition with the introduction of selected renewable energy options.

This concept was reinforced at the National Energy Strategy Hearing held in Honolulu on January 11, 1990. This was one of 15 public hearings conducted throughout the USA by DOE Secretary James Watkins to obtain input for the development of national energy policy and program decisions. Representatives from Hawaii, American Samoa, and the Commonwealth of the Northern Mariana Islands were quite effective in presenting testimony that showed that the energy problems and opportunities of the insular areas are vastly different from those of the mainland United States. The Pacific Island Hearing participants emphasized 1) their near-total dependence for energy on imported oil--the majority of which is foreign crude; 2) the long shipping supply lines, which become quite vulnerable during emergency, short-fall conditions; and 3) the potential of their indigenous renewable energy resources as substitutes for imported oil.

The following Renewable Energy Plan of Action for American Samoa presents an up-date both on local conditions in American Samoa and on the changes in the various renewable energy technologies over the eight years since the Territorial Energy Assessment Firal Report was prepared. This plan of action is also more specific in establishing priorities and recommending time frames for proposed installation. However, its purpose remains totally consistent with Congressional intent in mandating the original energy assessment--to reduce territorial dependence on imported oil through the development of indigenous renewable energy resources. 
CONTENTS

Page

EXECUTIVE SUMMARY

SECTION I. General Background Information ............................................. 5

Geographic Overview.................................................................. 5

Employment, Economic, and Financial Data ......................................... 6

Transportation and Power............................................................... 8

SECTION II. Planning for Renewable Energy Development............................. 11

The Territorial Energy Assessment ........................................................ 11

Five-Y'ear Plan of the American Samoa Power Authority............................ 12

SECTION III. Procedure for Establishing the Renewable Energy

Plan of Action for American Samoa .......................................... 17

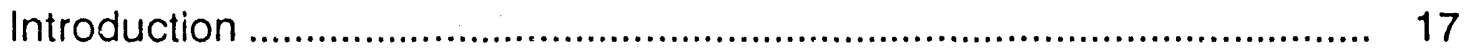

Site Visit to American Samoa ............................................................ 17

Renewable Energy Consultants ......................................................... 19

SECTION IV. Evaluations and Recommendations for Renewable Energy Technologies ............................................................ 23

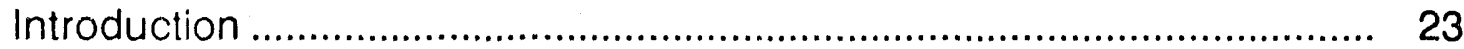

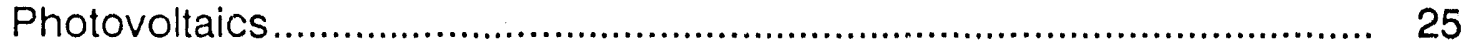

Solar Thermal Energy Systems ....................................................... 39

Solar Hot Water Supply Systems........................................................ 39

Solar Industrial Process Heat (IPH) Systems ….............................. 48

Wind Energy Systems .................................................................. 52

Battery Systems ……..................................................................... 61

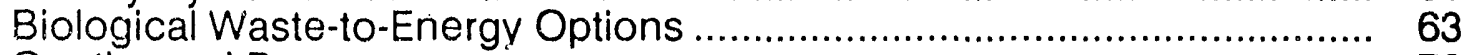

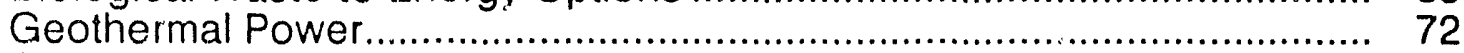

Ocean Thermal Energy Conversion ........................................................ 79

SECTION V. Summary of Recommendations and Conclusions ....................... 91

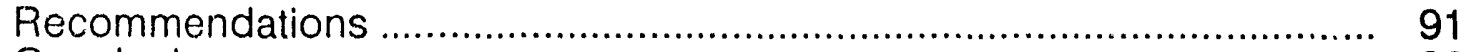

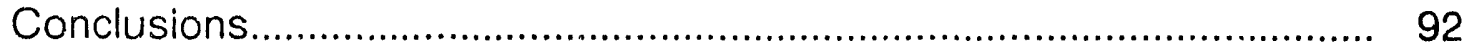

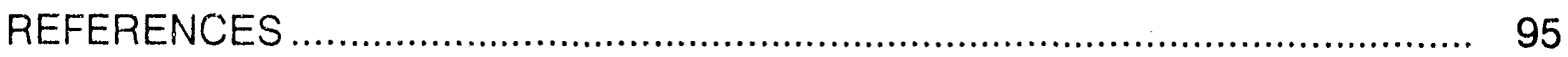




\section{CONTENTS}

Page

APPENDIX A Historical, Cultural, Political, Demographic, and Societal Information for American Samoa......................... A-1

APPENDIX B Biological Waste-to-Energy Options for American Samoa; Christopher Rivard.

B-1

APPENDIX C Recommended Exploration Program for Geothermal Development in Americari Samoa; Phillip M. Wright.

APPENDIX D Prospects for Wind Energy in American Samoa; Dennis L. Elliott.

D-1

APPENDIX E Preliminary Evaluation of Potential OTEC Sites; Andrew Trenka and Elizabeth Udui. 


\section{LIST OF FIGURES}

Figure Page

1 Typical "Stand-Alone" Photovoltaic System ............................................ 27

2 Typical Large Utility Intertied Photovoltaic System................................... 28

$3 \quad$ Solar Domestic Hot Water System...................................................... 41

$4 \quad$ Solar Thermal Industrial Process Heat System ..................................... 49

$5 \quad$ Typical Utility-Intertied Wind Energy System ........................................... 53

$6 \quad$ Flow Diagram for Biological Waste-to-Energy System ............................ 65

$7 \quad$ Geothermal Power Plant ........................................................................ 73

$8 \quad$ Closed-Cycle OTEC Power Plant ....................................................... 81

$9 \quad$ Open-Cycle OTEC Power Plant ......................................................... 82

10 Bathymetric Profiles....................................................................... 84

\section{LIST OF TABLES}

Table Page

1 Recommendations for Initiating Renewable Energy

Projects in American Samoa .....

2, 90

2 Technology Selection Criteria..... 


\section{EXECUTIVE SUMMARY}

American Samoa is almost totally dependent for energy on imported oil, much of which is foreign crude. Supply lines are long, and this U.S. Pacific Territory is highly vulnerable to the whims of the global oil market, both for price and for availability. Paradoxically, American Samoa is rich in a wide variety of renewable energy resources that could be substituted for impcrted oil.

This Renewable Energy Plan of Action represents the results of a joint effort by the Pacific Site Ofice of the U.S. Department of Energy (DOE) and Sandia National Laboratories, in collaboration with the government of American Samoa 1) to evaluate the major indigenous renewable resources in American Samoa, 2) to establish a list of recommended specific renewable energy projects, 3) to provide a realistic schedule for implementing these recommendations over a ten-year time frame, and 4) to furnish budget estimates necessary to support planning and preliminary design of the projects, as well as rough estimates on total construction costs.

Site visits were made to American Samoa from November 1989 through August 1990 by engineers and scientists from DOE, Sandia, the Solar Energy Research Institute, and the Pacific Northwest Laboratory to inspect sites and to confer with American Samoan officials from both the public and private sectors on possibie renewable energy projects. This evaluation has been a collaborative effort throughout, with periodic input and feedback provided by American Samoans.

Table 1 presents a summary of 26 recommendations involving seven different renewable energy technologies, plus the appointment of a Renewable Energy Supervisor. These recommendations are equally divided by numbers into 1) solar and wind fuel-saving projects--designated as " $\mathrm{F"}$; and 2) major baseload power plant projects--designated as "B". Those projects with high priority ratings of I, F-I, and $B-1$ total $\$ 482,000$ over Years 1 and 2. Many of these projects relate to resource assessment, and the completion of this group of high-priority projects should provide a much clearer understanding of the potential of renewable energy resources in American Samoa. 


\section{Table 1 - RECOMMENDATIONS FOR INITIATING RENEWABLE ENERGY PROJECTS IN AMERICAN SAMOA}

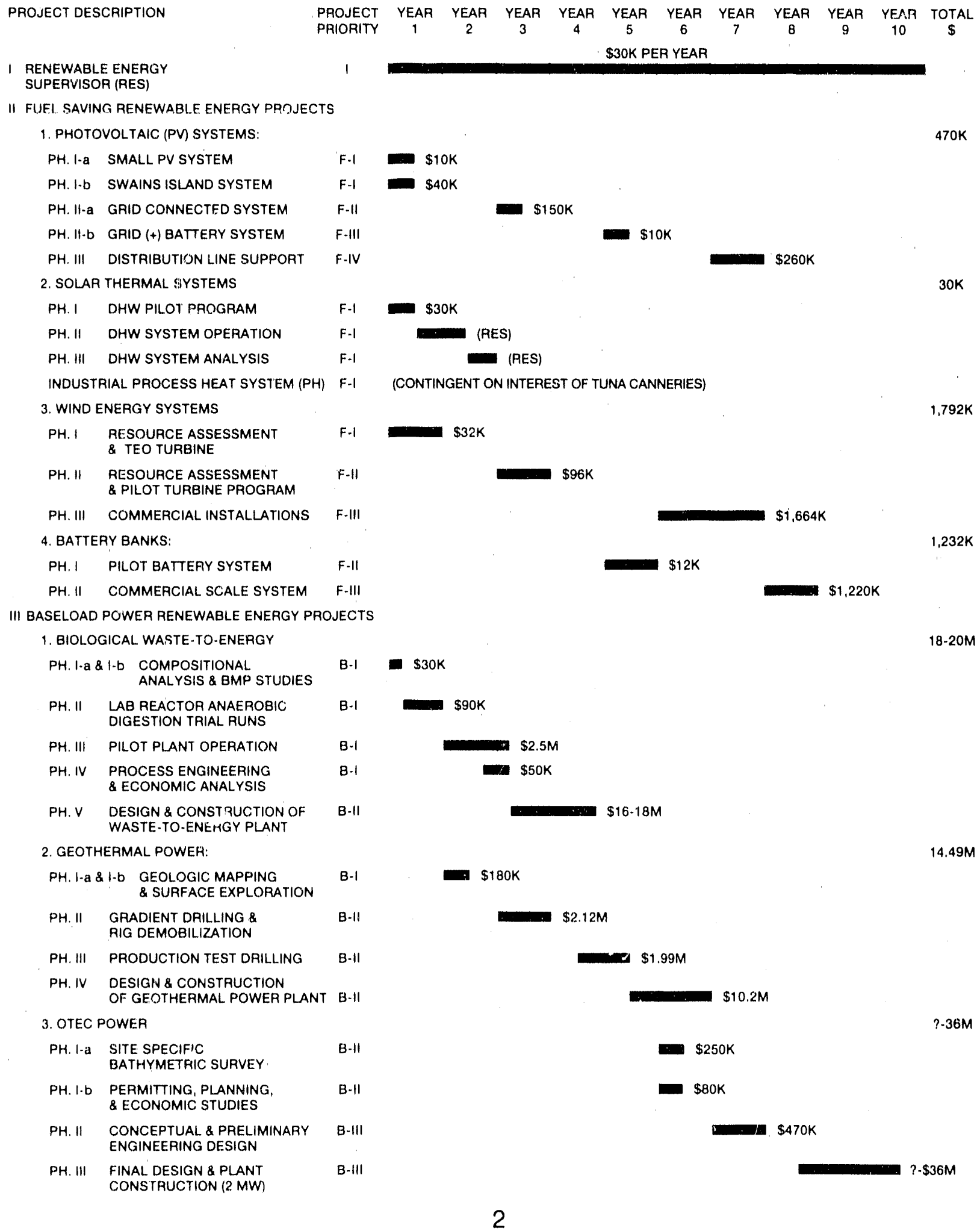

II FUEL SAVING RENEWABLE ENERGY PROJECTS

1. PHOTOVOLTAIC (PV) SYSTEMS:

PH. I-a SMALL PV SYSTEM

PH. I-b SWAINS ISLAND SYSTEM F-I \$40K

PH. II-a GRID CONNECTED SYSTEM F-II

PH. II-b GRID (+) BATTERY SYSTEM F-III

PH. III DISTRIBUTION LINE SUPPORT F-IV

\$3OK PER YEAR

1

2. SOLAR THERMAL SYYSTEMS

PH.I DHW PILOT PROGRAM

PH. II DHW SYSTEM OPERATION

PH. III DHW SYSTEMANALYSIS

$470 \mathrm{~K}$

INDUSTRIAL PROCESS HEAT SYSTEM (PHI) F-I

3. WIND ENERGY SYSTEMS

(CONTINGENT ON INTEREST OF TUNA CANNERIES)

$\begin{array}{cl}\text { PH.I RESOURCE ASSESSMENT } & \text { \& } \\ \text { PH. II TEO TURBINE } & \text { RESOURCE ASSESSMENT } \\ \text { \& PILOT TURBINE PROGRAM } & \text { F- } \\ \text { PH. III COMMERCIAL INSTALLATIONS } & \text { F- } \\ \text { 4. BATTERY BANKS: } \\ \text { PH.I PILOT BATTERY SYSTEM } \\ \text { PH. II COMMERCIAL SCALE SYSTEM F- }\end{array}$

$\mathrm{F}-1=\$ 32 \mathrm{~K}$

BASELOAD POWER RENEWABLE ENERGY PROJECTS

1. BIOLOGICAL WASTE-TO-ENERGY

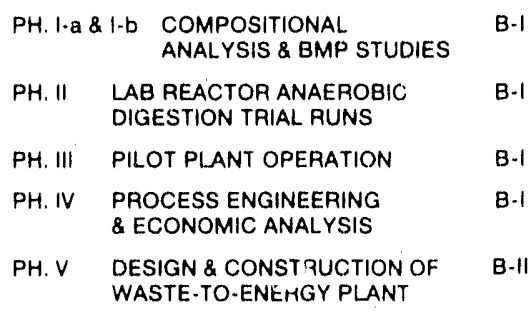

$\$ 30 \mathrm{~K}$

$18-20 M$

2. GEOTHERMAL POWEA:

$\begin{array}{lll}\text { PH. I-a \& } 1 \text {-b } & \begin{array}{l}\text { GEOLOGIC MAPPING } \\ \text { \& SURFACE EXPLORATION }\end{array} & \text { B-I } \\ \text { PH. II } & \begin{array}{l}\text { GRADIENT DRILLING \& } \\ \text { RIG DEMOBILIZATION }\end{array} & \text { B-11 } \\ \text { PH. III } & \text { PRODUCTION TEST DRILLING } & \text { B- } 11 \\ \text { PH.IV } & \begin{array}{l}\text { DESIGN \& CONSTRUCTION } \\ \text { OF GEOTHERMAL POWER PLANT }\end{array} & \text { B- } 11\end{array}$

$30 \mathrm{~K}$

$1,232 K$

3. OTEC POWER

\begin{tabular}{|c|c|}
\hline $\mathrm{PH} .1-\mathrm{a}$ & $\begin{array}{l}\text { SITE SPECIFIC } \\
\text { BATHYMETRIC SURVEY }\end{array}$ \\
\hline PH. I.b & $\begin{array}{l}\text { PERMITTING, PLANNING, } \\
\& \text { ECONOMIC STUDIES }\end{array}$ \\
\hline PH. II & $\begin{array}{l}\text { CONCEPTUAL \& PRELIMINARY } \\
\text { ENGINEERING DESIGN }\end{array}$ \\
\hline PH. III & $\begin{array}{l}\text { FINAL DESIGN \& PLANT } \\
\text { CONSTRUCTION (2 MW) }\end{array}$ \\
\hline
\end{tabular}


The baseload power plant technology assigned the highest and earliest priority is the biological waste-to-energy option. This process combines municipal solid waste with tuna sludge from major cannery operations into a single waste stream that serves as the feedstock for an anaerobic digestion system. This biological process converts the waste to energy, leaving a usable residue suitable for soil enrichment. The high priority given to this project was based more upon the removal of these two major waste sources and the environmental problems associated with their disposal, rather than upon the total amount of power (about 2 megawatts) that could be recovered.

This series of recommendations represerits an appropriate plan of action for encouraging renewable energy development in American Samoa, within the present time frame. As future trends regarding fossil fuel costs and the relative merits of the various renewable technologies become better defined, these recommendations should be reviewed and revised. This is necessary in order to proceed systematically toward the ultimate goal for American Samoa of a significant level of energy self-sufficiency with indigenous renewable resources. 

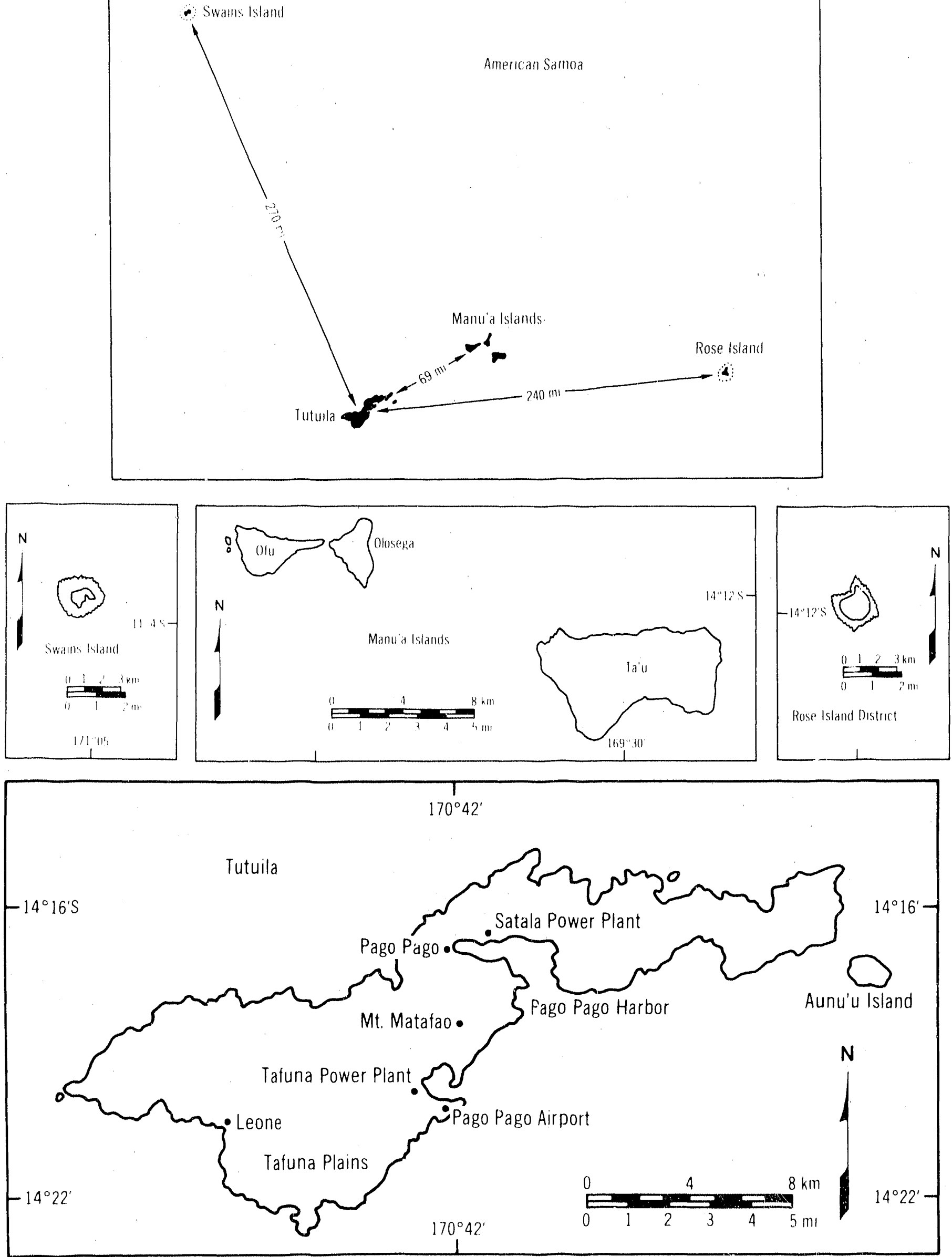
SECTION I. General Background Information

\section{Geographic Overview}

American Samoa is the only insular territory of the United States that is located south of the equator. It consists of seven tropical islands in the South Pacific, about 2300 miles southwest of Hawaii and 1600 miles northeast of New Zealand. The western islands in the Samoa chain constitute the independent nation of Western Samoa, the closest island group to American Samoa both geographically and culturally.

Tutuila is the major island of American Samoa, with 69 percent of the 77 square miles of area and 94 percent of the 47,000 population. Aunu'u, located one mile off the southeast coast of Tutuila, is roughly one square mile in area. The Manu'a group of islands--Ta'u, Ofu, and Olosega, which are about 70 miles east of Tutuila, make up most of the area and population not found on Tutuila. Tiny Swains Island (270 miles north of Tutuila) lists a population of 74 , while uninhabited Rose Island (240 miles east of Tutuila) completes the seven-island Territory of American Samoa.

The topography of Tutuila and the Manu'a Islands is rugged, volcanic terrain. Rose and Swains Islands are low, tropical atolls. Tutuila, which is about 20 miles long and from one to six miles wide, is a continuous, irregular volcanic ridge rising steeply from the sea. The Tafuna Plains on the southwestern portion of the island constitute the only expanse of relatively flat land. The ridge forms a drainage divide for the entire islanc', with many short, intermittent streams descending rapidly from the mountains to the ocean through steep valleys. Mt. Matafao, at $2141 \mathrm{feet}$, is Tutuila's highest peak.

American Samoa is located only $14^{\circ}$ south of the equator, so it experiences a typical tropical climate, with a dry season from June through August and a wet season from January through March. Average annual rainfall is between 125 and 250 inches, depending upon location, and can vary widely from year to year. Average temperature is around $80^{\circ} \mathrm{F}$, with little seasonal variation. Relative humidity can climb to as high as 90 percent, but is usually mitigated by steady tradewinds. These islands can be subjected to severe storms, as illustrated recently by Hurricane Ofa, which devastated Tutuila on February 4, 1990, with recorded winds of 
$145 \mathrm{mph}$. Power was out for two weeks, causing major problems with the water supply and other essential services.

The steep slopes, heavy rainfall, and rapid runoff experienced by the major volcanic islands keep the natural residuai soil cover shallow, with the soil held in place by dense, tropical vegetation. There is a narrow belt of coral around the edge of the islands on which a thin cover of sandy, organic material also supports abundant vegetation. A few inland valleys contain thick deposits of alluvial soil, but, even there, the heavy rainfall leaches the soil, requiring fertilization for crop growth.

A briof overview of historical, cultural, political, demographic, and societal information for American Sarnoa is included as Appendix A. This summary condenses and up-dates the extensive coverage of this information included in the Territorial Energy Assessment Final Report.

\section{Employment, Economic, and Financial Data}

The labor force in American Samoa has been steadily increasing in recent years--by a total of 15 percent over the four-year period from 1983 to 1987. There were 10,464 employees in 1987 , from a total population of 36,960 . Of these 10,464 wage earners, 3,801 were government employees; 3,745 were from the tuna cannories; and 2,918 were from all other employment categories.

Trie unemployment rate has held fairly steady around 13 percent, although the rate of unemployment varies significantly with place of birth. Those born in Western Samoa have an unemployment rate of 16 percent; those from American Samoa, 12 percent; and from the United States, 7 percent. In 1985, 7 percent of those persons employed in American Samoa earned less than $\$ 1000$ a year; 36 percent earned between $\$ 1000$ and $\$ 5000$; 38 percent between $\$ 5000$ and $\$ 10,000$; 16 percent between $\$ 10,000$ and $\$ 25,000$; and 3 percent earned more than $\$ 25,000$.

Amsrican Samna differs from most of the other Pacific Islands in that it has a substantial export industry-tuna processing--which provides employment for 34 percent of all wage earners. Two major canneries (Star-Kist Samoa, Inc. and 
Samoa Packing Company--formerly Van Camp) are located on the shoreline of Pago Pago Bay, where they serve as the primary base for making this area the economic center for American Samoa.

In 1987, canned tuna represented 93 percent of the $\$ 288$ million of export from the territory, with most of the remaining 7 percent coming from pet food, fish mial, and other cannery by-products. The 120 boats that constitute the fishing fleet providing the tuna for the canneries are, for the most part, individually owned. The bulk of these vessels are operated by Korean crews, which engage in long-line fishing, with eight or ten U.S. purse seiners rounding out the fleet.

Total imports for American Samoa in 1987 were $\$ 346$ million, resulting in a trade deficit of $\$ 58$ million The United States is the leading nation for both imports and exports, with 72 percent of the imports originating from this single nation. Leading the imports at 40 percent were metals, used primarily for fish canning operations, followed by buildirg materials at 18 percent, food, 17 percent, and petroleum products, 14 percent.

In addition to the tuna canneries, other major economic activities are a) government operations (health, education, public works, power, water); b) port operations associated with the excellent deep water harbor at Pago Pago Bay; c) industrial and commercial development located in the Tafuna plains; and d) u small tourism industry. Expansion goals are directed toward port facilities, the industrial park, and increased agriculture production to lessen the large out-lay for food imports. Tourism is limited by a) the general reluctance of Samoans to change traditional customs to accommodate visitors; b) having orly one tourist hotel; and c) limited air service to this isolated site--two major international airlines terminated service to Pago Pago in the early 1980 s.

In 1987, the American Samoa Government spent about $\$ 103$ million, while taking in $\$ 109$ million, resulting in a $\$ 6$ million surplus. However, nearly $\$ 11$ million was received that year in emergency grants and relief programs for families and facilities affected by Hurricane Tusi, so these figures may be somewhat skewed. The total government revenue of $\$ 109.2$ million consisted of $\$ 51.7$ million in federal funds ( 47.3 percent) and $\$ 57.5$ million in local revenues (52.7 percent). The $\$ 10.2$ million in revenues credited to the American Samoa Power Authority represented the 
largest component of revenues generated by any single enterprise in either the public or the private sector.

\section{Transportation and Power}

American Samoa shares with its island neighbors a near-total dependence for energy on imported oil. In recent years, the annual outlay for energy has exceeded $\$ 30$ million, with the majority of this figure going for land, sea, and air transportation fuels--the largest portion of which is consumed by ma tine operations associated with the fishing tleets. In 1987, there were 985 vessels cleared through Pago Pago Harbor, 4609 private, commercial, and government vehicles registered for operation on Arisrican Samoa's streets and highways, and 3522 commercial carrier air flights recorded for Tafuna International Airport.

Another major consumer of imported oil is the American Samoa Power Authority (ASPA), which is responsible for providing reliable electrical power for the five major islands of the Territory, as well as a dependable water supply and wastewater service. Two power plants on Tutuila generate electricity for that island, and deliver it through an undersea electric cable to the offshore island of Aunu'u, as well. Both Ta'u and Ofu have small diesel power plants that provide electricity for the Manu'a Islands.

The two power plants on Tutuila are the Satala Station, located in Pago Pago adjacent to the tuna canneries, and the Tafuna Station near the airport and industrial park. These plants are about 12 miles apart, but are connected by a tie-line, which allows transmission in either direction. The ASPA grid, with 84 miles of transmission lines, services every village on Tutuila and Aunu'u. At the two power plants are 17 separate units, mostly diesel generators (EMDs, Caterpillars, Nordbergs), along with two Allison gas turbines. Currently, there are about $24 \mathrm{MWs}$ of firm generating capacity, fairly evenly distributed between the two plants, although this can change quickly because of scheduled maintenance or unscheduled repairs. Some of these units are nearly 20 years old; and, with a peak load on the Tutuila system of 14.7 MWs in 1988--and rising, it is a tribute to the skill and the ingenuity of the ASPA staff that power blackouts, which were quite common and of lengthy duration through the mid-1980s, are now a rarity and seldom exceed 15 minutes. 
All electricity users are now metered: a) 6122 residential customers, b) 621 small commercial customers, c) 123 large users, and d) 274 government customers-for a total of 7140 metered customers. The kilowatt-hours of electricity generated by the entire ASPA system in 1988 are listed as follows:

$\begin{array}{cr}\text { Tutuila } & \text { Generation in thousan } \\ \text { Satala Plant } & 41,155 \\ \text { Tafuna Plant } & 53,741 \\ \text { Subtotal } & 94,896 \\ \text { Manu'a } & \\ \text { Faleasao Plant } & 844 \\ \text { Ofu Plant } & 590 \\ \text { Subtotal } & 1,434 \\ \text { Combined Total } & 96,330\end{array}$

In nearly every respect, 1988 was an excellent year for ASPA. The utility earned an annual net income of $\$ 1,296,000$. This was only the second year in which ASPA had turned a profit, and the FY88 figure exceeded the FY87 net income by a factor of 3 . Total generation was 9 percent greater than for 1987, sales increased by 15 percent, and losses decreased by 5 percent, primarily due to the discovery of previously unmetered services and a reduction in transmission line losses.

The only statistic with a minor negative dip was for fuel consumption efficiency. This figure decreased slightly in FY88 from $11.54 \mathrm{kWh} / \mathrm{gal}$ to 11.50 $\mathrm{kWh} / \mathrm{gal}$ of fuel consumed. During the first quarter, due to downtime of some of the Caterpillar generators, it was necessary to use the two less efficient clas turbines to provide baseload power, which lowered the fuel efficiency during that quarter. This illustrates the type of problem ASPA experiences in juggling its aging generators to provide the most efficient operation.

The American Samoa Power Authority was created by executive order of the Governor in 1981 and given total authority to engage in contracts, to purchase and lease property, and to establish rates in order to cope with the mounting power 
generation problems. From 1982 through 1986, the pattern of sporadic outages and power rationing continued. Following a three-month period of rolling blackouts in late 1986, the ASPA Board of Directors was reconstituted and a new general manager appointed. Reliability of service has improved significantly, much to the credit of ASPA's current administration, although the basic problem of obsolescent generators and marginal auxiliary equipment remains. 
SECTION II. Planning for Renewable Energy Development

\section{The Territorial Energy Assessment}

The Territorial Energy Assessment Final Report, published in December 1982, stated that the electrical generating system for Tutuila barely sufficed for capacity and reliability--then, as now--even with the new diesel generators that were installed earlier that year. While acknowledging that the basic diesel generating system should be reinforced, the report also recommended that a variety of additional options be initiated to reduce the reliance of American Samoa on imported oil.

The report put these options into three categories:

\section{Near Term ( $0-5$ years)}

Energy efficiency, demand side management

Solar water heaters

Hydroelectric power

Biomass, both treefarms and biogas

Municipal solid waste (MSW)

\section{Mid Term (6-15 years)}

Photovoltaic solar cells

Solar thermal systems

Wind energy

Geothermal energy

Liquid fuels from biomass

Ocean current and waves

Long Terim (16-40 years)

OTEC, ocean thermal energy conversion

Ocean currents and waves

Coal

The report included the best existing knowledge on the resource base for each of these alternatives in American Samoa, as well as a current summary of the state of the art of the energy conversion technology for each of these options. This provided an excellent reference source on the potential of the various renewable energy alternatives in American Samoa--as well as for the other seven U.S. territories in the Pacific and the Caribbean--at the time the manuscript was assembled in 1982. 
Table 2 summarizes the technology selection criteria in the Territorial Energy Assessment for American Samoa, as established by the team of scientists, engineers, and consultants from DOE, the national laboratories, and the private sector. Categories evaluated by this team for each technology included 1) how well established the resource base was, 2) whether the technology was ready for application in the Pacific, 3) whether it would be reliable and durable, 4) what some of the possible restraints were to its introduction, 5) what the estimated range would be for the capital costs of installation and for operation and maintenance charges, 6) when the technology would be cost-effective, and 7) what the anticipated range of oil savings or avoidance would be.

A great deal of worthwhile information is provided in this table, as well as in the entire report. For reasons listed in the preface to this document, little has been done to implement its recommendations. In the eight years since the material was assembled, better understanding has emerged on the potential and the cost for installing many $r$, these renewable technologies in American Samoa. To update the information in the Territorial Energy Assessment and to proceed with the evaluation of some of the renewable energy options for introduction into ASPA's generation system, site-specific analyses reflecting current technical and economic data should be undertaken. This report is a first step toward this update.

\section{Five-Year Plan of the American Samoa Power Authority}

In February 1990, ASPA published its five-year development plan, Agenda for Growth, 1991-1995. This publication sets forth a $\$ 61.7$ million capital improvement program for American Samoa's power, wastewater, and water utilities. ASPA estimates that $\$ 10$ million of this total can be provided through earned net income on operations and debt financing, while the remaining $\$ 51.7$ million will be requested primarily from U.S. Tepartment of the Interior capital improvement grants.

The power utility will provide a much greater percentage of bcal support for its development projects than either the wastewater or water utility. Of the estimated $\$ 22.3$ million for power projects over the next five years, $\$ 8.7$ million--39 percent--of this amount will come from ASPA. For the wastewater and water 
Table 2

Technology Selection Criteria

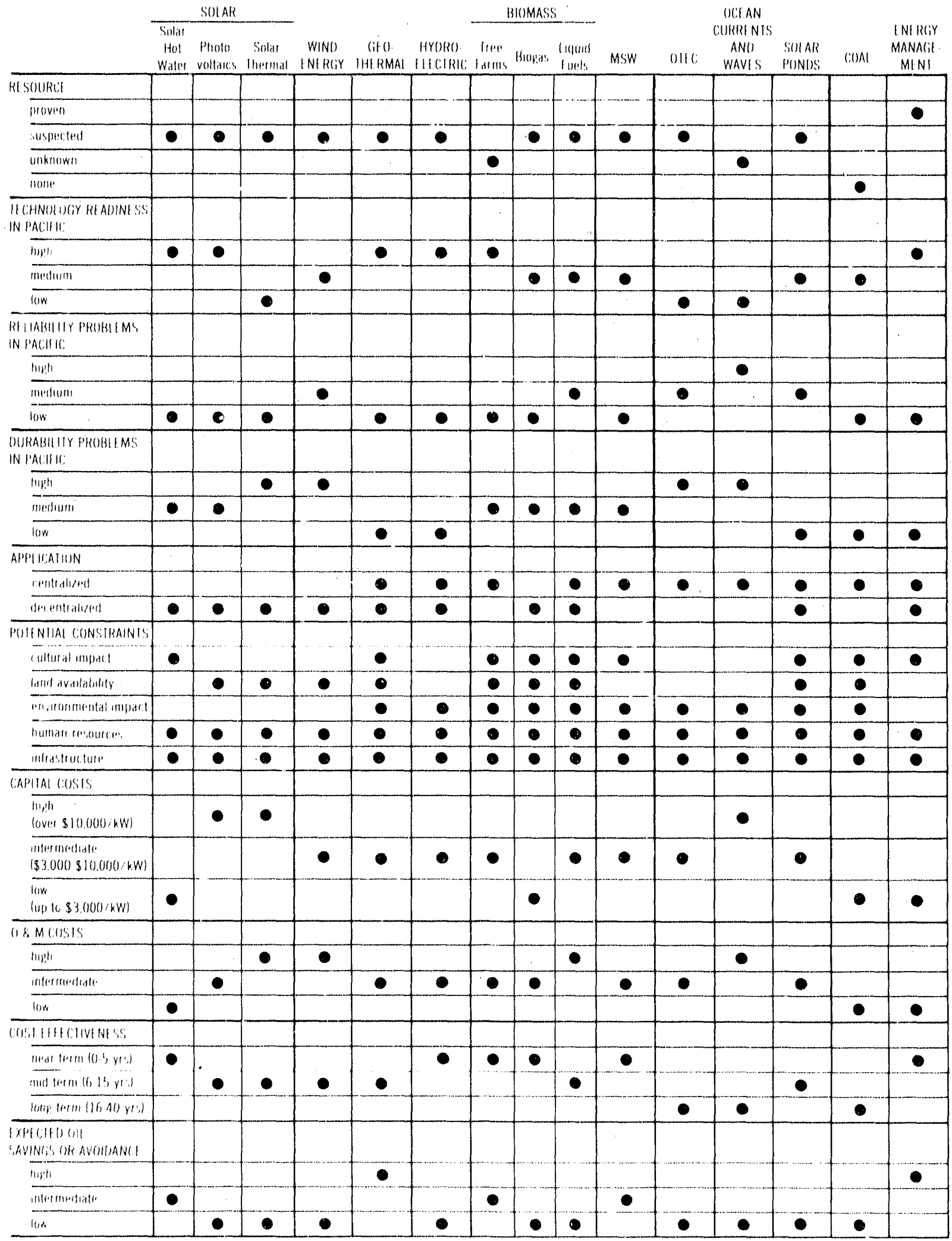


projects, only $\$ 1.3$ million, or 3.3 percent of its $\$ 39.4$ million total, will be provided locally.

Electric power will be the only one of the three utilities summarized from Ag $\_$nda for Growth in this report. The power system improvement projects are listed as follows:

A. Construction of new Satala power station complex: raze existing structures; design and construct power station (four units), new machine shop, generator foundations, and new switchroom annex; purchase and install new $13.2 \mathrm{kv}$ switchgear.

B. Installation of generators in the Satala station: purchase and install three new 4.75 MW fuel-efficient saseload generators, with auxiliary equipment to provide cogeneration steam tor the two tuna canneries.

C. Upgrading existing power station facilities: purchase and install one secondhand 2.5 MW EMD generator at the Tafuna station; overhaul the 3.0 MW Norciberg generator at Satala; relocate existing fuel storage tanks and install additional storage capacity at Satala.

D. Upgrading transmission and distribution system: reconstruct power lines and tieline between the two stations; construct line crew facilities at Tafuna.

E. Performing general improvements to assure reliability of ASPA power generation and transmission system.

Collectively, these five projects should provide adequate facilities and equipment to permit ASPA to continue to improve its customer service. Unlike mainland utilities, ASPA cannot purchase power or share loads with adjacent utilities during emergencies. This major capital investment is necessary to improve reliability and to ensure the security of the power supply.

Projected costs in $\$ 1000$ to accomplish these five improvement projects are summarized by fiscal year in the following table: 


\begin{tabular}{crrrrrrr}
\hline $\begin{array}{c}\text { IMHROVEMENT } \\
\text { PROJECT }\end{array}$ & 1991 & & 1992 & $\underline{1993}$ & $\underline{1994}$ & $\underline{1995}$ & TOTAL \\
A & 1,500 & 1,500 & 100 & 100 & 0 & 3,200 \\
B & 0 & 2,800 & 2,800 & 2,800 & 0 & 8,400 \\
C & 2,000 & 200 & 0 & 0 & 0 & 2,200 \\
D & 700 & 600 & 1,000 & 600 & 600 & 3,500 \\
E & 1,000 & 1,000 & 1,000 & 1,000 & 1,000 & 5,000 \\
& $\$ 5,200$ & $\$ 6,100$ & $\$ 4,900$ & $\$ 4,500$ & $\$ 1,600$ & $\$ 22,300$ \\
& $\times 1000$ & $\times 1000$ & $\times 1000$ & $\times 1000$ & $\times 1000$ & $\times 1000$ \\
\hline
\end{tabular}

In order to begin funding capital improvements on its own, ASPA will have to increase its already high electricity rates. The uncertainties of the future oil market cast doubts on the reliability of this source of funding. Although the proposed fiveyear development plan is intended to improve overall fuel efficiency from 11.1 to 13.0 $\mathrm{kWh}$ per gallon, there is no guarantee that the cost of oil will not rise at an even greater rate and compensate for this increase in efficiency.

As long as imported oil represents the sole energy source for its power generation, American Samoa will remain tcially dependent upon the vagaries of the global oil market and upon the nations and oil companies that supply this vital commodity. ASPA recognizes this fact and is cooperating fully in this study to determine whether there are any indiç enous renewable energy resources in American Samoa--solic waste, geothermal, ocean resources, wind energy, solar power--that are technically and economically feasible to consider as partial or total replacements for oil.

Although the fuel costs for the renewable energy resources listed above are essentially "free," the capital investment for most renewable energy installations is high in comparison to that for diesel generators. Therefore, the life-cycle economics may favor either renewable or conventional systems, depending on the current price of oil. Since no reference was made in ASPA's five-year development plan to renewable energy options, it should be noted that any funding identified for nearterm renewable energy projects would be in addition to the $\$ 22.3$ million requested for improving ASPA's existing power generation and distribution system. 
SECTION III. Procedure for Establishing the Renewable Energy Plan of Action for American Samoa

Introduction

As the need to establish current renewable energy plans of action for the Pacific territories began to emerge in the late-1980s, the decision to initiate this series of studies resulted from interaction between 1) the Pacific Site Office (PSO) of Honolulu, which is a component of the San Francisco Operations Office of DOE, and 2) the Renewable Energy Design Assistance Center of Sandia National Laboratories, which is funded through the Committee on Renewable Energy Commerce and Trade (CORECT). Agreenent was reached between these two organizations to cooperate on joint renewable energy resources studies for selected U.S. Pacific territories.

$\mathrm{PSO} /$ Sandia chose Anterican Samoa as the first territory for which to develop a plan of action, based on the following rationale: 1) American Samoa has a wide variety of renewable energy alternatives, both natural resources and "waste" byproducts, 2) the government of American Samoa is stable and, under the leadership of Governor Peter Tali Coleman, is strengthening its infrastructure--including electric power, 3) both the director of the American Samoa Energy Office and the general manager of ASPA are open-minded to renewable energy alternatives, and 4) the governor has endorsed and pledged his full si'pport in helping to develop and implement this plan of action.

\section{Site Visit to American Samoa}

A site visit was made to American Samoa by PSO/Sandia in November 1989 to confer with appropriate industry and government officials; to identify existing information relating both to the overall economy and to specific energy-related issues; to obtain an on-site evaluation of the nature and extent of renewable energy resources in American Samoa; and to develop an appreciation for the potential of these resources as substitutes for imported oil. The site visit was conducted by John Shupe of PSO and John Stevens of Sandia. They were accompanied by Dennis Elliott of Battelle Pacific Northwest Laboratories. 
The site visit team spent most of the week in American Samoa on the major island of Tutuila, with two of the members taking an overnight trip to Ofu and Ta'u in the Manu'a Islands to inspect a hybrid PV/wind system for a TV relay station. During the week the entire island of Tutuila was traversed to view a) potential wind turbine and PV system sites; b) the volcano crater, where geothermal resources may exist; c) an excellent shoreline site for an OTEC power plant; d) the two tuna canneries-the source of the tuna sludge problem/resource; $\theta$ ) the municipal land-fill operation; f) the LBJ Hospital, a candidate for a solar thermal project; g) the experimenta! treefarm projects, funded under earlier DOE support; $h$ ) the PV-powered NOAA atmospheric monitoring station; and i) isolated villages considered for PV hybrid systemis or battery banks.

Appointments and logistics while in American Samoa were ably handled by Matt Le'i and the Energy Office staff. A great deal of constructive input was received from Abe Malae and the ASPA engineers, while Sheila Wiegman of EPA was an excellent source of information on tuna cannery operations and municipal solid waste. A partial list of the people with whom one or more of the site visit team interacted is listed as follows:

\author{
Governor Peter Tali Coleman \\ Territorial Energy Office (TEO) \\ Matt Le'i, Director \\ Jerome Laupapa, ICP Program Manager \\ American Samoa Power Authority (ASPA) \\ Abe Malae, General Manager \\ Ace Toga, Treasurer and Acting Chairman, Board of Directors \\ Perelini Perelini, Chief Engineer \\ Joan Cahill, Mechanical Engineer \\ Environmental Protection Agency (EPA) \\ Pati Faiai, Director (ASG appointee) \\ Sheila Wiegman, EPA (Federal employee) \\ Department of Planning and Economic Development \\ Lydia Faleafine, Director \\ Department of Public Works \\ Edward Schutter, Chief Engineer \\ LBJ Memorial Hospital \\ Dr. Iotamo Saleapaga, Director \\ "Scratch" Sotoafaiga, Maintenance Engineer
}


National Oceanographic \& Atmospheric Administration (NOAA)

Emily Wilson-Godinet, Electronics Specialist

Television Station KVZK

Robert Blauvelt, Operations Manager

VCS Samoa Packing Company (formerly Van Camp)

Gordon Stirling, General Manager

John Perry, Director of Maintenance

Star-Kist Samoa, Inc.

Maurice Callahan, President and General Manager

\section{Renewable Energy Consultants}

The two principals responsible for this REPOA have only limited knowledge in some areas of renewable energy technology. Consequently, successful efforts were made to identlfy a series of renewable energy experts from within DOE, its consultants, the National Laboratories, and the private sector to assist in filling the voids in technical competence, to help in the evaluation of those renewable alternatives that may contribute to American Samoa's energy future, and to provide input on cost estimates and time frames for the introduction of these technologies. Assistance in obtaining appropriate consultants was provided by colleagues from Sandia National Laboratories and from DOE-Headquarters, particularly from the DOE Directors of the Offices of Biofuels and Municipal Waste, Geothermal, and Wind and Ocean Technologies.

The following listed consultants were invaluable in furnishing technical expertise in the evaluation and development of recommendations for the respective renewable energy technologies. Reports from most of these consultants are attached as appendices. However, the opinions, priorities, and recommendations expressed within the body of this report are solely the responsibility of the coauthors, based upon their existing knowledge, their interpretation of the input provided by the consultants, and frequent interaction with American Samoa officials throughout the preparation of the plan of action.

1. Dr. Christopher Rivard

Biotechnical Research Branch

Solar Energy Research Institute (SERI)

Golden, Colorado 
Dr. Rivard spent four working days in Pago Pago in January 1990 and returned for three additional days in August to confer with appropriate energy, utility, and environmental officials, as well as representatives of the two tuna canneries. His site inspections included visits to the municipal waste landfill on Tutuila and to the tuna processing plants. The time for Dr. Rivard's site visits and report preparation was provided by SERI. His report, "Biological Waste-to-Energy Options for American Samoa," is attached as Appendix B.

2. Ms. Barbara Goodman

Manager, Energy from Municipal Waste

Solar Energy Research Institute (SERI)

Golden, Colorado

Initial contact for requesting assistance from SERI in evaluating the various waste problems and opportunities in American Samoa was directed to Ms. Goodman. She responded very positively and was responsible for making $\mathrm{Dr}$. Rivard's time available to conduct the site visit and prepare the report. Ms. Goodman conferred with Dr. Rivard on the evaluation and concurred with his attached report.

3. Dr. Phillip M. Wright

Technical Vice President

University of Utah Research Institute (UURI)

Earth Sciences Laboratory

Salt Lake City, Utah

The Earth Sciences Laboratory of UURI has had experience with island geothermal projects on Adak and Ascension Island, and was recommended by DOE Headquarters as the appropriate research group to investigate the geothermal potential for American Samoa. Dr. Wright conducted an extensive review of existing literature, including a preliminary study, "Geothermal Energy for American Samoa," funded by DOE and conducted by Keller and Grose of the Colorado School of Mines in 1980. Dr. Wright is positive on the potential of geothermal for Tutuila and presents a recommended exploration program in Appendix C.

4. Mr. Dennis L. Elliott

Senior Research Scientist

Atmospheric Sciences Department

Battelle Pacific Northwest Laboratories

Richland, Washington 
Mr. Elliott was a member of the American Samoa site visit team at the request of and with funding provided by the DOE Director for Wind and OTEC Technologies. He took an active role in all aspects of the site visit, including the trip to the Manu'a Islands, concentrating on the wind potential of the area. Mr. Elliott's report on his fincings, "Prospect for Wind Energy in American Samoa," is included as Appendix D.

\section{Dr. Andrew R. Trenkd \\ Director, Energy and Resources Division \\ The Pacific International Center for High Technology Research (PICHTR) Honolulu, Hawaii}

PICHTR is the leading research and development institution for Ocean Thermai Energy Conversion applications in the Pacific Islands. PICHTR and DOE jointly funded a preliminary feasibility study on Ocean Thermal Energy Conversion power for the three U.S. Pacific flag territories, including American Samoa--with PICHTR conducting the study. As Director of PICHTR's energy programs, Dr. Trenka has provided advice and assistance in the planning and preparation of the Ocean Thermal Energy Conversion section of this plan of action. Attached as Appendix $E$ is a "Preliminary Evaluation of Potential OTEC Sites" prepared by $A$. Trenka and L. Udui, based on the DOE/PICHTR technical report 5 and feasibiiity study. 6

A great deal of assistance was also provided by Sandia National Laboratories staff, primarily 1) Earl E. Rush, Senior Technical Staff, Solar Thermal Test Facility; 2) David F. Menicucci, Senior Technical Staff, Solar Thermal Electric Technology; and 3) Henry M. Dodd, Division Supervisor, Wind Energy Research. Ms. Anne Van Arsdall, Publications Specialist for Solar Energy Department, Sandia, provicied invaluable editing and publication services, while the bulk of the original manuscript was typed by Mrs. Irene Asato of the Pacific Site Office SAN/DOE. 
SECTION IV. Evaluations and Recommendations for Renewable Ei:ergy Technologies

\section{Introduction}

In evaluating the potential of each of the renewable energy technologies for meeting a portion of American Samoa's energy needs, it must first be determined if an adequate resource base exists to justify its conversion to useiul energy. Is there sufficient solar radiation or wind or biomass or ocean temperature differential or a geothermal resource available for energy conversion?

The next aspect to consider is the status of the energy conversion technology. Is it a proven technology or is it still in the experimental stage? With the scarcity of skilled technicians and replacement parts in the Pacific Islands, the past performance of experimental and developmental renewable energy projects for this area has been poor. Has the technology been utilized only in benign locations on the mainland or does it have an established track record in a hostile, moist, saltladen environment that may be subjected to hurricaries?

Is the cost of a particular renevabie option competitive with conventional diesel power systems or with other renewabie technologies? Is it intended for utility grid distribution or for isolated village application? Is it appropriate for base Inad, peaking, or intermittent power? Those renewable technologies that are dependent upon solar radiation or wind are intermittent irı nature. Although they are effective in replacing fossil fuels when the sun is shining or the wind is blowing, there are times at night, during rainy spells, and when the wind is calm that these renewable options do not function and redundant, stand-by power or energy storage systems are necessary.

To assist in the evaluation of these issues, the following factors are discussed for each of the energy technologies:

1. General description of the renewable energy option.

2. Resource base in American Samoa.

3. Maturity of conversion technology.

4. Will the technology work in American Samoa? 
5. How will the technology be used in American Samoa?

6. Cost estimates of technology in American Samoa.

Item 7 presents recommendations for the introduction of these technologies in American Samoa. A number of intangibles are involved in any decision about a specific renewable energy project. Unfortunately, the resolution of many of these variables may be beyond the control of the decision maker. Examples are what the future trend will be in the price of diesel fuel; whether major technological or fiscal break-throughs will occur with competing renewable alternatives; whether the greenhouse effect or other environmental issues will limit future energy supplies.

There are no fuel charges for renewable energy technologies, and the operation and maintenance costs for these systems are comparable to those of conventional diesei power. Although the life-cycle economics for many of the renewable options may be cost-competitive with fossil fuels, particularly when all external charges are considered, the initial capital investment for the installation of most renewable energy systems is high--in some cases, many times that of diesel generators.

All renewable energy projects for American Samoa should consist of proven technologies that are well installed, well operated, and well maintained. With major projects, such as geothermal or waste-to-energy power plants, the capital investments are sufficiently high to justify the assignment of ASPA engineers and technicians to keep these systems operating efficiently. It is equally important for small, isolated solar or wind projects to be installed and operated properly, as well as be provided with adequate preventive maintenance, if these systems are to perform as specified.

The first recommendation of this report, which will impact many of these technologies, is for American Samoa to designate a Renewable Energy Supervisor (RES). Although this person may not be an expert on all renewable technologies, the RES should be sufficiently knowledgeable arid persi: tent to be able to understand the performance of these system;, as well as to conduct a monitoring and evaluation program on the preventive maintenance and operation of each of the renewable energy projects installed in American Samoa. 
The RES should also develop and implement training programs to assure that the project users understand what will happen if they abuse their systems or neglect maintenance procedures. The Renewable Energy Supervisor should prepare written instructions on each of these technologies and provide hands-on training to all of the system operators. It would seem logical for the RES to be attached to the Territorial Energy Office--or possibly to the American Samoa Power Authority. In either case, the RES would be responsible for monitoring the performance of all of the smaller, isolated renewable energy projects, and would also be the resource base for information and spare parts should the operators encounter problems. Such a position is essential, if solar and wind systems are to have a chance for successful introduction in American Samoa.

Frequently, the decision to proceed with a particular renewable energy option may be affected by non-energy considerations such as economic development, creation of local jobs and tax base, improving economic stability and security, or helping resolve a major environmental concern. The high priority given later in this section to a waste-to-energy plant for the disposal of tuna sludge and municipal solid waste is based more upon the solution to environmental problems on Tutuila rather than on the relatively small amount of power generated.

With the above caveats, a series of recommendations are presented which, in the opinion of the authors, should have a significant impact on the introduction of renewable energy technologies in American Samoa. Some of the recommended projects are directed toward resource assessment. Others will help determine system performance of the renewable options in a hostile island environment. Also included, however, are some major renewable energy projects that could have a positive impact on moving American Samoa away from its total dependence on imported oil as it enters the 2lst century.

\section{Photovoltaics}

\section{General Description of Photovoltaics}

Photovoltaic systems convert light energy into dc electrical energy. The amount of energy produced is directly related to the intensity of light striking the photovoltaic (PV) modules. Some solar radiation even penetrates the cloud cover 
on overcast days, providing reduced energy from flat-plate systems. Photovoltaic modules are available in two general categories: flat-plate and concentrating. The flat-plate module is the type most often seen where the module covers (usually glass) have PV cells sandwiched between them. Concentrating modules depend on a lens to concentrate sunlight on smaller cells. This lens arrangement requires that the modules always be pointed directly at the sun, which requires a sun-tracking mechanism. The lens arrangement also limits the energy that can be used to that portion of the sunlight that is referred to as "direct-normal radiation" (that portion which casts a sharply-defined shadow). In areas with significant clouds and rainfall, such as American Samoa, the energy produced from a concentrating system is usually substantially less than that produced by a flat-plate system, which can convert total sunshine as opposed to only the direct-normal component.

Concentrating photovoltaic systems are not presently recommended for American Samoa because of 1) the increased complexity of the tracking system when compared to fixed flat-plate systems, 2) the lack of commercial fielded systems to establish a track record for these systems, and 3) the lower energy output that would be expected from a concentrating system in American Samoa when compared with a flat-plate system.

Photovoltaic systems often include storage batteries so that energy is available on demand, as shown in Figure 1. Because of this battery relationship, PV modules are made available in 12-volt increments. (Actual module voltages are nearer 16 volts because this is what is required to properly charge 12 -volt batteries.) The modules can then be connected in series to increase voltage (48 volts is needed for many communications applications), or in parallel to increase current, or any combination of parallel and series to fit the desired load.

Dc energy can be converted to ac through use of a power converter, or inverter, as shown in Figure 2. This is often necessary because certain loads require ac, but if a function can be performed with dc, it should be for four reasons:

1) roughly ten percent of the energy is lost in an inverter, 2) the addition of an inverter, like any other piece of equipment, adds expense and one more possible point of failure, 3) dc loads are typically more efficient than ac loads (not because of anything inherent in ac or dc, but because designers of small dc loads are normally more sensitive to efficiency, while ac load designers are usually more interested in durability), and 4) dc loads typically operate at lower voltages than ac loads (12 or 24 volts versus 120 volts), which reduces the chance of safety problems. 


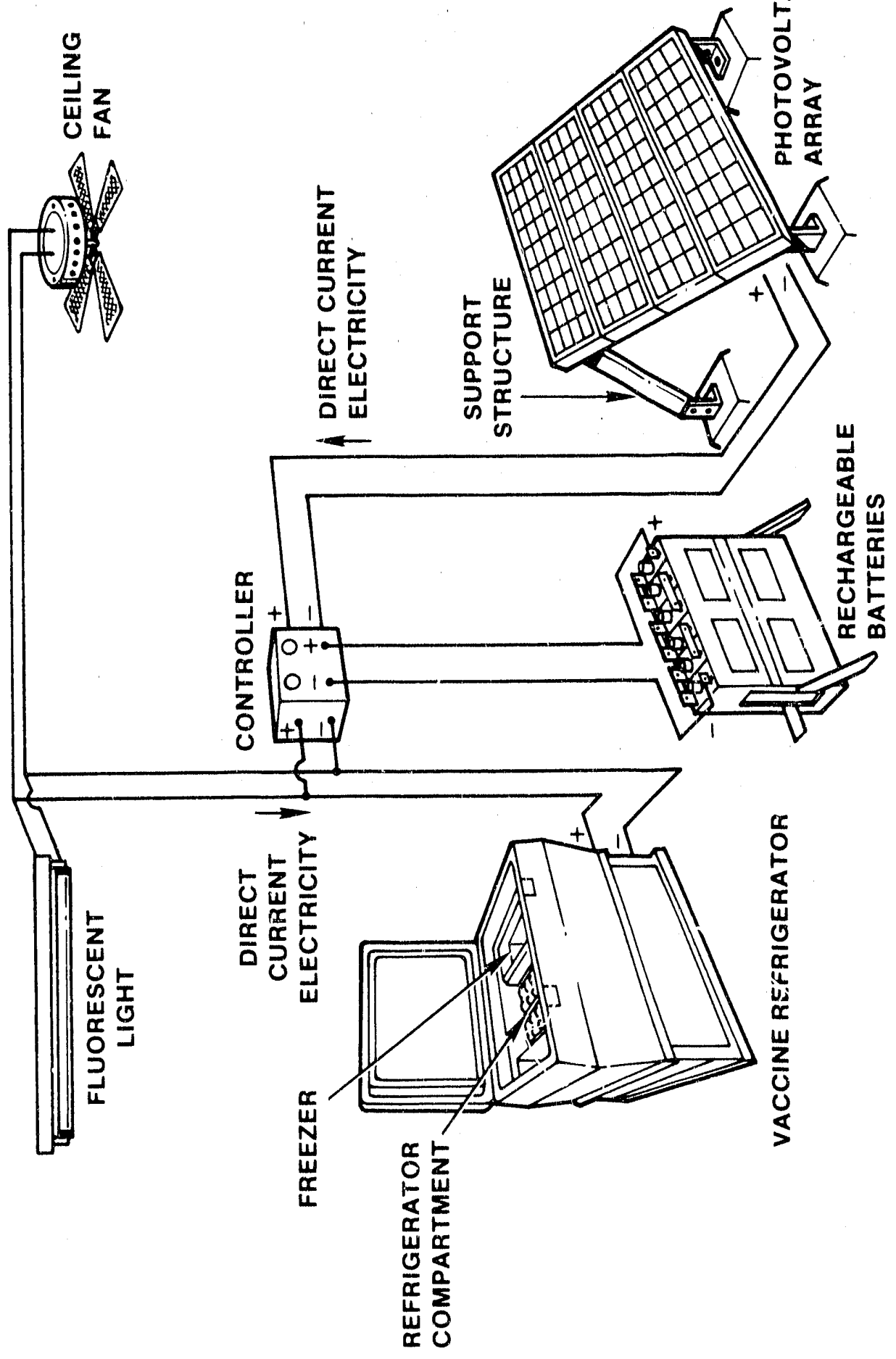

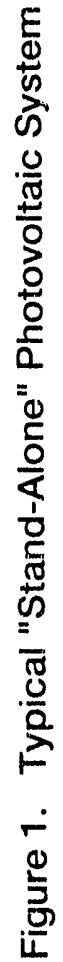




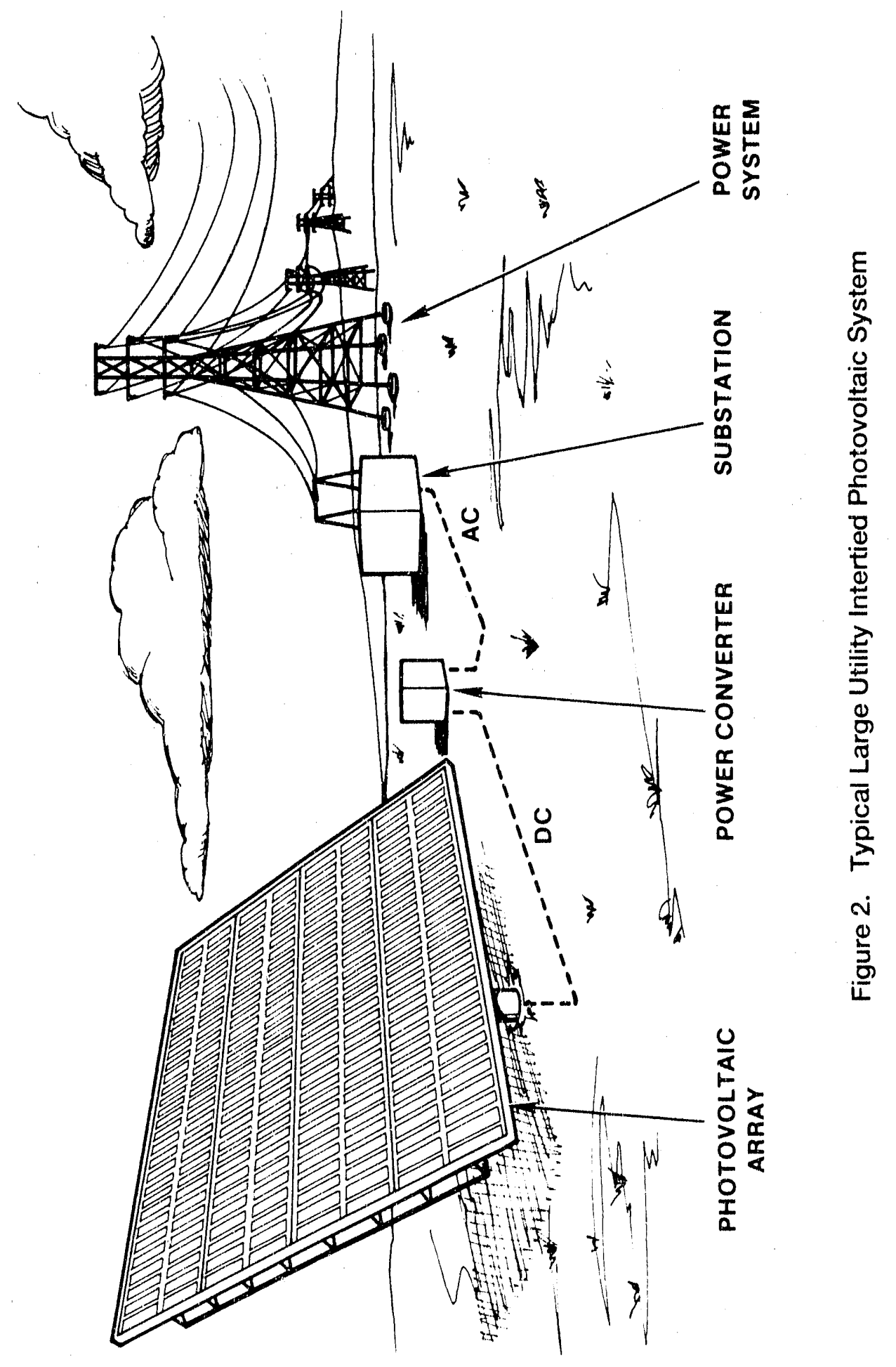


The energy produced by a PV system is deponcient on the energy conversion efficiency of the particular system and on the amount of sunlight or incoming solar radiation ("insolation" for short) available at the site. Some typical values will give a feel for what can be expected from a PV system. An overall system conversion efficiency (that is, the amount of sunlight that is converted to dc electricity) of 10 percent is common. With the sun overhead on a clear day, insolation is about 1000 watts per square meter. This means that, during midday with clear skies, the PV system will produce about 100 watts per square meter of array area. To convert this from power to energy, the time that conditions equivalent to midday clear sky ("sunhours per day") must be factored in. This is where site-specific information becomes important. Data taken at a particular site will provide an average number of sunhours per day for that site over a year, preferably on a month-to-month basis (every location has some months that have notoriously bad weather, which are usually the months that control the system design). In American Samoa, insolation varies between 4 and 6 sunhours per day. This means that a one-square-meter PV system will produce between 400 and 600 watthours per day.

\section{Resource Base in American Samoa}

Significant variation exists in the solar energy available in different locations in American Samoa. Typically, the coastal areas will receive more insolation than the mountains. The geophysical monitoring station at Cape Matatula, which has been monitoring solar insolation since 1976, indicates summer averages of 4 hours per day and winter averages near 7 hours per day. A person familiar with the relation between sunshine at Cape Matatula and other Samoan locations can use these values to estimate insolation availability at other locations. To get really accurate values, however, monitoring at a specific site is necessary.

Specific site data shouldn't be considered absolutely necessary before a PV system is installed. There are two reasons for this. First, there can be variation in weather patterns from one year to the next, with irisolation varying as much as 20 percent. Therefore, having a year's worth of insolation data may not mean as much as one would think. Second, one of the advantages of PV is its modularity, that is the ease with which sections can be added to an existing system. If it is determined that a PV system would provide a definite and immediate benefit in some location, then a "best guess" should be made for insolation and a system designed and 
installed. As part of the system, an insolation monitor should also be installed. If, after sufficient operating experience with the system, it is determined that the system size is too small, then the insolation data can be used in determining an appropriate expansion size (assuming the original system design was flexible enough to allow expansion).

If there are sites where future PV systems might be beneficial, then it is prudent to install insolation monitoring equipment so that data are available at a later date to use in designing a system.

\section{Maturity of Conversion Technology}

As with any other technology, a thorough understanding of system design, and those things to which the design is sensitive, is crucial to success. The photovoltaic modules themselves are the most resilient part of a PV system. Over the past decade, the U.S. DOE PV program has assisted manufacturers in developing progressively more durable modules. This was done by the Jet Propulsion Laboratories (JPL) "block buys." In these blocks buys, JPL wrote a specificalion for certain mechanical and environmental tests that a module must meet, then purchased enough modules from U.S. manufacturers to enable them to justify building new modules to this test specification. The final of these test specs was referred to as JPL Block V, and is the specification to which most U.S. manufacturers design today. The JPL Block $V$ test is designed to provide modules with a 30-year life, and includes mechanical bending and twisting, heat/humidity cycles, hail withstand tests and voltage withstand tests. Itundreds of thousands of modules in the field were designed to pass this test series, and all indications are that these modules will meet the design life of 30 years.

The weaknesses in PV systems are components that are not PV related, like batteries and electronic components. Batteries are familiar to most people, and are often taken for granted as a result. Therein lies the problem--batteries are an enerģy bottleneck in PV systems and should be designed with the thought in mind that every electron the PV modules produce inust pass through the battery, so the battery should be properly protected from such harmful elements as high temperatures, continua! overcharge, total discharge and low electrolyte levels Electronic components fail occasionally, so there should always be spares on hand for immediate replacement. 


\section{Will Photovoltaics Work in American Samoa?}

Experience in Samoa and other Pacific islands indicates that PV will work in American Samoa. The currently operating TV translator on Ofu is a good example of what can be expected. The PV system there works fine, but does not produce adequate energy, as it was originally designed as only a supplemental power source. Current plans are to expand the PV system, which reinforces the modularity concept--if energy is inadequate, add more. This PV system was completely destroyed by hurricane Tusi several years ago. (That is to be expected because the Block $V$ test requirement is only $50 \mathrm{lb} / \mathrm{t}^{2}$, equivalent to about $100 \mathrm{mph}$ winds. It is interesting to note that this is not simply a test of applying $50 \mathrm{lb} / \mathrm{tt}^{2}$ to the module, but requires 10,000 cycles of alternate plus and minus $50 \mathrm{lb} / \mathrm{ft}^{2}$ pressures. The modules are rugged, but not tough enough to withstand another Tusi.) Replacing the system was a matter of acquiring new modules and installing them where the others had been--not a desirable situation while cleaning up from a major hurricane, but at least a straightforward task. Wind damage is something that is inevitable with a photovoltaic system when $200 \mathrm{mph}$ winds occur, and the best approach to handling it is to expect it and plan on means to get the system back in operation after the storm passes. By using PV to power critical emergency equipment, such as communication systems, and keeping spare modules on hand, PV can be an important part of an emergency preparedness system.

Corrosion from the salt-laden atmosphere is the only major concern for PV systems on Samoa other than wind. The modules themselves have proven to be resistant to this problem. All other components, particularly structures and electrical junction boxes and connectors, should be designed to minimize corrosion. Anticorrosion compounds should be used on all electrical connections. One of the materials that receives both good and bad reports in moist salt-laden atmospheres is aluminum. Aluminum is a very good choice if precautions are taken to ensure that galvanic corrosion can't occur. This means if any metals other than aluminum are in contact with aluminum, these metals should be carefully selected with similar oxidation potentials to aluminium to minimize corrosion. Ideally, structures and junction boxes using only aluminum should be used. Installations on other tropical islands show that this can be done, but corrosion resistance must be specified and designed into systems. A major advantage of flat-plate PV systems is the simplicity of the systems, which is enhanced by the fact that they have no moving parts. 


\section{How Will Photovoltaics be Used in American Samoa?}

Photovoltaic power systems have become prevalent the world over for supplying energy to remote loads. The best known of these are communications repeaters. These are often installed in locations where access is difficult and reliability is important. These are the very reasons that communications repeaters on American Samoa are ideal loads for PV systems, as are any other remote loads where the cost of installing a power line is greater than the cost of the PV system.

Electric utility companies in the mainland U.S. are ber oming increasingly aware that photovoltaic installations, under the right conditions, save money the day they are installed. With economic evaluations tailored to American Samoa, this same type of installation is sure to save money for ASPA. The important ingredient of this analysis is that the load being served be small--for example, monthly energy consumption of less than $100 \mathrm{kWh}$. The cost of installing the required line extension and transformer is often more than the cost of a photovoltaic power system to serve the load. Examples of loads that various utilities have found to be best served by PV include warning lights, remote monitors for various environmental or system related data (for example water level or wind speed sensor), communication equipment, cathodic protection systems, remotely controlled equipment (for example sectionalizing switches), and lights.

Another growing use of photovoltaics is in "hybrid" systems, where PV, batteries and an engine/generator operate in tandem. The normal mode of operation is for the PV and batteries to serve the load. The engine/generator is only called upon when the PV system can't maintain adequate charge on the batteries. This may be the case because of bad weather or because of the periodic use of a large load, for which the PV system was not intended to be the energy source. These hybrid systems have proven to be effective fuel si.vers for the engine/generator. This is particularly valuable in locations where fuel delivery is expensive o: awkward. The presence of an engine/generator in the hybrid system allows the PV and battery portions of the system to be smaller (hence, less expensive) than in a PV-only system. This is because the PV and batteries are normally large enough to carry the load through extended periods of bad weather. With the hybrid system, this is not necessary because the engine/ generator will furnish any energy which the PV system can't supply. It should be stressed that a 
hybrid system is not achleved by simply paralleling $\mathrm{PV}$, batteries and engine/generator. The crucial function of controller is required to bring on the engine when needed and operate the engine in a fuel-efficient mode. Hybrid system controllers often sense battery condition, PV output and several engine parameters, including operating temperature and run time, with these parameters then determining the system operating mode.

For utility-Interconnected systems, IJV energy cannot be scheduled or dispatched, because its availability is dependent on the whims of nature. PV is, therefore, an intermittent resource, and is used as a fuel saver, not a source of utility capacity. A PV system with a battery for energy storage can be considered as firm capacity, since the battery system can be discharged upon demand. In areas where electric demand peaks in the daylight hours, PV has proven useful in reducing system peaks and in providing voltage support of heavily loaded lines. To avoid difficulties in system dispatch, PV installations probably shouldn't exceed 15 to 25 percent of system capacity.

\section{Cost Estimates for Photovoltaics in American Samoa}

The costs for installing PV systems on the mainland vary from about $\$ 8.50$ per watt for a $100-\mathrm{kW}$ grid-intertied system to about $\$ 15.00$ per watt for a complete stand-alone system, including batteries. Roughly three-quarters of this cost is for material, and the remainder is for installation. It is expected that PV systems in American Samoa will cost about 25 percent more than on the mainland because of the expenses of transportation and contractors' unfamiliarity with site and working conditions.

As a rough rule-of-thumb, for a small, stand-alone PV system, figure that a load requiring 500 watt-hours per day can be supplied by a complete PV system (including batteries and controllers) for about $\$ 2500$ or less. Because PV systems are modular, larger systems are simple multiples of smaller systems. With this perspective, it becomes apparent that the farther a load is from an existing line, the larger it can be and still be economically served by PV.

Photovoltaic system energy costs around $\$ .30$ to .40 per $\mathrm{kWh}$, clearly too high for $\mathrm{PV}$ to be installed as a pure energy source. These costs are based on 
twenty-year system life, 99 percent system availability (that is, nothing is broken, so If the sun shines, energy will be produced), and 1500 equivalent full sunhours per year. There are, however, instances in which the energy cost is not the important factor in selecting a power source. If PV can be installed for less money than a conventional energy source (generally for loads requiring less than $1000 \mathrm{kWh}$ per year), then energy cost is immaterial. If a remote load is being served by an engine/generator and fuel delivery is costly, cumbersome or sporadic, then a $\mathrm{PV} /$ battery system can be used to provide a small base generation with the engine/generator being used when large amounts of energy are needed on an irregular basis and to charge the batteries during lengthy spells of bad weather. These two scenarios, loads with low energy requirements and remote loads served by engine generators are today's cost effective PV applications.

\section{Recommendations for Photovoltaics in American Samoa}

Introduction--The recommendations for PV systems fall into two categories: those systems that will add immediate economic benefit, and those that will provide operational experience that can be applied to future grid-intertied systems. A threephase photovoltaic energy plan is recommended. Both recommendations in Phase I provide immediate economic benefit. Phases II and III are not predicated on successful completion of Phase I, but will benefit from the experience gained in Phase I. Phase III is predicated on successful completion of Phase II.

\section{Phase 1--PV Installations with Immediate Benefit}

1-a. Small systems. In this first phase, ASPA should install five small (50 to 500 watt) PV systems as pilot systems. This will provide experience in procuring, installing and operating PV systems and provide the necessary historic information needed to determine maintenance requirements. These systems should be the type that are installed because PV is the least-cost option.

It is recommended that ASPA set up criteria for determining when a load is more appropriately served by PV than by conventional service. This criterion should be based on cost of initial installation only and should be graduated to reflect the correlation between load size and distance to load. A hypothetical example will illustrate this type of criterion. If a load only requires addition of a transformer, 
arrestor, fused cutouts and a service drop at an installed cost of $\$ 1000$, then a 65-watt PV system can be installed for the same price. (These are estimates, and they should be confirmed by ASPA data and price quotes from PV vendors.) In most locations in American Samoa, a 65-watt PV array will produce about 250 watt-hours daily. Therefore, any load that uses less than 250 watt-hours daily (on an annual basis, that is, less than $250 \times 365=91.25 \mathrm{kWh} / \mathrm{yr}$ ) is a good candidate for FV service, even if it is right beside the utility line. Other criteria can also be developed. For example, the cost of line extension can be added to the cost of service. This will then result in a larger size of PV system bre aking even with conventional service.

Utilizing these criteria, ASPA should review new loads it installs having low energy requirements and screen them for potential service with photovoltaics. The screening process will help identify the type of load that fits the established criteria, from which five projects should be selected. The five projects should be selected both on the basis of the economic criteria and on easily accessible locations. This will encourage frequent visits to the sites during the early operation period. These visit, will provide high visibility for the PV project, as well as help to establish the maintenance requirements for PV systems in American Samoa. These installations will not only provide American Samoa with financial benefit because of the reduced cost of service, but will also provide PV system reliability and performance information that can be used in future PV installations.

1-b. Large Systems. A specific site where a larger PV system can be of benefit is Swains Island. It is recommended that a PV system, including batteries and system controller, be designed and installed to operate as a hybrid system with the existing engine/generator on Swains Island. Unconfirmed infor:mation indicates that a 2-kW PV system with a 2000-ampere-hour battery system should serve the needs well. This would include lights, communication gear and a vaccine refrigerator. Such a system installed on Swains $\mathrm{k}$ 'and will cost approximately $\$ 40,000$. Before such a system is designed, however, more precise information on present and projected loads on Swains should be obtained. 
II-a. PV Only. There are a couple of locations where a larger PV system can be installed to gain operational experience with PV in anticipation of the time when $\mathrm{PV}$ will be an economic choice for energy generation on Samoa. Such systems vary from those in the previous discussion in that they include an inverter to allow interconnection with the utility's ac system, but don't typically include batteries. The site selection criteria for such an installation should include factors such as good solar resource (Cape Matatula is a better choice than the mountains surrounding Payu Pago harbor, finer analysis isn't necessary for an early project like this), ease of access (to encourage frequent visits by interested parties), available unshaded ground (rules-of-thumb: $1 \mathrm{~kW}$ requires $10 \mathrm{~m}^{2}$ surface area, $100 \mathrm{~kW}$ requires 2000 $m^{2}$, or roughly $1 / 2$ acre, because internal system access for a large system doubles land requirement), and an existing distribution line that could benefit by energy support. A 10-kW system should be installed. This should be a complete utilityintertied system, including an inverter designed for use with a photovoltaic system. Such systems on the U.S. mainland have been instailed recently at about $\$ 10$ per watt. It is estimated that such a system can be installed on Tutuila for $\$ 15$ per watt, giving a total system cost of $\$ 150,000$. Over a 20 -year life this works out to roughly $\$ .35 / \mathrm{kWh}$ (this energy value is heavily dependent on economic assumptions, such as inflation and cost of money).

II-b. Battery Addition to PV System. After the system in II-a has successfully operated for a minimum of one year, the system should be retrofitted with batteries. At that time, the inverter should also be changed to one specifically designed for PV/battery operations. (Such inverters are not commercially available today. However, the development required to produce such inverters is minimal compared to that alr zady invested in the current PV specific inverters, and is not expected to pose any serious problems. This phase of the project should not be started until such inverters have been thoroughly tested and proven to be commercially sound.) The battery should be sized for four hours' operation at the rated inverter output, or $40 \mathrm{kWh}$. This battery, completely installed will cost approximately $\$ 10,000$. 
Phase III--Support of Remote Distribution Lines

An additional application that could be very beneficial to American Samoa is power support of distribution lines serving individual semi-isolated communities. A utility-intertied PV system with batteries could provide voltage support during normal system operation with the added benefit of reducing line losses, as well as maintaining power to such locations for a few hours during outages. In addition, the batteries in the system can act as a load-leveling device. The size of such a system is dependent on exactly what is to be accomplished. Sume examples will illustrate the options, using the two communities of Aunu'u and Fitiuta.

Both these locations are at the end of relatively long feeders needing voltage support; thus they fit the criterion of having significant losses and are subject to weather-induced outages. Average daily loads for the winter of 1989/90 were $385 \mathrm{kWh}$ for Aunu'u and $595 \mathrm{kWh}$ for Fitiuta. The basic discussion will be for Aunu'u, with Fitiuta discussed when points specific to Fitiuta need addressing. All numbers for Aunu'u can be increased by 50 percent to apply to Fitiuta.

If a PV/battery system were installed to provide total support for Aunu'u, the PV array would need to be about $80 \mathrm{~kW}$ and the battery would need to store about three days' energy (to account for cloudy days when the PV can't recharge the batteries), or roughly $1200 \mathrm{kWh}$. With PV system installed costs of $\$ 15 /$ watt and battery costs of $\$ 200 / \mathrm{kWh}$, that means a system cost of close to $\$ 1.25$ million dollars.

Changes in the philosophy of what the PV battery system is to accomplish can dramatically impact the size of the system, and therefore its cost. The Fitiuta system is a good example. Note that the 50 percent greater load means that a roughly $\$ 1.8$ million system is required to support Fitiuta totally. But perhaps total support isn't necessary. A system can be installed with the aim of daily load leveling (with the associated. benefits of loss reduction) and the added goal of maintaining only critical loads (the proposed new airport, for example) during power outages. More accurate figures are needed to properly determine system size, but enough information can be estimated to take a first cut at what is necessary. What follows is strictly an estimate. 
Assume that, on the average, the daily peak load is roughly $20 \mathrm{~kW}$ greater than the daily average load. In addition, assume that this daily pe. $k$ lasts roughly from 6 p.m. to 9 p.m. Two points should be noted. First, the daily peak is too late for $\mathrm{PV}$ to be directly beneficial; that is, the sun is setting. Second, the additional energy required to meet this peak is $60 \mathrm{kWh}$. If a PV/battery system is installed that can generate and store enough energy to meet this $60 \mathrm{kWh}$ daily need, it will satisty many of the same needs as the $\$ 1.8$ million system described above. Such a system would require a $15-\mathrm{kW}$ array and a $180-\mathrm{kWh}$ battery for a total estimated cost of roughly $\$ 260,000$--or roughly one-sixth the cost of the original system. Both of these strategies have the additional benefit that if peak load is near generation capacity, new capacity additions can be delayed.

Two interesting aspects of this discussion deserve a bit closer attention. First, the benefits of load leveling, loss reduction and voltage support don't require the photovoltaic system--batteries alone can accomplish this. The batteries can be charged during off-peak hours and discharged during on-peak hours. Southern California Edison currently has an experimental 40-MWh battery installation performing this function. A battery-only system for Fitiuta would reduce system cost to roughly $\$ 40,000$. Batteries are discussed further in a separate section of this report. Second, with the photovoltaic array, and judicious sectionalizing, those loads considered critical to the community could be served indefinitely in the case of a prolonged outage. With the $15-\mathrm{kW}$ PV array and $180-\mathrm{kWh}$ batteries, roughly $60 \mathrm{kWh} /$ day can be served, probably adequate for airport and medical needs in the case of emergency.

Budgot Summary--Estimated Total Costs for Recommended Photovoltaic Program

$\begin{array}{llr}\text { Phase I-a } & \text { Small Systems } & \$ 10,000 \\ \text { Phiase I-b } & \text { Large Systems (Swains) } & 40,000 \\ \text { Phase II-a } & \text { Grid-Connected PV } & 150,000 \\ \text { Phase II-b } & \text { Add Batteries } & 10,000\end{array}$




\section{Solar Thermal Energy Systems}

The sun has been used as a source of heat since man's early days; however, in the past century the sun was rapidly displaced by fossil fuels as a heat source. With the escalation in the cost of fossil fuels during the last couple of decades, many people are turning to alternative means for heating, including turning back to the sun,

Solar energy can be used for heating in different ways. Flat-plate collectors are appropriate for heating water to around $120^{\circ} \mathrm{F}$ to $180^{\circ} \mathrm{F}$, as is required in homes or buildings for hot water supplies. If the sun is concentrated by mirrors or lenses, temperatures up to $1000^{\circ} \mathrm{F}$ can be obtained, as is required for process heat. Concentrating solar thermal systems depend on the "direct-normal" component of sunshine (that portion which casts a sharply-defined shadow), while flat-plate systems can utilize all solar energy. Areas with significant cloudiness don't usually have as good a solar resource for concentrating systems as they do for flat-plate systems. In addition, concentrating systems must be aimed directly at the sun, and thus they require a tracking mechanism. The areas of hot water supply and process heat are treated separately in the discussion that follows.

\section{A. Solar Hot Water Supply Systems}

\section{General Description of Hot Water Supply Systems}

Flat-plate solar thermal collectors, as are used in hot water supply systems, are both simple in concept and simple to use. Unfortunately, they are not necessarily simple to build. In the early 1970 s many people tried to build and sell flat-plate thermal collectors and later found that there was more to building them than simply putting black pipes in a box covered with glass. Some of these early projects resulted in such bad experiences that solar heating has a bad connotation in some locations to this day. Fortunately, the solar industry has come a long way since those early experiences and today there are certification laboratories that test and certify solar thermal flat-plate collectors, and many suppliers who have had their products certified. 
Solar hot water systems applicable to American Samoa can be quite simple, thanks to the lack of freezing temperatures, which allows designs without freeze protection. As illustrated in Figure 3, a typical system will utilize a solar collector installed in the incoming water line before the conventional water heater. This allows the sun to heat the incoming water before it enters the water heater, so the conventional heater does not have to do any heating whenever the sun is shining. If hot water is required at night or on cloudy days, the conventional heater works as though the solar heater were not there. Even on moderately overcast days, the solar heater will add warmth to the water, so the conventional heater will not require as much fuel to get the water to the desired temperature.

Another benefit from using residential solar hot water systems is the reduction of ASPA's evening peak. Even though this peak occurs after sunset (around 7 p.m. to 8 p.m.), the solar collectors have adequate storage (around 40 to 60 gallons) to provide families with most of their hot water needs. This storage allows the hot water generated during the day to be used at night, without the use of energy from ASPA.

Solar hot water systems can also be used on larger buildings where the hot water requirements are a little more complex (see sidebar on LBJ Hospital). Because of their increased complexity, these systems are usually individually designed, and are not a standard packaged system, as is normal for residential hot water systems.

\section{Resource Base in American Samoa}

Some types of solar energy systems require a rather precise knowledge of the local solar resource for design purposes. Residential DHW systems do not require this detailed information because they always include a conventional water heater in the system. Thus the solar heater provides what energy it can from the available resource, and the conventional heater makes up the difference. Therefore, a precise knowledge of the resource base is not necessary. The area for which the available solar resource is important is economics--the better the solar resource, the more rapidly the solar heater pays for itselt. In American Samoa, the solar resource varios between moderate and good, meaning that solar residential hot water systems will have a typical payback period of around 5 years when compared to heating water with electricity. These systems should last at least 20 years. 


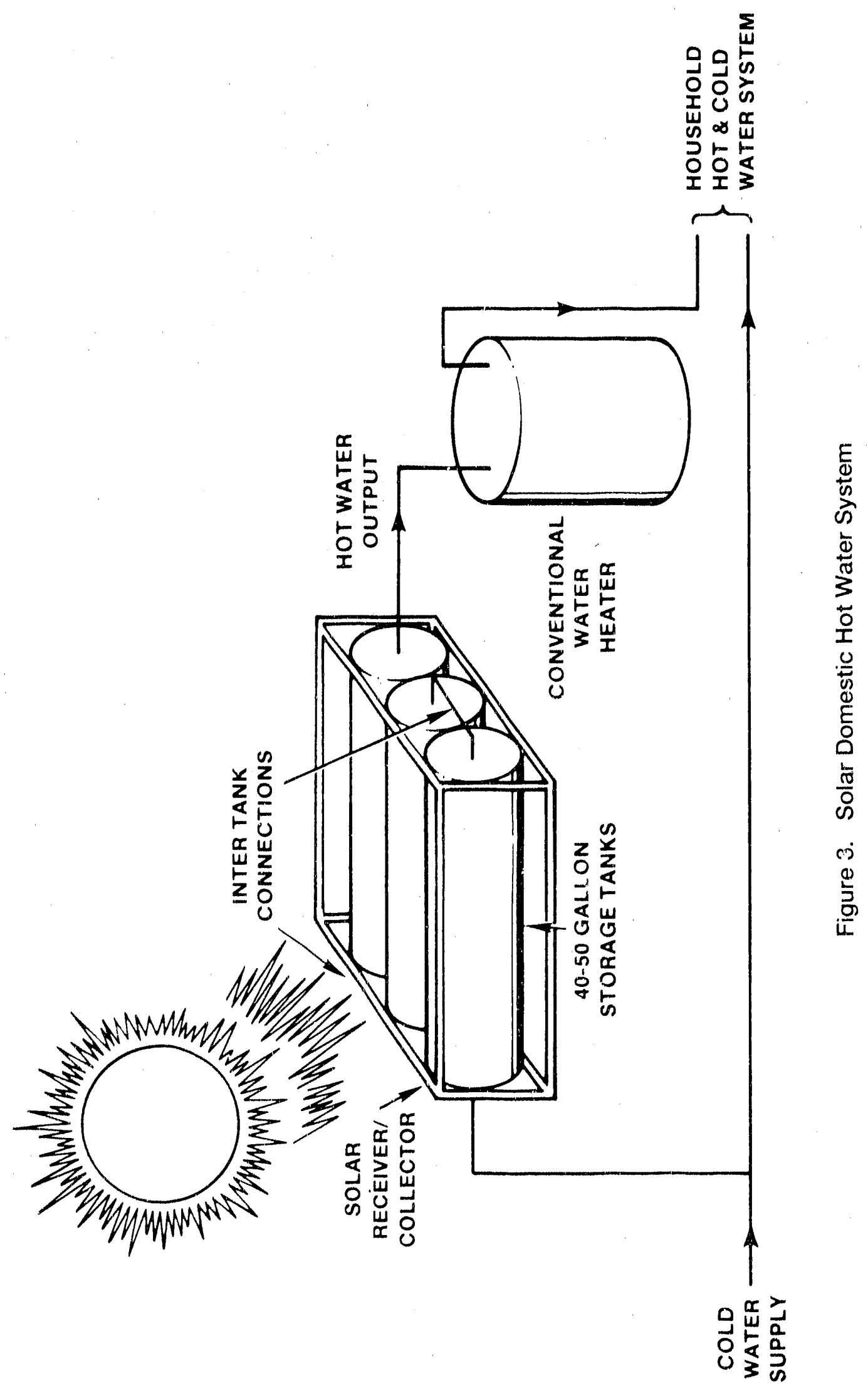




\section{LBJ HOSPIT 1 L SOLAR THERMAL SYSTEM}

A solar thermal system was installed at the LBJ hospital in 1981. The system was to operate approximately 30 tons of absorption chillers for air conditioning the hospital. Because of a number of problems (most of them associated with the complexity of the absorption chilling process, not with the solar thermal system), the system was never fully functional. Conversion of the solar thermal collectors to hot water production was found to be a better use than trying to resurrect the absorption cooling system.

The U.S. Department of Energy made $\$ 20,000$ available for the conversion and asked Earl Rush of Sandia National Laboratories to visit the site and to design the retrofit as a service of the Renewable Energy Design Assistance Center. Mr. Rush made an initial visit to confirm that conversion of the system to hot water production was feasible and to check on the adequacy of the panels left from the original installation. He will monitor details of selecting new materials and will check out the system when the project is completed.

Personnel with the Territorial Energy Office have removed many of the collectors from the support structure to test for leaks. They found some of the collectors are damaged from sitting unused with daily heat cycling, which concentrates corrosive minerals in the water left standing in them. Also, the uncovered wooden support structures are rotting at many of the connection points. New solar panels will be purchased using funds from an insurance settlement on damage caused by Hurricane Ofa in February 1390 . This system would be a supplement to the existing water system, one using a diesel engine to generate steam to be used in a sterilizing process for hot water.

With water usage at the hospital averaging 3500 gallons per day, approximately 200 square meters of collector (100 collectors) will provide all the hot water required on low-usage days and will provide a useful supplement on high-usage days. The project will be beneficial to the hospital, with solar energy displacing about 65 percent of the energy normally used to heat water. Completion is expected to be in late 1990.

Both cooling loads and hot water production loads could be reduced if the hot water pipes were insulated. The presently uninsulated pipes lose significant heat into the building, where it adds to the heat that must be removed. Insulating hot water pipes usually pays for itself in a short time, two or three years depending on the cost of the fuel used to generate heat. 


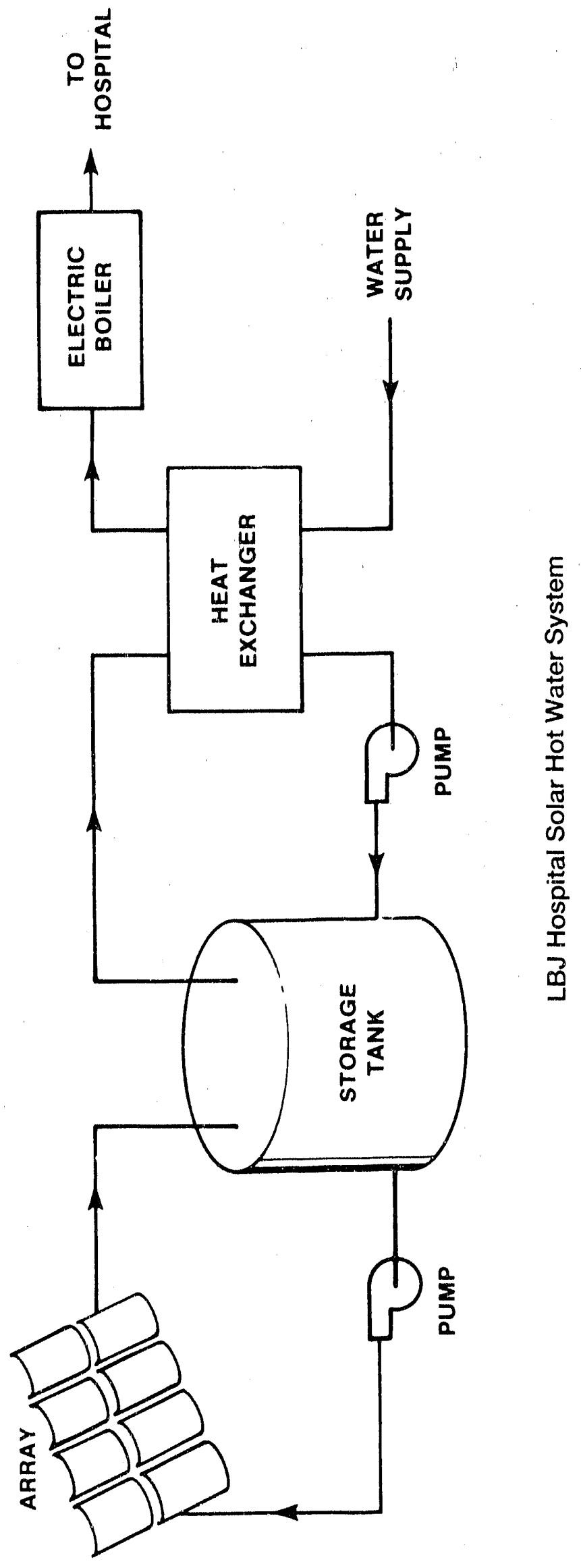




\section{Maturity of Conversion Technology}

Solar thermal hot water systems using the equipment available today are a relatively new technology having less than 20 years' experience. However, the number of systems installed in that time (at least 100,000 ) has provided a tremendous experience base from which the industry has gained insight into design and construction techniques. As a result, today's certified collectors are very dependable and the simple installations that a non-freezing environment allows are equally dependable.

\section{Will Solar Thermal Hot Water Systems Work in American Samoa?}

There should be no major problems with solar hot water systems in American Samoa as long as carefully selected components are used. As previously mentioned, selecting collectors that have been certified by one of the U.S. certifying agencies (Solar Rating and Certification Corporation is the largest and best known) is a means of ensuring a quality product. In addition, the manufacturer's warranty should be examined. Many manufacturers offer a fiveyear warranty, with some offering ten-year warranties.

The quality of installation is equally important. All installations should use new copper pipes and be installed by qualified personnel to ensure a long system life. If these precautions are followed, solar hot water systems should work very well in American Samoa with life expectancies near 20 years.

5. How Will Solar Hot Water Systems be Used in American Samoa?

The main application of solar hot water systemis in American Samoa is anticipated to be residential use. These systems are easy to install and lend themselves well to prepackaging without the need for detailed design for each installation. The systems pay for themselves in a matter of a few years when compared with using electricity to heat water. An additional use for solar hot water is in commercial buildings, such as hotels and restaurants. For commercial buildings that use electricity to heat water, solar hot water systems will have payback periods similar to those for residential systems, that is, around 5 years. 
The anticipated payback compared to those presently using gas to heat water will not be as rapid because gas is generally a cheaper heat source than electricity.

\section{Cost Estimates for Solar Hot Water Systems in American Samoa}

Collectors for solar hot water systems are the major co:.. On the U.S. mainland, collectors with 40 -gallon storage, as are appropriate for residential systems, typically cost $\$ 1000$. Such collectors, after transport to American Samoa will probably cost about $\$ 1200$. Installation is straightforward, requiring roof mounting and rerouting of plumbing. A completely installed residential system will probably cost $\$ 1500$.

For larger systems, about 1000 square meters of collector will provide 6 MBTU per day in a sunny location on Tutuila, at an installed cost of $\$ 500$ per square meter. Such systems will generally be cost competitive with conventional energy sources that cost $\$ 5 / M B T U$ or greater.

\section{Recommendations for Solar Hot Water Systems}

Introduction--Residential solar thermal hot water systems will benefit the individuals who use them by reducing utility bills and will benefit ASPA by reducing peak demand, thereby postponing the requirement for adding new generating capacity. The degree of these benefits can only be speculated on without actual experience. The purpose of these recommendations is to gain the required experience, determine the degree of benefit and then establish future objectives. A three-phase program is outlined to gain a thorough understanding of the impact of residential solar hot water systems in American Samoa.

\section{Phase 1--Initiation of Pilot Program}

A number of participants (ideally 20 or more) should be selected to have solar hot water systems added to their homes. These people should be carefully selected based on the following criteria:

1. Willingness to cooperate in this program--the program may require access to their homes for periodic system inspection, or periodic reporting of water usage information. 
2. Having lived in the same home for at least a year--in order to see the impact of the solar hot water system on their utility bill, they must have past information to compare with.

3. A relatively stable home environment--the addition of a new child to a family can have a dramatic impact on water usage, making before and after comparisons difficult.

4. Selected people living in a variety of locations--to gain information on the effectiveness of these systems in different parts of Tutuila.

Once the participants have been selected, the hot water systems should be installed, preferably using collectors purchased by either the TEO or ASPA (to ensure quality collectors) and installed by a local business (to gather information on installation costs and potential problems). The Renewable Energy Supervisor should be intimately involved in these installations to establish a thorough understanding in case of any future problems.

\section{Phase II--Systems Operation}

The solar hot water systems should be operated for at least one year, during which time their performance would be monitored to ensure proper operation and to ensure that the required information is being obtained. Required information includes the impact of the solar hot water system on electricity consumption and customer satisfaction with the system. During this period, the Renewable Energy Supervisor should examine the bills of the people with solar systems, comparing them against bills for the same period in previous years, to determine the trends that are being seen. The RES should investigate any apparent unexpected data and determine its cause, and should contact the homeowners to establish the level of satisfaction with the systems.

\section{Phase III--Analysis}

After a suitable period (one year minimum) the information gathered should be analyzed from the point of view of 1) benefit to the customer, 2) benefit to American Samoa, and 3) benefit to ASPA. This analysis should determine whether 
an aggressive program to install solar hot water systems should be pursued in American Samoa. The pilot program should be considered a success if any of the following criteria are met without causing negative impacts elsewhere.

1. Customers with solar hot water systems see a reduction in electric bills that would pay for the solar system in less than 5 years, with no negative impact on hot water availability.

2. It can be demonstrated that these hot water systems offset fossil fuel consumption as well as provide employment opportunities for system installers.

3. It can be demonstrated that the solar hot water systems reduce electricity demand during ASPA's system peak.

Assuming that at least one criterion is met with no offsetting negative impacts, then a program should be established through either the TEO or ASPA (or both working jointly) to make solar hot water systems readily available to all residences. Effective means of accomplishing this can include letting customers pay for the systems over a number of years with no interest as part of their utility bill. The degree of assistance given to homeowners to obtain solar systems should be based on the benefit to all parties involved, with greater benefit resulting in greater ease in acquiring systems.

Budget Summary--Estimated Total Costs for Recommended Residential Solar Hot Water Program:

$$
\begin{aligned}
& \text { Phase 1. Pilot Program } \\
& \text { (assuming } 20 \text { participants) } \\
& \text { Phase II. System Operation -0- } \\
& \text { Phase III. Analysis -0- } \\
& \text { Total } \quad \overline{\$ 30,000}
\end{aligned}
$$

Note: Phases II and III require no additional funding as no hardware is required. Labor for these two phases should be supplied by the TEO or ASPA (or both). 


\section{B. Solar Industrial Process Heat (IPH) Systems}

\section{General Desicription of Solar Industrial Process Heat Systems}

Solar industrial process heat (IPH) systems differ substantially from those for domestic hot water. Because the temperature required for process heat is higher than for domestic use (from a few hundred to a thousand degrees $F$ ), the collectors must be able to concentrate sunlight. As shown in Figure 4, this requires the use of lenses or mirrors, and they in turn require that the collector move during the day to follow the sun. Because of the focusing by lenses or mirrors, these systems can only utilize the direct-normal component of solar energy. Knowing what portion of total insolation is direct-normal requires instruments capable of making that specific measurement. It is not known if such instruments are currently in use in American Samoa. These systems also require a working fluid that will not boil at the high operating temperatures used for process heat. This results in such fluids as oil or water/glycol circulating in the collectors and then using heat exchangors to transfer the heat to water, producing steam. The working fluid can also be stored so that a smooth flow of energy can be deliv ared over the necessary time period ( 24 hours per day can be accomplished) in spite of fluctuations in solar intensity. As an alternative, the solar energy can be supplemented with LPG to even out energy flow.

The tracking systems required to keep the sun focused on the working fluid have a level of complexity greater than flat-plate systems, which are permanently fixed in place. This increased complexity means that a solar IPH IPH system must be of a certain minimum size to justify the expense of the which will produce about 2 MBTU per day in most locations in American Samoa. Because of the nature of solar IPH systems, they are best installed on facilities where there is an interested and knowledgeable maintenance superintendant or facility engineer who will be able to inspect the system on a regular basis and will be able to understand and correct adjustment problerns as they occur. These systems are not complex, but they must be attended to on a regular basis in order to get maximum benefit from the installation. 


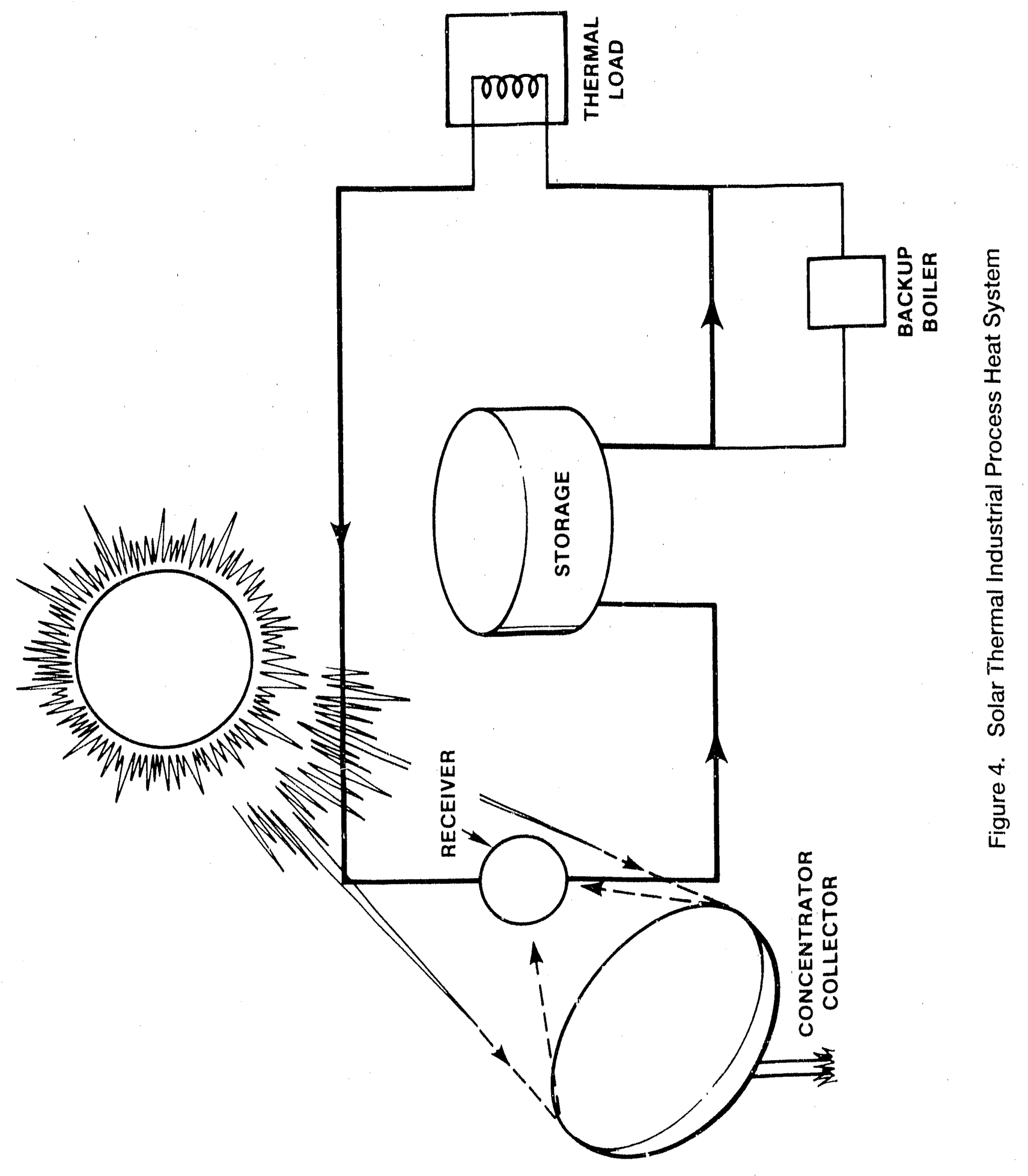




\section{Resource Base in American Samoa}

The solar resource in American Samoa is generally good, but significant variation exists in the solar energy available in different locations. Also, it is not known what portion of the insolation is direct-normal, which is the portion required for IPH systerns. Typically, the coastal areas will receive more insolation than the mountains. The geophysical monitoring station at Cape Matatula, which has been monitoring solar insolation since 1976, indicates summer averages of $4 \mathrm{kWh} / \mathrm{m}^{3}$ per day and winter averages near $7 \mathrm{kWh} / \mathrm{m}^{2}$ per day. Again, it is not known what portion of this is direct-normal. A person familiar with the relation between sunshine at Cape Matatula and other Samoan locations can use these values to estimate insolation availability at other locations. To get really accurate values, however, monitoring at a specific site is necessary.

\section{Maturity of Conversion Technology}

The trough and tracking technology for these systems has benefitted tremendously from the experience gained at the Luz facility in southern California. This site currently has about 1.9 million square meters of installed parabolic trough receivers. The system uses natural gas as a supplement to thie slil so that energy flow can coritinue smoothly when cloud cover reduces solar heat gain. This same principle can be used in American Samoa for process heat.

There are also commercial IPH systems operating at Brighton and Aurora, Colorado; Phoenix, Arizona; and Tehachapi, California. The first of these was installed in 1982. There are several commercial suppliers of solar systems designed to produce process heat.

4. Will Solar Thermal Industriai Process Heat Systems Work in American Samoa?

American Samoa may be a good location for solar IPH systems. The solar resource and generally mild climate appear favorable. The impact of hurricanes on the tracking structures required for IPH systems could be devastating, and particular care should be exercised to include adequate wind loading in specifying systems. All components shou!d be specified with due consideration for the moist, salt-laden tropical air, which is extremely corrosive to many materials. As with any system having moving parts, maintenance will be an issue with these systems. One criterion 
for determining whether a solar IPH system should be installed is the availability of an individual at the system site who will have both the interest and ability to examine the system several times a week to ensure that it is functioning properly and adjust it if necessary. This person will not be the Renewable Energy Supervisor, but someone associated with the facility using the IPH system.

\section{How Will Solar Industrial Process Heat be Used in American Samoa?}

Solar IPH can be used in any location where process heat is required. These requirements are normally for a continuous supply of process heat, so some form of supplement or storage must be used. Process heat as required at the tuna canneries is a prime example of this application.

\section{Cost Estimates for Solar Industrial Process Heat Systems in American Samoa}

In American Samoa a solar IPH system utilizing about 1000 square meters of collector will produce roughly 6 MBTU per day (dependent on good site selection). Such a system has an installed cost near $\$ 300,000$, and its life expectancy on the U.S. mainland is 20 years. Insufficient data exist to predict its lifetime in American Samoa, but IPH system designers would design for 20 years. The only question would be whether they had foreseen all factors that affect lifetime and had included them in the design.

\section{Recommendations for Solar Industrial Process Heat Systems}

Users of process heat in American Samoa should investigate the economic benefit from a solar thermal system to generate heat because of the relatively high cost of gas in Samoa. Depending on the size of the system, solar thermal systems in Samoa can generate heat at \$9/MBTU. (Increasing the system size reduces the price per unit of energy.) Perhaps the most important criterion for installing a solar thermal system is not economics, but the availability at the site of a technically capable individual who is interested enough in the system to learn about it in detail and to see to proper operation and maintenance of the system. Solar thermal systems are no more complicated than conventional process heat systems. However there are differences, and these differences require that a person have enough interest to learn the details of day-to-day opcration. 
The tuna canneries in Samoa are ideal first users of solar thermal energy for process heat because of their requirements for process heat and the availability of in-house technical expertise. It is recommended that the canneries be contacted to determine interest in such a project. Should the interest exist, then a preliminary design can be performed by the Design Assistance Center at Sandia National Laboratories, and a cost analysis can be performed to determine a payback period for the system. The preliminary design would include gathering solar data at the cannery site for a minimum of six months (spanning both dry and rainy seasons). If the results of the analysis appear favorable to the cannery(ies), the companies could then make the decision to purchase such a system.

\section{Wind Energy Systems}

\section{General Description of Wind Energy}

Wind energy systems harness the wind and convert it into another form, such as mechanical energy to pump water or electrical energy. This discussion focuses on wind energy to generate electricity, as illustrated in Figure 5. The principles of operation are quite simple and well known; wind energy systems have been in operation for hundreds of years worldwide. Modern systems take the principles of the past and apply today's engineering and materials knowledge to extract the most energy from the wind at the lowest cost.

Wind energy technology has benefited dramatically from the experience of wind machines installed for commercial purposes in California and Hawaii. These two states share a total of nearly 15,000 wind machines with a capacity of around $1300 \mathrm{MW}$. With that many machines, there are bound to be failures, and there have been. Both the failures and the successes at these installations have provided both the U.S. Department of Energy and the private companies involved in the projects with an enormous test bed to evaluate the various aspects of designing and manufacturing wind turbines. This experience has significantly improved the reliability of wind turbines and has identified areas where directed research can further benefit the wind energy industry. In the right environment and with proper maintenance, today's wind turbines can produce energy competitively with the more expensive conventional energy sources. 


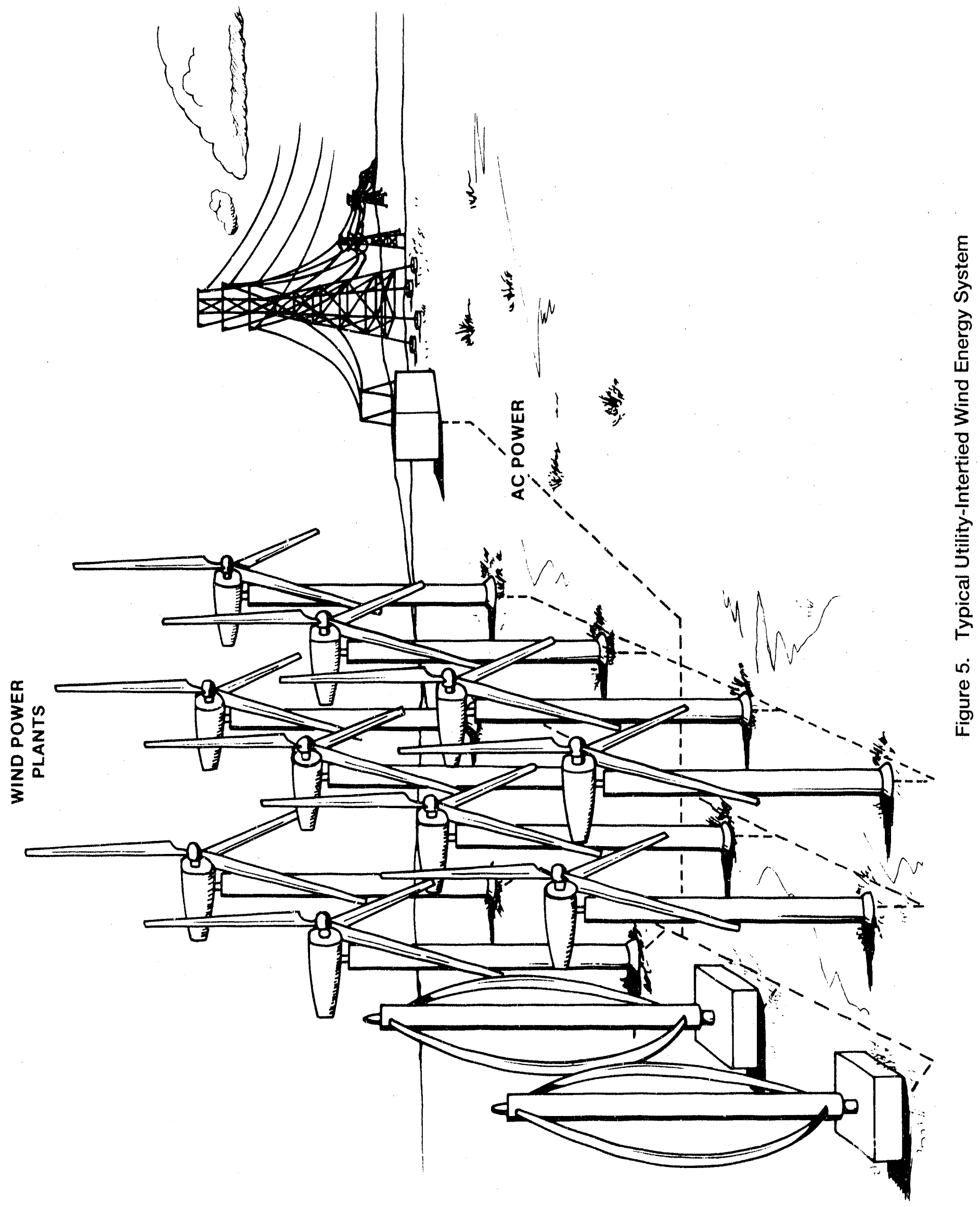


The California and Hawaii experience base has concentrated for the most part on machines in the range of $100 \mathrm{~kW}$. Significantly smaller--or larger--machines have different mechanical designs and often use different materials. Therefore, the lessons learned in the large windfarms are not directly transferrable to wind machines in sizes of either 1 or $10 \mathrm{KW}$.

Wind turbines are more subject to high degrees of variability in energy output and component lifetime than are many other technologies. This variability is a function of the wind resource at the specific location where the turbine is installed as well as the turbine's design. For example, an increase in wind speed from $13 \mathrm{mph}$ to $15 \mathrm{mph}$ will result in a 50 percent increase in energy production, but will also result in a reduction in component lifetime. This lifetime reduction is difficult to predict, because it is a complex function of wind speed distribution, turbine design, and component materials.

Current experience suggests that the tradeoff be made toward higher average wind speeds and increased maintenance because the value of the increased energy production will be greater than the cost of the increased maintenance. The only way to answer tradeoff and value questions for a specific location, such as American Samoa, is to install pilot systems inlocations similar to where one would install commercial machines. Properly maintained and monitored, such a system will prove valuable in determining the prospects for future wind turbines. Such pilot installations should include wind turbines of a size and design similar to the proposed long-range plans for the installation.

\section{Resource Base in American Samoa}

Islands with the mass and dramatic topography of those in American Samoa usually have several sites where the wind is of adequate intensity and duration to support installation of wind turbines. The unmodified trade winds found in the area are insufficient for wind energy production. The Samoan islands, however, are capable of modifying the winds by diverting windflow from some areas and concentrating it in others. Since monthly average energy available from trade winds is relatively predictable on a year-round basis, it makes the associated enhanced winds equally predictable. Estimates show many sites that are favorable from the standpoint of a wind resource (see map, Appendix D). It remains to be seen 
whether these sites are favorable from the standpoint of access for people and equipment or access to a power line. It should be understood that the wind power levels shown on the map in Appendix D are estimates, and must be verified by instrumented monitoring before a site is selected for wind energy production. Such monitoring should be for a minimum of a year.

\section{Maturity of Conversion Technology}

In many ways, wind energy technology is quite mature. The thousands of systems in the field have provided an extensive test bed for development and refinement of wind machines. As a result, operation and maintenance requirements and energy production can be predicted relatively accurately in areas with which the designers are familiar, which includes most areas of the U.S. mainland and Hawaii. These locations include everything from severe winter climates such as mountaintops in Montana, where ice buildup and the associated increased wind and structural loading is a problem, to warm, salt-laden climates such as are found in Hawaii and the Caribbean, where corrosion and hurricane-force winds are the main problem.

An area of specific concern to American Samoa is the increased wind speeds associated with hurricanes in the region. Most wind system designers use $120 \mathrm{mph}$ as the maximum wind speed for design purposes, with modifications for special applications. One designer uses $165 \mathrm{mph}$ as the basic design wind. This same designer has supplied two systems that were designed and warranted for winds of $200 \mathrm{mph}$. These two systems have not yet been exposed to this magnitude of wind. The system designer said that such a modification added roughly 75 percent to the cost of the system.

\section{Will Wind Energy Work in American Samoa?}

Two areas of question exist regarding use of wind energy technology in American Samoa. The first is the periodic occurrence of $200 \mathrm{mph}$ winds and the second is the maintenance requirements in the Samoan environment. Two approaches can be taken to resolving the high wind issue. One is to design a strong enough system to withstand this wind, and the other is to design the systems to be lowered to the ground and secured when a hurricane is approaching. This latter technique has been used successfully in Barbuda where 
the wind turbines were lowered to the ground and thus survived Hurricane Hugo, during which winds were clocked at more than $200 \mathrm{mph}$. The first method, designing the systems for $200 \mathrm{mph}$ winds, has not been field tested, which is the only means for confirming that it will work. Such designs can be tested by static loading, but the buffeting actual winds produce has a dramatic effect on structures that static loading cannot produce. There is no technological reason why wind energy systems cannot withstand $200 \mathrm{mph}$ winds, but there is an associated expense. This expense then affects the energy value of the systems.

Maintenance and troubleshooting of unfamiliar equipment can be uvercome through a workshop and familiarizing session provided by the person or firm associated with installing the original equipment. In addition, increased understanding of the equipment, which comes from living with it for a period of time, will help with establishing maintenance routines. Technicians capable of working on diesel generators will probably find wind machines quite simple, once the basics are understood.

5. How Will Wind Energy be Used in American Samoa?

Since wind energy is an intermittent resource, it may not be available during system peaks. Wind energy, therefore, should be considered as a fuel-saver, rather than as part of the utility's base generation unless experience shows it to be dependably available when needed. Experience with wind systems indicates that patterns of wind energy availability are soon established for a given installation, and these patterns can later be used in dispatching conventional plants to take full advantage of the wind energy when available. Such patterns are site-specific, and various sites on American Samoa will probably produce different patterns, which helps in diversity of energy availability. Because of the intermittent nature of wind energy, there will be some peak generation capacity for wind machines that should not be exceeded to avoid problems in system dispatch. This value is system specific, but is probably in the range of 15 to 25 percent of a system's capacity.

\section{Cost Estimates for Wind Energy in American Samoa}

The costs for installing wind turbines at readily accessible sites on the U.S. mainland are in the range of $\$ 1100 / \mathrm{kW}$. Installation of wind machines at good sites 
on American Samoa will be significantly more expensive because of the remoteness and the rugged terrain. The more machines installed at a given site, the lower will be the cost per kilowatt because of spreading the site development costs over more installed capacity. Until cost estimates are calculated for a specific site on a detailed basis, it is wise to use a high estimate of twice the mainland installed cost, or $\$ 2200 / \mathrm{kW}$.

Energy costs are often quoted for wind systems, and current rumbers are in the range of $\$ .08 / \mathrm{kWh}$. (Such values require assumptions on net energy generated, installed cost, operational life, annual maintenance costs and inflation and interest rates. The values used to arrive at $\$ .08$ are gained from the experience with wind energy in California, none of which may hold for American Samoa.) One aim of early wind installations in Samoa should be the collection of energy output data, maintenance costs and system lifetimes so that energy value specific to Samoa can be determined.

\section{Recommendations for Wind Energy Projects in American Samoa}

Introduction--Wind energy systems may be an economical energy source in American Samoa today when installed in carefully selected locations. If the energy value can come close to the mainland figure of roughly $\$ .08 / \mathrm{kWh}$, the benefit would be immediate. It must be remembered when contemplating potential energy value that maintenance will have a significant impact on energy value from wind turbines. Lack of proper maintenance will guarantee failure. Maintenance intervals will change with different locations as will component replacement intervals. For this reason it is recommended that early installations be on Tutuila where inspection and maintenance will be easier than on any of the other islands. Such installations will help establish inspection and maintenance schedules suitable for the Samoan environment.

It is also recommended that whenever a wind turbine is purchased, replacement parts be purchased so that they are on hand when maintenance is performed, and that new replacements be purchased as soon as existing supplies are used. A final point is to reinforce the recommendation made in the introduction of appointing a Renewable Energy Supervisor who will be made responsibie for monitoring these systems and seeing that regular maintenance is performed. This 
individual should be selected on the basis of a desire to be involved with these systems to ensure the highest probability of success. The RES selected should also be-given the opportunity to be on site when a turbine is being installed, and the installer should be required to give a maintenance and troubleshooting class at which the RES, as well as others, should be in attendance.

A three-phase wind energy program is recommended. Advancement from one phase to the next is dependent on successful outcome of the previous phases.

\section{Phase 1--Wind Resource Assessment}

This phase consists of two parts; replacement of the nonfunctional wind turbine at the Territorial Energy Office, and installation of wind data recording systems.

The nonfunctional wind turbine at the TEO Energy House should be replaced with a new unit from a supplier who can be in a position to supply future turbines to American Samoa. This unit can be small, on the order of a kilowatt or two, but should be a fully functional turbine intertied with the ASPA system in order to gain experience with all the components required for small utility-intertied wind systems. It is important that the Renewable Energy Supervisor be involved with this installation from the beginning, including specifying the system.

In addition, several recording anemometers should be installed at appropriate locations on Tutuila to identify sites for future wind systems. The sites for these anemometers should be selected from those areas on the map in Appendix $D$ that show wind class 4 or higher (13 mph or higher). It is recommended that a wind energy expert be brought to Tutuila to help in siting the anemometers, because their location is crucial. A difference in location of 100 feet one way or another or failure to select the proper height can mean the difference between data that will support turbine installation and data that will not.

The sites should also be carefully selected with maintenance in mind. The first wind turbine installations should have easy access for installation, inspection and maintenance, as well as good access to power lines. Every effort should be aimed toward making the first systems as successful as possible to ensure a 
positive outlook for future installations, and placement of the anemometers should reflect this. Data should be collected for a minimum of one year, and these data should be compared with data from the airport to establish how typical the year has been, before a decision is made to proceed to Phase II. Early in this data-gathering effort, a careful analysis should be performed to determine the expectations, including energy value, for wind energy in American Samoa.

\section{Phase II--Installation of Pllot Systems}

Assuming favorable results from Phase I, some pilot wind systems should be installed. Great care should be taken that they be installed in the locations identifled in Phase I, and not just "pretty close" to these locations. Two or three machines in the 10-kW range should be installed, each from different suppliers. This will provide input on reliability of different machines in the Samoan operating environment, and the 10-kW size will be characteristic of machines applicable on outer islands. Significant design differences generally exist between 1 - and 10-kW machines, as well as between 10- and 100-kW machines. The wind systems installed in this phase should have their energy output carefully metered (perhaps with time-of-day metering) and a log should be kept of maintenance requirements.

The information gathering of this pilot phase should last about three years, longer if no severe weather is encountered in the first three years. The purpose of this installation is to verify the performance and life expectancy, as well as maintenance requirements, of $10-\mathrm{kW}$ wind systems in Samoa. This cannot be considered complete until the systems have been subjected to hurricane conditions, nor should it be implied that what is learned for small machines will necessarily apply to $100-\mathrm{kW}$ machines.

Also at this time additional recording anemometers should be installed on the Manua Islands to investigate the potential for wind energy systems there. As with the first anemometers, these anemometers should be installed by a person well versed in wind energy system data acquisition and system siting.

\section{Phase III--Install Commercial Wind Turbines}

Once the 10-kW machines have been in service for an adequate period to have proven their usefulness, some larger machines should be installed on Tutuila, 
and some small machines on the Manua Islands. These machines should be considered commercial installations, and the sizes should be chosen as appropriate to the power systems to which they will interconnect. To avoid possible problems in system dispatch, Tutuila should not have more than about $3 \mathrm{MW}$ of wind turbines, starting at significantly less than that, say $1 \mathrm{MW}$. This implies the use of ten 100-kW wind turbines, a good size for an initial installation. These 100-kW machines have more data on performance and on operation and maintenance than machines of any other size, because the bulk of the commercial units in California are of this size.

For the same reasons, Ta'u should have an initial installation of three $10 \mathrm{~kW}$ machines and Ofu should have three or four smaller machines with a total capacity of $10 \mathrm{~kW}$. The reason for several smaller machines instead of one larger machine is the diversity in output from several machines tends to result in a smoothing of the input to the power system, which results in less apparent load variation for the cunventional generators.

These commercial installations will probably cost less than the estimated $\$ 2200 / \mathrm{kW}$ used earlier, but more than the $\$ 1100 / \mathrm{kW}$ experienced on the mainland. A figure of $\$ 1600 / \mathrm{kW}$ is used in the following estimate.

\section{Estimated Total Costs for Recommended Wind Energy Development Program:}

\begin{tabular}{clr}
\hline Phase I. & Resource Assessment & $\$ 30,000$ \\
& TEO Turbine & 2,000 \\
\hline
\end{tabular}

32,000

Phase II. Pilot Turbines Additional Res. Asses. 66,000 $\underline{30,000}$

96,000

Phase III. Commercial Installation Tutulla Commercial Installation Ta'u Commercial Installation Ofu 


\section{Battery Systems}

\section{General Description of Battery Systems}

Although not a renewable energy resource themselves, battery systems are frequently used in conjunction with renewable energy technologies to smooth the flow of power into the utillity system. (Batteries are a standard part of non-utility interconnected PV systems for the reason that the sun is not always shining and the load requires a continuous energy flow.) These systems require a power converter that can control the flow of energy into the battery when charging is desired and out of the battery when support of the utility is desired. Batteries used for energy storage also show promise in assisting utllities in peak shaving and providing support for long or heavily loaded lines.

\section{Resource Base in American Samoa}

No particular indigenous resource is required for battery systems.

\section{Maturity of Technology}

The technology concerned with batteries is considered quite mature, because batteries have been employed for many tasks for many years. The batteries used for such systems are, in essence, standard deep-cycle floodedelectrolyte lead-acid batteries, and millions are currently in service. Some questions do remain concerning charge/discharge rates to have optimum life from the batteries, but these questions will be answered as part of current experiments that are ongoing on the U.S. mainland.

The area of utility-intertied battery systems in which the technology is not mature is the power converter, a component that switches between the utility's ac and the battery system's dc. Such converters are not a commercial product today, but are currently under development. The 40-MWh battery system experiment at Southern California Edison uses a converter built by General Electric as a prototype for future production. Several smaller manufacturers with experience in converter technology for renewable energy systems are also developing power converters for use with battery systems. The development process is expected to be 
straightforward, with no anticipated hurdles. A converter for battery systems is much easier to develop than, for example, a converter for photovoltaic systems and mosit of these manufacturers have already successfully accompllshed this feat.

\section{Will Battery Systems Work in American Samoa?}

Battery systems will work well in American Samoa. The technology of batteries is already famillar to many people the world over, so no new concepts are required. One of the possible problems with batteries is dramatic swings in ambient temperature. Batteries are designed to operate at $77^{\circ} \mathrm{F}$. If the amblent temperature is significantly lower than this, the battery capacity is reduced. If the temperature is significantly higher, battery lifetime is reduced. With the moderate temperatures in Samoa, operating temperature extremes will not be a problem.

\section{How Will Battery Systems be Used in American Samoa?}

The main benefits from battery systems expected by the utility industry will be realized in American Samoa. As with most utilities, ASPA experiences a daily peak of a few hours which drives the need to install new generating units. By storing energy in batteries during off-peak and then using that energy on peak, ASPA can better control the use of generating units, and can postpone investment in new units. An additional benefit is the support of weak or overloaded parts of the distribution system. By judiciously placing the battery systems where the distribution system needs support, problems related to voltage regulation and excessive line losses can be eliminated at the same time energy is stored for peak shaving.

\section{Cost Estimates for Battery Systems in American Samoa}

Since this is a technology that is in a growth and experimental phase, it is difficult to predict costs accurately. Fortunately much is known about costs of the most expensive component of the system; the battery itself. It appears that smallto-moderate battery systems ( $40 \mathrm{kWh}$ to $4 \mathrm{MWh}$ ) can be installed for roughly $\$ 300 / \mathrm{kWh}$. 
7. Recommendations for Battery Systems in American Samoa

Introduction--Until converters for utility interconnection of battery systems have been developed to the point that they are a proven commercial product, it is inappropriate to install this type of battery system in American Samoa. However, the time at which these converters are available is expected to be within 5 years, at which point battery systems can be a definite advantage to American Samoa. A two-phase program is recommended to introduce battery systems to American Samoa.

Phase 1--Pilot Battery System

When battery system converters are commercially viable, a $40-\mathrm{kWh}$ battery system should be installed on ASPA's system on Tutuila, for example on the feeder that serves Cape Matatula. This system should be installed far enough from the Satala Generating Station that its impact on the feeder can be seen, but in an easily accessible location to encourage frequent inspection trips. In this way, maintenance requirements for future installations can be established.

\section{Phase II--Commercial Battery Systems}

After operating the Phase I system for a minimum of one year, two additional systems should be installed. These systems should be sized to achieve goals that ASPA determines. Examples are a 4-MWh system on Tutuila to shave system peaks and a 60-kWh system on Ta'u near Fitiuta for peak shaving and line support.

Budget Summary--Estimated Total Costs for Recommended Battery System

Phase 1. Pilot Systems \$ 12,000

Phase II. Commercial Systems $1,220,000$

Total $\$ 1,232,000$

Biological Waste-to-Energy Options

1. General Description of Vvaste-to-Energy Options

Two waste sources in American Samoa present major disposal problems-but also provide the opportunity for enercy recovery. Tuna sludge from processing 
operations of the two huge tuna canneries on Tutuila is presently shipped daily 2.5 miles offshore to an ocean dumping site approved by the U.S. Environmental Protection Agency (EPA). However, this current disposal site is under review bs EPA and may be extended to 5.0 miles, increasing the disposal charges for tuna sludge significantly.

The other waste disposal problem/opportunity is municipal solid waste (MSW). Current disposal practices for MSW involve standard landfill operations. However, there is a serious shortage of available land and cover material, so that the landfill is not operated under sanitary conditions. There is also only marginal compaction of the existing landfill, making it a dangerous surface for dump-truck operations.

The U.S. Department of Energy and the Forest Service of the U.S. Department of Agriculture collaborated in 1986 with the Alnerican Samoa Energy Office, Department of Agriculture, and the Community College Land Grant Program to install a series of test plots of fast-growing trees of different species, for possible use as fuel to replace imported oil. The early results of this test program were promising, ${ }^{7}$ until Hurricane Ofa leveled most of the experimental plots. This continuing risk factor, along with the difficulty in obtaining a long range commitment of commercial land for treefarm operations, raises serious doubts on any significant impact of fuel wood for energy generation. This leaves tuna sludge and MSW as the major candidates for biomass contribution to American Samoa's energy future.

Technologies exist for converting both MSW and tuna sludge to energy by separate processes. Dr. Christopher Rivard, consultant to this project on waste-toenergy recovery from the Solar Energy Research Institute (SERI), proposes a process developed by the Biotechnology Research Branch of SERI to use the combined waste stream of MSW and tuna sludge in a single anaerobic digestion system that would produce energy and a usable residue, as well as eliminate sludge disposal and greatly decrease landfill operations.

The flow diagram for this high solids anaerobic digestion process is shown in Figure 6. utilizing the initial estimates on amounts and composition of American Samoa's MSW and tuna sludge waste flow streams. This proposed proce's 


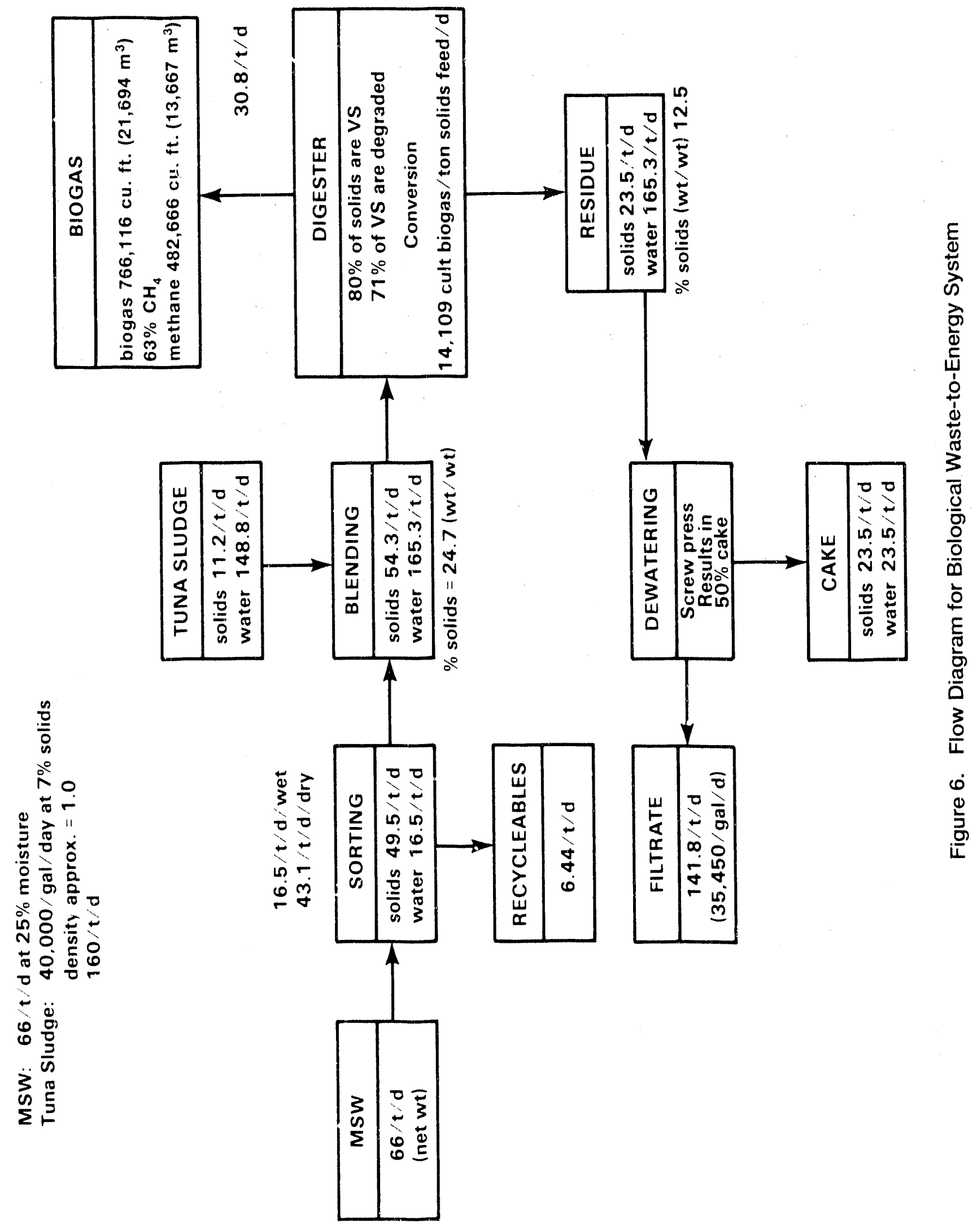


would incorporate a standardized sorting and processing unit for the raw MSW, followed by a blending section in which the tuna sludge is mixed with the MSW.

Various modifications will be introduced to this system in the trial reactor tests that are to be conducted at SERI. It may be desirable to further dewater the tuna sludge using continuous ce.,trifuges, in order to decrease the excessive water loading of the reactor. Sufficient reactor trials will be conducted to establish the optimum conditions for the anaerobic digestion process.

\section{Resource Base in American Samoa}

The amounts of tuna sludge and MSW generated on Tutuila are fairly well established. A recent EPA report 8 lists an average tuna sludge production ofaround 40,000 gallons per day. This figure represents the combined output from both StarKist Samoa Inc. and VCS Samoa Packing Co. (formerly Van Camp). The tuna sludge contains approximately 7 percent solids and 93 percent water. Any interruption in tuna sludge disposal presents a serious problem to the canneries, since they have a sludge storage capacity of less than two days. Once the waste effluent reaches the storage capacity, the canneries must shut down.

Estimates from recent studies on the amount of MSW generated on Tutuila vary from 37 to 87 tons per day. Dr. Riyard favors 94 tons per day (refer to Appendix $B$ ). This figure is consistent with SERl's estimate for daily per capita production of MSW of around 4 pounds a person, so that the 47,000 people on Tutuila generate around 94 tons per day of MSW. However, the average per capita figure of 4 pounds per day may vary greatly with season and location.

Mainland MSW cumposition consists of about 80 percent combustibles in the form of paper products, food, and yard wastes, and 20 percent non-combustibles including glass, aluminum, and ferrous metals. A possible difference on Tutuila could be a higner perc entage of metal packaging of food and beverages over glass packaging, because most food materials are imported. The actual composition of the MSW, as well as of the tuna sludge, in American Samoa must be determined before the design of any waste-to-energy system can proceed. 


\section{Maturity of Waste-to-Energy Conversion Technology}

The technologies for converting each of the waste streams on Tutuila to energy is well-established. There are a greai many successful MSW-to-energy installations throughout the world, running all the way from simple incineration of municipal waste to more complicated separation and resource recovery systems. Similarly, anaerobic digestion of sewage and other organic materials to produce methane gas, followed by incineration or recovery of the residue, is a well-known process.

The process proposed by SERI represents a possible solution to the combined disposal of MSW and tuna sludge, resulting in the production of energy and a useful residue. Mixing the MSW and tuna sludge to provide a single feedstock for an anaerobic digestion system would improve the quality of the combined waste stream over that of the individual components. The cellulose and polymers from paper and yard cuttings in the MSW, when combined with the nitrogen and phosphorous nutrients from the tuna sludge, result in an ideal mix for anaerobic digestion. A flow diagram for one of the trial runs is shown in Figure 6.

Another major reason for considering this system is that it is a high-solids process in which the tuna sludge would be dewatered before being combined with the MSW. Therefore, there would be a greatly reduced volume of material to be processed, in comparison with the conventional low-solids process, in which no dewatering of the 7 percent solids tuna sludge would take place. Reducing the total volume significantly would result in a much smaller anaerobic digestion plant than that required for the low-solids process. To digest a given amount of solid waste in a low-solids process, a much larger plant and more land area would be required. Because land is at a premium around Pago Pago Harbor, it would be easier to find sufficient acreage for a high-solids than for a low-solids plant.

SERI recommends that reactor tests be conducted with sample MSW and tuna sludge from American Samoa both for a) the standard continuously stirred, lowsolids process and $b$ ) the recently developed low-volume, high-solids process. A qualified engineering consulting firm will be contracted to independently evaluate these two processes and to recommend the preferred choice. 
Rather than proceeding directly from the laboratory reactor tests to a full-size anaerobic digestion plant, SERI further recommends that an intermediate pilot plant be established either at SERI or at the site in American Samoa. A single digestor would be used for the pilot plant, which would be operated to develop optimum design parameters for the full-scale plant. It is felt that the above steps would assure the successful operation of a combined MSW and tuna sludge anaerobic digestion plant in American Samoa.

\section{Will the Technology Work in American Samoa?}

Since the system will be a site-specific design for American Samoa, based upon the MSW and tuna sludge waste streams generated on Tutuila, it should work as designed. The inclusion of the one-year pilot plant phase will allow both a) the development of a reliable, workable process, and b) the training of local personnel at the pilot plant to operate the full-scale facility.

\section{How Will the Energy be Used?}

The composition of biogas from the anaerobic digestion of MSW is usually around 60 percent methane and 40 percent carbon dioxide. The combination with the tuna sludge could alter these percentages somewhat. End use of this type of biogas on the U.S. mainland frequently involves upgrading the medium BTU biogas to 98 percent methane for substitution as natural gas. Since there is no natural gas distribution in American Samoa, the direct conversion of the medium BTU biogas to electricity through an internal combustion engine, would probably be the preferred use. Arrangements could be made for the tuna canneries either to generate theelectricity and sell any excess to ASPA, or provide the biogas directly to ASPA, which would use this fuel source as a substitute for imported oil.

\section{Cost Estimate of Waste-to-Energy Recovery in American Samoa}

Considered only as a power source, the economics of this waste-to-energy system would not be very favorable. There would only be around $2 \mathrm{MW}$ of power generated from the combined flow, and the total cost of the system could approach $\$ 20$ million. However, when the direct and indirect benefits of eliminating the tuna 
sludge disposal problem and of greatly reducing the landfill problem are factored into this project, it becomes much more cost-effective.

The residue from the anaerobic process is stable and relatively odor free, with a high $\mathrm{pH}$ factor. Dr. Rivard has discussed with the American Samoa Community College Land Grant Program the possible use of this residue for soil enrichment on Tutuila or for export to Western Samoa. An overall economic analysis, including electricity generated, savings on tuna sludge disposal, tipping charges for MSW, minimizing landfill problems, and utilizing the residue would provide a more realistic evaluation than one based on power generation alone.

\section{Recommendations on Waste-Energy Projects}

Introduction--The strong interest evidenced in this option results more from the positive impact it would have on eliminating most of the major waste disposal problems with tuna sludge and MSW, rather than to its contribution in reducing the amount of imported oil into American Samoa. The installation of a high solids anaerobic digestion plant, accepting the waste streams from both the tuna canneries and the general public, would have a significant impact on minimizing major environmental problems and improving the quality of life on Tutuila.

\section{Phase 1-a--Compositional Analysis of Waste Stream}

Several anaerobic digestion studies are required with the actual waste materials to determine the necessary parameters for accurate process engineering designs and economic evaluations. Although there have been previous studies on the composition of tuna sludge and MSW generated on Tutuila and elsewhere, it is essential to determine accurate, current, on-site compositions of waste sources, in order to proceed with system design. Representative samples of both tuna sludge and MSW must be collected and shipped to SERI for analysis.

\section{Phase 1-b--Biological Methane Potential}

These studies are used to determine the maximum level of degradation that is possible for a particular feedstock. The levels of biogas production and 
degradation are used to assess the effectiveness of the prociess. Phases I-a and I-b will require two to three months to complete.

\section{Phase II--Low-Solids and High-Solids Digestion Studies}

These experimental studies will use SERl's laboratory scale reactors and the waste flow samples obtained from American Samoa to examine actual process dynamics with various mixes of MSW and tuna sludge. Both the low- and highsolids systems will be investigated. The residue of these processes will be returned to Tutuila for evaluation by the Land Grant Program on the benefit of this material as soil supplement. Phase II will require around nine months to complete the reactor tests and to allow time for comparative evaluations of the two processes by the independent consultant.

Phase III--Operation of the Pilot Plant

Depending on the results of the evaluation, a single-digestor pilot plant would be established either at SERI or in American Samoa in close proximity to the tuna canneries. The advantage of establishing the pilot plant at SERI would be having the control and evaluation at the laboratory. The major disadvantage would be having to ship samples of tuna sludge and MSW from Pago Pago to Colorado. Locating the plant in American Samoa would require having a manager from SERI on site and would limit the use of other SERI staff and equipment, but would greatly ease the problem of obtaining representative waste material. It would aiso help in training local personnel to work at the plant, and might make it possible to incorporate the digestor for the pilot plant as a component or module in the fullscale plant.

The design, construction, and operation of the pilot plant would require around 15 months. This would delay a full-scale plant, but would help assure that the appropriate process was being used for this key project.

\section{Phase IV--Process Engineering and Economic Analysis}

Many of the technical aspects to improve operational efficiency will be reviewed in the Phase III pilot plant operation. Additional studies on the location 
and preparation of the site, the feasibility of further dewatering the tuna sludge, and obtaining the appropriate approvals and permits must also be made. Economic analyses will include tipping fees for MSW, appropriate charges for disposing of tuna sludge, and projected revenues from electricity, the process residue, and any recycling. The preliminary engineering design documents resulting from Phase IV will identify the design, size, and how to proceed with the system. This information will be the basis for preparing a request for proposal, should the decision be made to build an anaerobic digestion plant. This phase will require six months, which could overlap with the final period of Phase III.

Dr. Rivard estimates the cost of this plant could approach $\$ 18$ million (Appendix B). However, he developed a rough approximation for the annual rate of return on the electricity produced from the total waste streams of MSW and tuna sludge, based on a value of electricity of $\$ 0.08 / \mathrm{kWh}$. This annual rate of return comes to $\$ 2.1$ million. When comparable figures are allocated for tipping fees associated with the disposal of MSW and tuna sludge, as well as any return on the residue and recycling, the overall economics of this system may seem reasonable.

Budget Summary--Estimated Total Costs for Recommended Development of Biological Waste-to-Energy Plant:

Phase I-a Compositional Analysis of Waste Stream 15,000

Phase I-b Biological Methane

Potential Studies

15,000 $\$ 30,000$

Phase II. Digestion Studies 90,000

Phase III. Operation of Pilot Plant $\$ 2,500,000$

Phase IV. Process Engineering and Economic Analysis

Subtotal $\$ \frac{50,000}{2,670,000}$

Phase V. Design and Construction of an Anaerobic Digestion Plant (Approximately 2MW): $\$ 16-18,000,000$ 


\section{Geothermal Power}

\section{General Description of Geothermal Energy}

In the word 'geothermal', geo- represents the earth; -thermal relates to heat. Simply stated, geothermal energy is any heat that comes from the earth. Magma--or molten rock--possesses a tremendous amount of geothermal energy, but in an extremely difficult form to convert to useful power. Reservoirs of steam and hot water trapped deep beneath the earth's surface under high pressure represent a more readily usable form of thils resource.

When the pockets of geothermal fluids are penetrated by wells drilled into these reservoirs, the high-temperature fluids are forced to the surface under pressure. When the pressure is released at the surface under controlled conditions, the superheated water flashes to steam, which spins a turbine to generate electricity, as illustrated in Figure 7. In contrast to conventional fossil fuel or nuclear power plants, which heat water to steam in order to drive a generator, a geothermal resource requires no additional heat to convert it to steam. There are no fuel charges for a geothermal power plant.

There are also many nonelectric or direct uses for geothermal energy which, on a global scale, result in economic benefits--particularly in colder climates. Buildings are heated directly by geothermal energy, which also has industrial application as process heat--such as that required by the two major tuna canneries in Tutuila. Geothermal spas are located in Europe and Japan, where tourists gather to enjoy the warmth and the reputed therapeutic benefits of geothermal fluids. In Hawaii, geothermal heat has been used in processing tropical fruits, germination of plant seeds, and aquaculture. Geothermal energy is a versatile resource, and there could be a positive spinoff of nonelectric uses should geothermal resources be identified ir American Samoa.

\section{Resource Base in American Samoa}

Many spots in the Pacific have islands formed by recent (in a geologic time frame) volcanic activity, that show good potential for geothermal power. The movements of tectonic plates beneath the Pacific Ocean have led to the existence of 


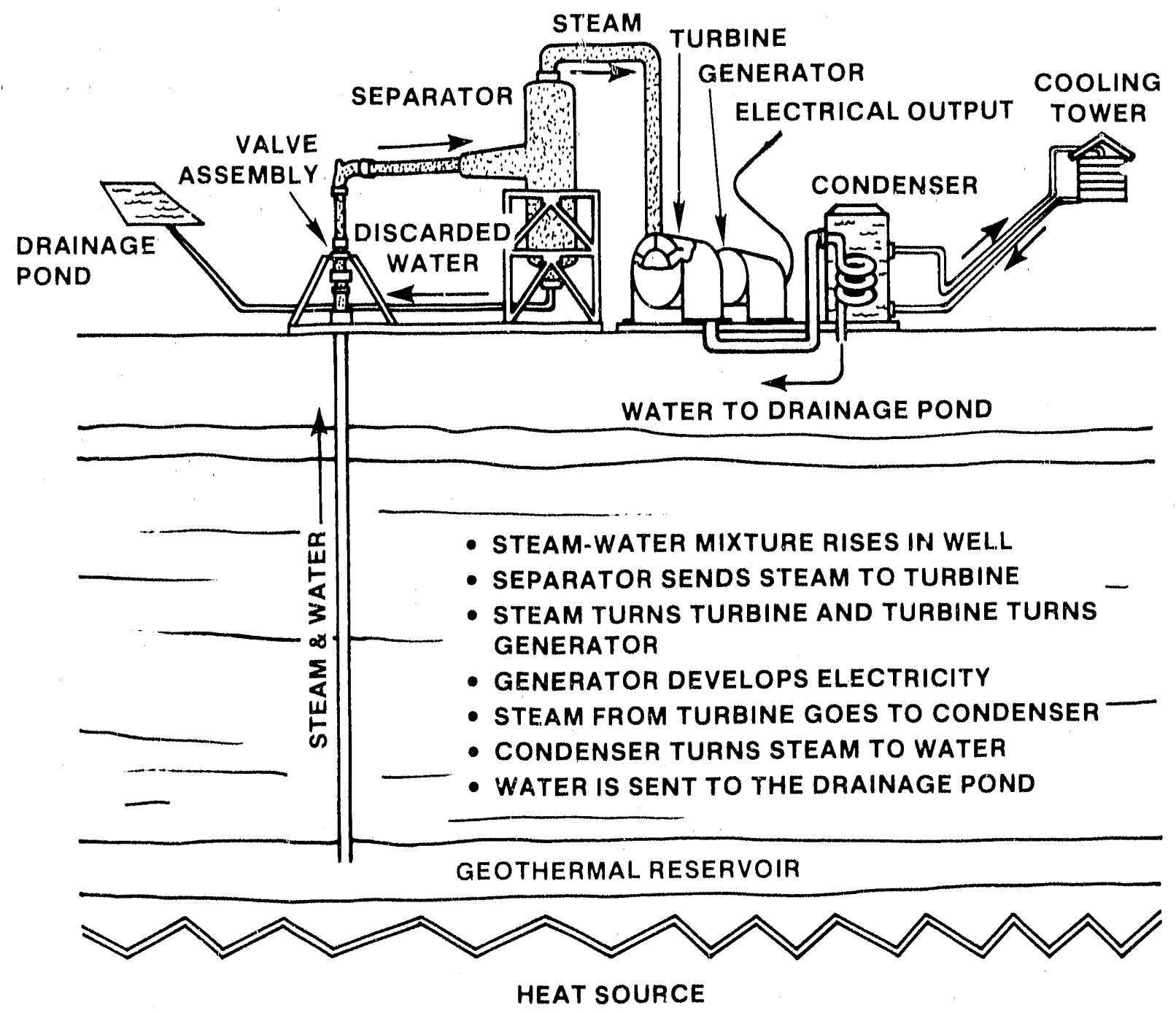

Figure 7. Geothermal Power Plant 
a "ring of fire" throughout much of the Pacific and this has contributed to some of the major geothermal power producing nations in the world. The Phillppine Islands rank second only to the United States in geothermal power generation, with more than $900 \mathrm{MW}$ on line. Japan ranks fitth in generating capacity with $300 \mathrm{MW}$, and New Zealand sixth with just over $200 \mathrm{MW}$. Hawall is in the early stage of major geothermal development.

Whether geothermal resources exist in American Samoa is unknown at this time. Although there are some positive indicatlons, until a successful well identifies a geothermal reservoir with sufficient temperature and flow capacity to generate electricity, it is pure speculation as to whether a commercially vlable geothermal power plant is a reallstic option for American Samoa.

A 1980 preliminary study 9 funded by DOE and conducted by the Geothermal Exploration and Development Corporation (GEDCO) led to the conclusion that "... American Samoa does possess a geological environment conducive to geothermal development." This evaluation was based upon a review of all avallable geological and geophysical data bearing on the existence of a geothermal resource for Tutuila. Drs. Grose and Keller, who perfomed the revlew, held an on-site inspection of the geology in American Samoa in January 1980, gathering as much information as possible, including waterwell logs from local drillers, soil sampling, and aerial surveys.

GEDCO's positive evaluation that existing geological and geophysical information justifies additional exploratory surveys is reinforced by Dr. Phillip Wright of the Earth Science Laboratory, University of Utah Research Institute. Dr. Wright's report, which covers both an evaluation of the potential resource base and recommendations for confirming the existence of a geothermal resource, is included as Appendix C.

\section{Maturity of Conversion Technology}

Geothermal energy has been used successfully to generate electricity since 1913, when the first geothermal power plant was installed in Italy. The generation of geothermal power is now world-wide and is a reliable, cost-competitive alternative to fossil fuels, wherever the resource is known to exist. The U.S.A. is the top producer of geothermal power, with more than 2000 MWs generated in the Western states-- 
primarily Callfornla. However, major geothermal development also exists in Europe, Central Amerlca, Japan, Iceland, and many of the Paclfic Island nations.

The technology for convertling geothermal flulds to electricity has 77 years of experlence to draw on. Once the steam has been recovered and cleaned, power generatlon is similar to that for conventional steam power plants. Drilling technology is borrowed primarlly from the oil and gas industry, with essential modifications provided for controlling the high-temperature, high-pressure geothermal fluids. As greater sensitlvity has been directed to environmental concerns, recent developments have been responsive in curtaillng objectionable discharges through improved treatment and/or reinjectlon. In summary, proven technology does exist for the efficient conversion of geothermal resources to electricity.

\section{Will Known Geothermal Technology Work in American Samoa?}

There should be no major problem in utllizing existing geothermal power technology in American Samoa. There has been extensive experience in island environments with geothermal development. With adequate provision for corrosion resistance in both the well drilling and power generation phases, the transfer of currerit gecthermal technology should proceed satisfactorily.

\section{How Will Geothermal Power be Used in American Samoa?}

A major benefit of geothermal energy is that it can provide reliable, 24-hour baseload power. Experience at major geothermal fields throughout the world, as well as at the developmental geothermal project in Hawail, confirms that geothermal power plants have high load-factors and operate efficiently as baseload generators. Should a significant geothermal resource be identified on Tutuila, this could ultimately lead to a drastic reduction in dependence on imported oil for power generation.

\section{Cost Estimates of Geothermal Power in American Samoa}

It is difficult to estimate the cost of power from a geothermal field until the nature of the reservoir providing the resource is known. The temperature and quality of the geothermal fluid will determine the conversion and the disposal 
systems. The location of the resource, both geographically and geologically, would also have an economic impact. The relative isolation of American Samoa and the cost of mobllizing exploration and commercial drilling rigs on Tutulla from New Zealand, Singapore, or the U.S.A. would be expensive. The depth of the reservoir and the degree of difflculty in drilling in the tough basaltic rock would also influence cost.

In general, geothermal power has been quite cost-competilive with fossil fuels. It is the least expensive power source in the huge Paciflc Gas and Electric Company generation system. Its rapid development in the Philippines and the major effort in Hawall to transmit $500 \mathrm{MWs}$ of geothermal power by undersea cable nearly 200 miles from the geothermal resource on the Big Island of Hawail to the energy market in Honolulu, also suggest that it is a preferred option over oil. Should a major geothermal resource be discovered on Tutuila, it almost certainly would be cost-competitive with imported diesel fuel using a life-cycle analysis.

\section{Recommendations for Geothermal Projects}

Introduction--The first and most basic issue to be resolved is whether or not a commercially viable geothermal resource exists in American Samoa. This can be accomplished sequentially, and the four-part recommendation that follows is predicated on the successful completion of each consecutive phase, leading ultimately to the installation of a 5-MW geothermal power plant on Tutuila.

The major input for the recommendations on the first three phases is provided by Dr. Phillip Wright (Appendix C). Additional information was furnished by Dr. Harry J. Olson of the Hawaii Natural Energy Institute through reports 10,11 and consultation. Also influencing these recommendations is the GEDCO report ${ }^{9}$ and the six-year experience of co-author John Shupe as Director of the Hawaii Geothermal Project during the exploratory and well-drilling phases. 12

\section{Phase L--Geological Mapping and Surface Exploration}

1-a. Geologic Mapping. This phase would consist of geologic mapping and reconnaissance geochemical sampling of Tutuila. The main objectives of geologic mapping are 1) to identify and determine the configuration of the various rock types; 
2) to determine the relative ages among them; and 3) to determine the nature and location of geologic structures. Geologic structures such as rift zones and calderas control hydrothermal systems in known ways, and their mapping is essential to any further exploration. Phase l-a would be accomplished by two geologists with the part-time assistance of a geochemist, and would take about three months to complete. The product would be a geologic map of the 50-square-mile island at a scale of 1:50,000 (or other scale depending on available maps) sultable for planning subsequent surface exploration and drilling.

1-b. Surface Exploration. Following the geologic mapping, and guided by the results, a program of surface exploration would be carried out. The primary survey for this stage would be some form of electrical geophysical survey. Hydrothermal convection systems affect the electrical properties of rocks in a number of ways. Electrical conductivity is increased by hot, saline fluids circulating in a permeable area and by the clay and zeolite minerals that form when hydrothermal fluids react chemically with the reservoir rocks. The objective of the surface electrical survey would be to locate areas of high subsurface conductivity. The survey would be carried out by a crew of two geophysicists and two technicians, who could be local labor. The electrical surveys would take about two months to complete, and one more month would be required to interpret the results, although preliminary interpretations could be made more quickly.

During Phase $\mathrm{I}-\mathrm{b}$, any soil geochemical work would also be carried out. Depending on the results of the geologic mapping, a soil mercury survey might be conducted to help determine the locations of open faults and fractures. Previous experience has shown that mercury often marks the location of these open faults and fractures, which would be the targets for drilling. During Phase $1-b$, it might also be advisable to perform a detailed aeromagnetic survey, which could be of material assistance in locating and mapping geologic structures. This may be necessary on Tutuila, where vegetation could obscure structures and make geologic mapping difficult.

\section{Phase II--Gradient Well Drilling}

The objective of Phase $I 1$ is to locate an area of high subsurface geothermal gradient in order to site a production-sized well. The possibility of down-flowing 
meteoric water (recent rainfall, in contrast to entrapped, geologic sources) obscuring heat anomalies coming from depth is a real problem in the volcanic environment. Test holes in excess of 3000 feet are often required to get beneath the zone of meteoric water and measure a temperature gradient representative of deeper levels. Four slim coreholes are recommended for this purpose, each of which may be drilled to a 4000-foot depth. In addition to identifying the temperature gradient, the cores will provide information on any thermal deposition.

The main reason for drilling slim coreholes for thermal gradient measurement in advance of spotting production-sized wells is to decrease the costs and risks of the exploration program. If the gradient drilling does not succeed in locating anomalous subsurface temperatures and hydrothermal minerals indicative of a hydrothermal system, significantly less money will have been spent than if the program had proceeded directly to large-diameter holes. If an area of high thermal gradient is located, a deep, production-sized hole can be spotted with much less risk of failure. If no high thermal gradient is located, the program can be terminated at this point.

\section{Phase III--Production Well Testing}

In Phase III, a large drill rig will be mobilized on Tutuila and a production-scale test well drilled. The purpose of this phase is to test the temperature gradient discovered in Phase II and to engage in the production of geothermal fluids. The mobilization of a drill rig, the drilling of a $95 / 8$-inch diameter hole to a depth of 6000 feet, and preliminary well testing can easily require a year--longer if major problems are encuuntered, which is not unusual for a new geothermal reservoir.

The costs of a full oil-well rig and experienced crew required for this type of drilling are high. Actual costs at the time of drilling would depend on the availability of rigs and the giobal oil-drilling activity-the drillers charge wl tever the tratfic will Dear. If the drilling is suscessful, a production test of the well would be necessary, and would be conducted by a reputable consultir, reservoir engineering firm.

Phase IV-installatirn of a 5-MW Geothermal Power Piant

Depending upon the results of the well production test, a decision must then be reached on whether to proceed with a geothermal power plant. The earlier this 
decision can be made the better, since it would be preferable, if possible, to drill a second production well while the heavy rig is still on Tutuila.

A rough estimate for a geothermal plant in American Samoa would run from $\$ 1600$ to $\$ 2000$ per installed kilowatt. Using the middle figure and selecting a 5-MW plant for the first installation, a \$9-million cost estimate for the geothermal powei plant would be reasonable.

Budget Summary--Estimated Total Costs for Recommended Geothermal Exploration and Developmen: Program:

\begin{tabular}{|c|c|c|c|}
\hline Phase 1-a & Geographic Mapping & $\$ 45,000$ & \\
\hline \multirow[t]{2}{*}{ Phase 1-b } & $\begin{array}{l}\text { Surface Exploration: } \\
\text { Resistivity Survey } \\
\text { Soil-Mercury Survey } \\
\text { Aeromagnetic Survey }\end{array}$ & $\begin{array}{l}60,000 \\
25,000 \\
50,000 \\
\end{array}$ & \\
\hline & & & 180,000 \\
\hline \multirow[t]{2}{*}{ Phase II } & $\begin{array}{l}\text { Gradient Drilling: } \\
4 \text { coreholes--16,000 ft } \\
@ \$ 125 / \mathrm{ft} \\
\text { Mobilization/demobilization }\end{array}$ & $\begin{array}{r}2,000,000 \\
120,000 \\
\end{array}$ & \\
\hline & & & $2,120,000$ \\
\hline \multirow[t]{2}{*}{ Phase III } & $\begin{array}{l}\text { Production Test Drilling } \\
\text { One well--6000 ft } \\
@ \$ 200 / \mathrm{ft} \\
\text { Mobilization/demobilization } \\
\text { Well-testing }\end{array}$ & $\begin{array}{r}\$ 1,200,000 \\
700,000 \\
90,000 \\
\end{array}$ & \\
\hline & & & $\$ 1,990,000$ \\
\hline \multirow[t]{3}{*}{ Phase IV } & $\begin{array}{l}\text { Geothermal Power Plant } \\
\text { Second production well } \\
5-\mathrm{MW} \text { power plant }\end{array}$ & $1,200,000$ & \\
\hline & @1800/installed kW & $9,000,000$ & \\
\hline & & Grand Total & $\frac{\$ 10,200,000}{\$ 14,490,000}$ \\
\hline
\end{tabular}

\section{Ocean Thermal Energy Conversion}

1. General Description of Ocean Thermal Energy Conversion Technology

The technology is hased on the concept that useful energy can be extracted from the temperature difference between the warm, surface 'water and cold, deep- 
ocean water. A temperature difference as low as $36^{\circ} \mathrm{F}\left(20^{\circ} \mathrm{C}\right)$ can be exploited effectively to produce electricity. The basic principle, which was discovered more than a century ago in France by D'Arsonval, consists of causing a working fluid to boil or to vaporize by use of the warm sea water. As the working fluid vaporizes it expands, spins a turbine, and generates electricity. The vapor is then condensed by the cold sea water. No other fuel source is required; but ocean thermal energy conversion (OTEC) certainly does not provide "free" energy. There is a high initial capital investment, plus moderate operation and maintenance costs.

There are two OTEC power cycles, each of which has certain advantages-and advocates: closed-cycle (CC-OTEC) and open-cycle (OC-OTEC). With CCOTEC, the working fluid is a refrigerant, such as ammonia, that circulates within a closed loop, where it is vaporized in a heat exchanger (evaporator) by the warm sea water. The vapor expands under moderate pressure to spin a turbine and is then condensed in another heat exchanger (condenser) using cold, deep-ocean water. The refrigerant continues to recirculate within the closed system, repeating the power cycle over and over. A schematic diagram of this system is illustrated in Figure 8.

The open-cycle system operates on the principle that lowering the pressure on a fluid also lowers its boiling point. For OC-OTEC, sea water is the working fluid. The warm, surface water is "flash" evaporated in a vacuum chamber that is maintained at a greatly reduced pressure. This vapor is then expanded through a low-pressure turbine, coupled to a generator to produce electricity. Upon exiting the turbine, the vapor is condensed by the deep-ocean water, either through a heat exchanger or by direct contact with a cold-water spray. If a heat exchanger is used, rather than direct contact, the condensed steam represents a source of desalinated, potable water. A schematic diagram of OC-OTEC is shown as Figure 9.

There has been strong interest in OTEC among the U.S. Flag Territories and Cummonwealth in the Pacific dating back to the late 1970s--due in part to their proximity to both warm and cold sea water, as well as to their conviction that, of all renewable energy uptions, OTEC showed the greatest potential for providing baseload power to replace imported oil. This conviction holds true today, and the OTEC developments in Hawaii conducted at the Natural Energy Laboratory of Hawaii by the State, DOE, PICHTR, and many segments of the private sector are followed closely. 


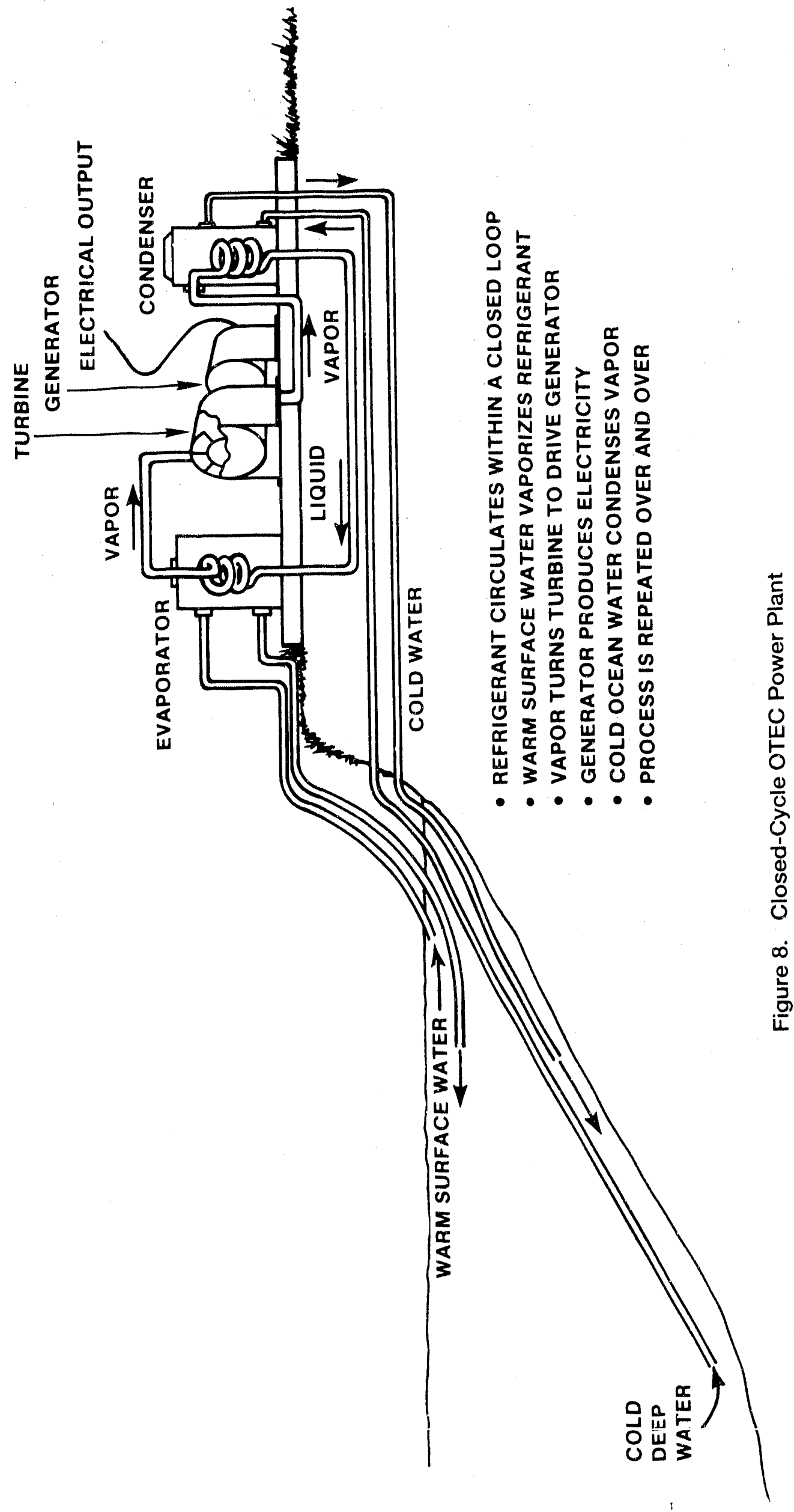




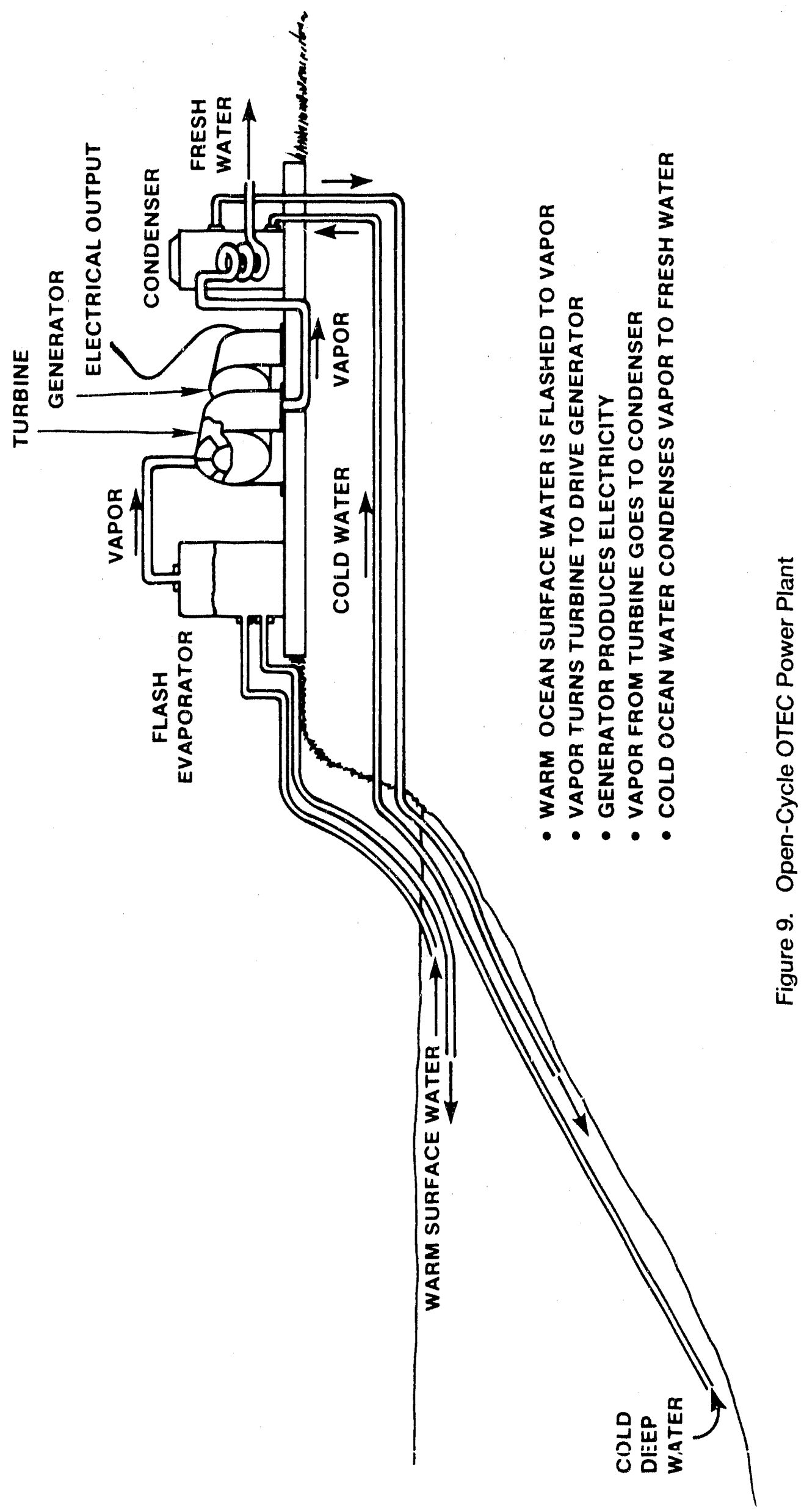




\section{Resource Base in American Samoa}

In 1981, American Samoa, in collaboration with Guam and the Northern Marianas, subritted a solicitation to DOE for the design, construction, and operation of an OTEC dower plant. Extensive preparation had gone into this solicitation; but the lack of any/bathymetric data, indicating the ocean depth as a function of distance from the shoreline, limited the report. In 1988, funding was provided by DOE, through the Territorial Assistance Program, to conduct a preliminary bathymetric survey of possible OTEC sites for American Sarnoa, Guam, and the Northern Mariana Islands. 5

The bathymetric data obtained from this survey are summarized in Figure 10. This chart provides bathymetric profiles (water depth in meters, based on distance from shore in meters) for selected sites in American Samoa, Guam, and Saipan (CNMI). The importance of locating deep-ocean sites close to shore relates to the economics of constructing and installing the large, cold-water pipes (CWP). Depending on the length of the CWP, its cost could represent as much as 30 to 40 percent of the total cost of the OTEC plant. The shorter the distance from the shoreline to the deep-ocean resource, the siilaller the capital investment for the power plant.

Preliminary bathymetric data, shown in Figure 10 for one site in each of the three Pacific Island entities, indicate that all three locations have attractive sites for installing OTEC plants. The American Samoa site, particularly--located at Fatuasina Point--shows outstanding potential for an OTEC installation. A depth of 1000 meters is reached at a distance of only slightly greater than 2000 meters from the shoreline. This is a much steeper drop-off than that experienced for NELH at Keahole Point, where the Hawaiian OTEC research and development program is conducted. Unless a sharp escarpment or other geological problems are encountered in a more comprehensive site-specific survey, the Fatuasina Point on American Samoa appears to be an excellent candidate for the location of an OTEC power plant.

\section{Maturity of Ocean Thermal Energy Conversion Technology}

There are no OTEC power plants in operation today. The first demonstration of the production of net power from OTEC took place in 1979 in Hawaii with a 50kivi ciosed-cycie piani operating ofí a îjoaing barge. The Japanese íliowed 


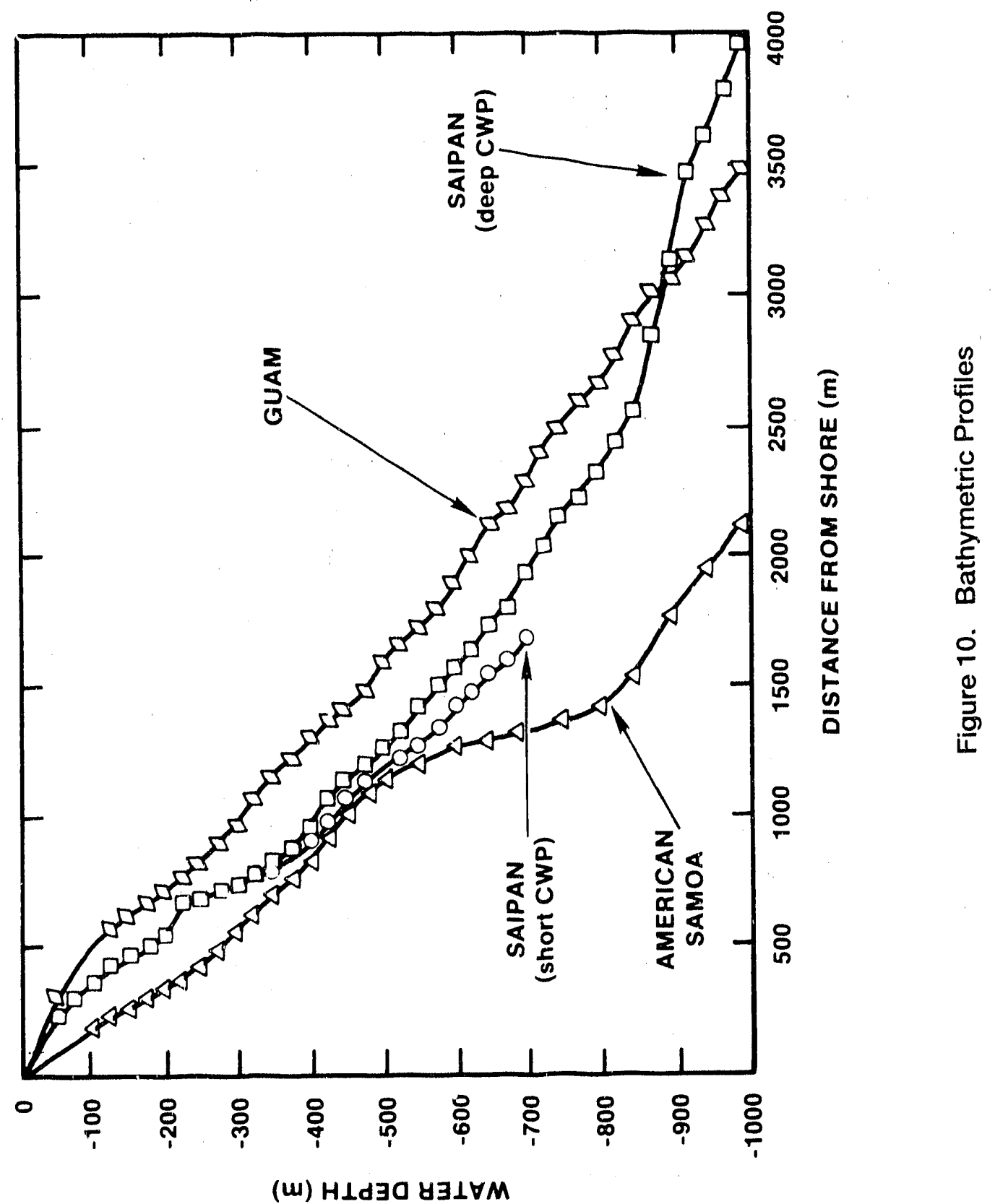


shortly with a shore-based 100-kW CC-OTEC plant in Nauru. There is no question of the feasibility of the century-old concept, but can it work economically? There are a number of major components that have given concern to U.S. industry on commercial-scale applications of OTEC. The construction, deployment, and survival of the cold-water pipe (CWP) is a major issue for both an open- and closed-cycle OTEC, particularly for shore-based plants. The surf-zone is a very hostile environment for the deployment and maintenance of a CWP. For CC-OTEC, the heat exchangers have been an extremely high-cost item; but recent breakthroughs by a British firm may have lowered this component to around $\$ 1,500$ an installed kilowatt. A possible roadblock to OC-OTEC is the development of a huge turbine that will operate with the low-pressure steam vacuum-flashed from the warm surface water.

Progress is being made in all of these areas, with much of the research and development activity concentrated in Hawaii. There are also active programs in many foreign nations, including Japan, Taiwan, Britain, Canada, and France. Under, consideration at this time for construction at NELH on Keahole Point are three projects: 1) a 160-kW closed-cycle plant, scheduled for completion in March 1991 ; 2) a $210-\mathrm{kW}$ net power producing open-cycle plant, scheduled for completion in June 1992, and 3) a 500-kW hybrid system, incorporating both open- and closed-cycle aspects into its design, scheduled for completion in December 1992. Taiwan is also seriously considering the construction of a much larger CC-OTEC plant to establish its position in this promising technology.

American Samoa should follow these and other OTEC developments closely. Although it is highly unlikely that an OTEC plant will be constructed on Tutuila in the near future, OTEC's great potential for providing baseload power for meeting American Samoa's increasing electrical requirements causes it to be included in the recommendations developed in this 10 -year plan.

\section{Will Known Ocean Thermal Energy Conversion Technology Work in American Samoa?}

As discussed in Section 3, both open- and closed-cycle OTEC technologies are in the developmental stage. Once a commercially viable technology emerges and is establisher as a proven system, it should be ready for application in American Samoa--provided that design consideration is given to the wind and wave 
forces generated by periodic hurricanes. It would not seem advisable to locate the initial commercial-scale OTEC plant in American Samoa, unless there is an éxtenuating circumstance, such as a company assuming all construction, operation and maintenance costs, and providing electricity to ASPA on a contract basis at a cost competitive to diesel power generation.

\section{How Will Ocean Thermal Energy Conversion Power be Used in American Samoa?}

As with geothermal energy, a strong advantage of OTEC over intermittent renewable energy resources is that it can provide reliable, 24-hour baseload power. The temperature of the deep-ocean water remains constant, and while there may be a small seasonal variation in the surface temperature, there is negligible cooling of the warm sea water overnight. When OTEC becomes costcompetitive with diesel power--and it should, eventually--this will help assure a secured source of baseload power for American Samoa. Another positive aspect of OTEC is the high potential for spin-off products such as fresh water, aquaculture, direct cooling, pharmaceuticals and other by-products--all of which have been produced (at least on an experimental basis) at NELH and the Hawail Ocean and Science Technology industrial park.

\section{Cost Estimates of Ocean Thermal Energy Conversion Power in American Samoa}

Since OTEC is still in the developmental stage, there has been little opportunity to proceed down the learning curve for this infant technology with new discoveries and modifications to improve the economics of the system. PICHTR has come up with some current estimates on the cost of building the first OTEC power plants of various sizes, and these estimates are not at all encouraging--more than ten times the cost of a diesel power plant. PICHTR's estimate for the first 5MW OTEC plant is $\$ 12,000$ per installed kilowatt, or $\$ 60$ million. For the first 2-MW OTEC plant, the unit cost increases to $\$ 18,000$ per installed kilowatt or $\$ 36$ million.

However, this enormous initial cost could drop significantly as the technology matures. There is also the possibility that a systems approach, providing not only OTEC electricity, but also fresh water and/or many of the byproducts of the cold, nutrient-rich, pathogen-free, deep-ocean resource could 
greatly improve the overall economics. It would be inappropriate for American Samoa to invest in an OTEC power plant at this time, but OTEC could become a viable alternative by the end of this decade.

7. Recommendation for Ocean Thermal Energy Converision Projects in American Samoa

Introduction--The preliminary bathymetric study for American Samoa, 6 described in Section 2, identified what appeared to be an outstanding OTEC power plant site at Fatuasina Point. This needs to be confirmed by a more comprehensive bathymetric survey before engineering design can proceed on the optimum OTEC plant to be located at this site. The recommendations that follow are based ur'un consultations with Dr. Andrew Trenka and information provided in Appendix $E$.

Phase 1-a--Site-Specific Bathymetric Survey

A much more comprehensive bathymetric survey must be conducted to confirm that the Fatuasina Point site on Tutuila is the best location for an OTEC power plant in American Samoa. This survey would identify if any sharp escarpments or other geological impediments exist that would adversely affect the deployment of the cold-water pipe (CWP). Data from this survey should determine if, where, and how a CWP could be deployed at this site. Sufficient oceanographic work should be conducted to assure that Fatuasina Point is the optimum OTEC plant site for Tutuila.

Phase I-b--Permitting, Planning, and Economic Studies

Shore-based, as well as oceanographic, reviews should be conducted, regarding compatibility of the plant location with the ASPA distribution system, permits required for the specific site, environmental concerns, and other related issues. Paralle! studies should also be initiated on whether this.OTEC plant wil! generate electricity only, or if a systerns approach is warrarited to provide desalinated water and/or other marketable by-products, as well. The overall economics on whether it is feasible to proceed with an OTEC project could very well be determined on the financial benefits of the nonelectric options. 
Phase II--Conceptual Studies and Preliminary Engineering Design

Based upon the input from Phases $\mathrm{I}-\mathrm{a}$ and $\mathrm{I}-\mathrm{b}$, decisions will be made on the size and the type of the OTEC plant, as well as the nature of the CWP, where it will be laid, and how it will be deployed. Specific location and configuration of all major plant components will be identifiel, along with any corollary systems for desalination, aquaculture, and/or other by-product development that proved feasible from Phase I-b.

The preliminary plant design and accompanying engineering drawings should provide answers for approximately 90 percent of the engineering questions that will arise regarding the installation of a specific type of OTEC plant at Fatuasina Point. These documents will allow bidders for the plant construction contract to proceed with sufficient confidence on what to expect, both on land and along the ocean floor corridor, so that their cost estimates will not have to be inflated excessively, based on ignorance of existing conditions. The more precisely and accurately this preliminary conceptual and engineering design can be prepared, the greater confidence the bidder will exercise in arriving at a realistic bid for final plant design and construction. This information will also permit the firm that ompletes Phase II to provide American Samoa with an estimated capital cost on the design and installation of the total system.

\section{Phase III--Final Plant Design and Construction}

The contractor chosen to install the OTEC power plant and any corollary systems will use ingenuity and experience to develop the most effective plant design for the selected site. Phase II information will be essential to this task, but sufficient flexibility should be retained in the bid document so that innovative approaches to the optimum solution will not be stifled. The Phase III contract would cover all final engineering plans and turnkey construction of the project.

Depending upon the results of Phases $\mathrm{I}-\mathrm{a}, \mathrm{I}-\mathrm{b}$, and II, as well as the global progress on the development of OTEC technology, American Samoa may choose to delay Phase $1 ! 1$. Should the costs of an OTEC power plant approach the estimates listed in Section 6 ( $\$ 60$ million for a 5-MW plant and $\$ 36$ million for a 2MW plant), and should there be no economic benefit derived from desalination 
and/or other by-products, it is highly questionable whether American Samoa would wish to proceed with an OTEC plant on Tutulla.

Budget Summary--Estimated Costs for Recommended Bathymetric and Conceptual Studies, Design, and Construction:

Phase 1-a--Site-Specific Bathymetric Survey

$\$ 250,000$

Phase I-b--Perrnitting, Planning, and Economic Studies 80,000

Phase II---Conceptual and Prelim.

Engineering Design

470,000

Subtotal

$\$ 800,000$

Phase III--Final Design and Plant Construction:

2-MW plant: ? to $\$ 36,000,000$

5-MW plant: ? to $\$ 60,000,000$ 
SECTION V. Summary of Recommendations and Conclusions

\section{Recommendations}

Table 1 summarizes the recommendations for initiating projects to introduce the varlous renowable energy technologles in American Samoa. There are three sections to Table 1. The first (and only) recommendation for Section 1 is to designate a Renewable Energy Supervisor and to provide $\$ 30,000$ a year for partial salary and support services for this position. The RES position is given a top priority of "I." This person would work primarily with the intermittent solar and wind projects, but also would assist in the preliminary phases of the baseload projects--such as obtaining tuna sludge and MSW samples for analysis by SERI.

Section II covers a number of intermittent wind and solar projects that can result in fuel savings, but do not affect capacity requirements. Battery systems are also included in this category, due to the intermittent nature of their charging cycles. Prioritles in Section II are preceded by a "F" for fuel saving. An "F-I" priority has the same level as the "I" priority from Section I, as well as the "B-I" category from Section III--where the "B" stands for baseload power. For most of the technologies, there is a sequential series of recommendations, beginning with resource assessment and proceeding to more capital-intensive projects, as the potential for the various technologies becomes better defined. Exceptions are the solar options, for which the insolation rates for American Samoa are sufficiently well known to warrant proceeding immediately with both PV and solar thermal projects.

The recommendations are not totally independent from one another. High success with one option could make a future option less crucial. If, for instance, a major high-temperature geothermal reservoir capable of providing all future baseload power for Tutuila were discovered, this would lessen interest in OTEC as a power source--unless the benefits of desalination and aquaculture by-products would dominate the consideration.

In the opinion of the authors, all of the projects that received priorities of I, F-I, and $\mathrm{B}-\mathrm{I}$ should be initiated as soon as funding can be identified. Including $\$ 30,000$ a year for the Renewable Energy Supervisor, this woulc require a total of $\$ 242,000$ for seven projects in Year 1 and $\$ 240,000$ for three proje ts in Year 2. This level of 
activity would accomplish a great deal in defining the future direction for renewable energy development in American Samoa.

Obviously there is a tremendous difference between the installation costs for small solar and wind projects and the capital investmerit required for major baseload power plants. Although the RES should coordlnate and be involved in the development for all renewable energy projects, it would seem appropriate for the Territorial Energy Office to take the lead for the solar and wind technologies, while the American Samoa Power Authority would have major responsibility for the baseload plants. Full cooperation among all governmental agencies is essential.

Section II-2 on Solar Thermal Systems may require clarification on two points. Phase I calls for the installation of a series of domestic hot water solar systems for selected residences at a cost of $\$ 30,000$. Phases II and III specify a year of operation, followed by an analysis of the performance of these systems. No additional funding is requested for these two phases, since the Renewable Energy Supervisor will plan and implement the necessary data acquisition and conduct the analysis. The industrial process heat system will be installed only if the tuna canneries feel that the project justifies the expenditure of their own funds, so no additional support is listed for this project.

\section{Conclusions}

Funding to implement these recommendations is essential if progress is to be accelerated in introducing renewable energy technologies into American Samoa. Unfortunately, no specific appropriations have been established for this purpose, so ingenuity and persistence should be oxercised in tapping existing programs. Some DOE grant funding, petroleum violation escrow funds, insurance settlement on hurricane damage, and possibly support from the new Territorial Assistance Program under consideration by Congress could help with the planning studies and the small solar and wind projects. However, for the major baseload power plants-each requiring in excess of $\$ 15$ million--federal support through the Department of the Interior or a direct appropriation from Congress would probasly be required, although the development of a power system capital improvements fund of its own is under consideration by ASPA. 
Arriving at a decision on which, if any, of the renewable energy projects to install is difficult. It is not a typical go/no-go choice on whether to proceed with a project; it involves the trade-off between the advantages and shortfalls of a variety of differeni technologies whose relative merits seem to shift with each new technology breakthrough. This is further compounded when it involves an ASPA commitment, since a power utility must be conservative in the selection of its power sources. ASPA cannot gamble on unproven technologies and still provide the necessary reliability of service for its customers.

Table 1 presents a series of recommendations on renewable energy projects for the next decade that seem reasonable in the present time frame. These recommendations should not be considered as set in concrete. As definite trends emerge in the future cost of diesel fuel, and as advances and breakthroughs occur with the various renewable technologies that may alter their relative reliability and economics, the Table 1 priorities should be reviewed and revised. Global warming and other environmental issues could also skew these figures. Hopefully, planners will become more adept at quantifying the externalities, such as the benefits of the economic stability and security associated with an indigenous energy supply, so that these elements could also be factored into energy decisions. In any case, indigenous renewable resources should play an increasingly important role in American Samoa's energy future. 


\section{REFERENCES}

1. "Territorial Energy Assessment Final Report," U.S. Department of Energy Report CP-0005/1, December 1982.

2. "American Samoa Statistical Digest--1988," Economic Development and Planning Office, American Samoa Government.

3. "American Samoa Power Authority 1988 Annual Report," American Samoa Government.

4. "Agenda for Growth, 1991-1995," American Samoa Power Authority, American Samoa Government.

5. "Bathymetry Surveys of Potential OTEC Sites in American Samoa, Guam and the Commonwealth of the Northern Marianas Islands," Edward K. Noda and Associates, Inc., Honolulu, Hawaii, August 1989.

6. "Preliminary Evaluation of Potential OTEC Sites: Bathymetry and Feasibility," G. Nihous, E. Udui, and L. Vega, Pacific International Center for High Technology Research, Honolulu, Hawaii, December 1989.

7. "Species Trials for Fuelwood Production in American Samoa," Whitesell, Craig D. and Rourke, Mary K., U.S. Department of Agriculture Forest Service, Report 4110-3.24, October 1987.

8. "Final Environmental Impact Statement for the Designation of an Ocean Disposal Site of Tutuila Island, American Samoa for Fish Processing Waste," U.S. EPA, Region 9, San Francisco, California, February 1989.

9. "Geothermal Energy for American Samoa," Geothermal Exploration and Development Corporation, U.S. Department of Energy Contract CM-304-80, March 1980.

10. Olson, Harry J., "Geothermal Development for Island Nations Situated Along the Pacific 'Ring of Fire,'" Hawaii Natural Encrgy Institute, Honolulu, Hawaii, January 1988.

11. Olson, Harry J., "Geoiogy and Geothermal Development Potential of the Volcanic Pacific Island Nations," Hawaii Natural Energy Institute, Honolulu, Hawaii, September 1988.

12. Shupe, John W., "Geothermal Power Development in the Pacific," Pacific Site Office, U.S. Department of Energy, May 1989. 


\section{APPENDICES}

Pages

A. Historical, Cultural, Political, Demographic.

A-1 to $A-5$ and Societal Information for American Samoa.

B-1 to B-16

B. Biological Waste-to-Energy Options for American Samoa, Chrisiopher Rivard.

C. Recommended Exploration Program for Geothermal Development in American Samoa, Phillip M. Wright.

C-1 to C-6

D. Prospects for Wind Energy in American Samoa,

$D-1$ to $D-8$ Dennis L. Elliott.

E. Preliminary Evaluation of Potential OTEC Sites, Andrew Trenka and Elizabeth Udui.

$E-1$ to $E-6$ 
APPENDIX A: Historical, Cultural, Political, Demographic, and Societal Information for American Samoa.

The first inhabitants of the Samoan islands were Polynesian seafarers, who came from the west, probably by way of Indonesia, Vanuatu, and Fiji, at least 1600 years before the birth of christ. Samoans are closely related to the Tongans, Tahitians, and Hawaiians, who also are Polynesians. Traditional Samoan stories describe Manu'a as the heart of Polynesia.

The samoan people evolved a complex social structure, centered on the aiga, or extended family, which included as many as several hundred relatives. At the head of the aiga were the matais (chiefs) who guided the communal economy, looked out for the clan's well being, controlled the lands, and represented the aiga in the village and äistrict councils. Life revolved around a settled, subsistence agriculture based on taro, breadfruit, bananas and fishing. Today, nearly 96 percent of the land in American Samoa is still communally owned.

First contact with the western world came when a Dutchman, Jacob Roggeveen, happened upon the islands in 1722, followed 46 years later by the French explorer, Bougainville. However, the islands were out of the way of the growing shipping traffic and whale fleets, and did not attract European interest until the $1830 \mathrm{~s}$ when missionaries arrived to Christianize the receptive Samoan population. American interest stemmed from the wilkes expedition in 1839, which explored the Samoar Islands and mapped the harbor and several bays. It was the natural, deepwater harbor in pago Pago which triggered America's particular interest in Eastern Samoa (American Samoa). In 1872, the U.S.S. Narragansett visited Tutuila; and its commander, Richard Meade, entered into a "Commercial Regula- 
tion" with High Chief Mauga, granting the U.S. harbor facilities and rights for a naval station.

International rivalry and confrontation between Germany and Great Britain, as well as warring between various Samoan factions, with the U.S. on the periphery, occasioned agreements in the late 19th century which effectively divided the Samoas between the United States and Germany. In 1900, the United States annexed Eastern Samoa under the Deed of Cession with the ruling chiefs. The Manu'a chain was added in 1904, and the act was finally ratified by the U.S. Congress in 1929.

American Samoa, as the islands became known, was placed under U.S. naval administration in 1901 and remained so until 1951. The peaceful islands and the quiet naval station for the south Pacific assumed a new and strategic importance at the outbreak of World War II when Pago Pago, and the Samoa Islands in general, became an advanced training and staging area for U.S. armed forces. Along with the extensive wartime construction program, this caused the rapid exposure of Samoans to the American way of life, resulting in the initial out-migration of samoan people, who wished to make careers in the U.S. military or to seek employment in Hawaii and the Mainland U.S.

The present administration of American Samoa was organized under the Deeds of Cession of 1900, which granted the inhabitants U.S. national status, protected them under the U.S. Constitution, and prevented their lands from being alienated. Day-to-day government followed U.S. naval regulations, which today, form the basis of the code of American Samoa. 
The Fono, a bicameral legislature, was formally organized in 1949 and became the territory's law-making body. In 1951, under Executive order 10264, administration of American Samoa was transferred from the Navy to the Department of the Interior. In 1960, a constitutional convention was held, and the resulting constitution became effective on July 1, 1960. In 1977, Samoa elected its first Governor and Lieutenant Governor, a step which further reinforced the process of local self-government. Samoa also elects and maintains a congressional delegate in Washington, D. C., who in 1981, became a non-voting representative of the U.S. Congress. This significantly elevated the national attontion given to samoa's needs and concerns. The current relationship between American Samoa and the United States is spelled out in Secretary order \#2657 of the Department of the Interior. With the installation on January 3, 1978, of the first popularly elected government in Samoan history, the American Samoans initiated an aggressive development program. This program called for economic and infrastructure development to bring the territory closer to self-sufficiency; greater economic and social participation in the community of emerging south Pacific nations; and greater self-government and political development within the U.S. community of states and territories.

The population estimate for American Samoa at the beginning of 1989 was around 39,000, an increase of just over 20 percent from the beginning of the decade. Population for the three islands of the Manu'a District remains at slightly more than five percent of the total population for the territory. The projected population for American Samoa in the year 2000 is $48,200 .^{2}$

2 From the American Samoa 1988 Statistical Digest, Economic Development and Planning Office. 
The steady population growth in American Samoa has occurred in the face of the continuous out-migration trend, which began shortly after world war II. Over the last 15 years there has been an annual out-migration of around 400 people, primarily to Hawaii and the mainland United States. Current estimates of American Samoans living in the United States approach 100,000.

The Eastern District of Tutuila is the most densely populated area of American Samoa, with 890 persons per square mile -according to the most recent (1985) census figures. The Western District of Tutuila follows with 501 people per square mile, although this figure may have increased significantly since the last census with the recent commercial and residential growth in the Tafuna Plains. Population density for the three Manu'a islands is only 72 persons per square mile.

The population base is young, but gradually rising, with the medium age increasing from 17 years to 20 years over the past decade. Males outnumber females 51 to 49 percent. The birth rate for American Samoa rose from 34 to 44 per 1000 persons between 1980 and 1987 .

Of the 1985 resident population, 58.3 percent were born in American Samoa; 29.7 percent in Western Samoa; 7.9 percent in the United States (including Hawail); and 4.1 percent from other areas. Samoan remains by far the dominating single ethnic group in the territory -- 91 percent.

Strong emphasis has been placed on education in American Samoa. In 1987, there were 14,207 persons enrolled in 128 different public and private institutions in the territory. While only six percent 
of the population had completed high school in 1960, by 1985 this figure had increased to 61 percent, and is still climbing. Sixteen percent have completed one or more years of college.

Much of the land in American Samoa is steeply sloping and virtually unaccessible. In 1986, only 6,777 acres of the 48,767 total territorial acreage (76 square miles) were listed under land ownership registration. Of this 6,777 acres of registered land, much of it is communally or church controlled. The aiga, or extended family concept, with its collective authority over land usage could contribute to problems in identifying adequate sites on which to locate some of the land-intensive renewable energy options, such as treefarms or even solar photovoltaic installations. 


\section{BIOLOGICAL WASTE-TO-ENERGY OPTIONS}

\section{FOR AMERICAN SAMOA}

\section{Prepared By}

Christopher Rivard, Ph.D.

Solar Energy Research Institute

Biotechnology Research Branch

Golden, Colorado

For

John Shupe, Ph.D.

Department of Energy

Director, Pacific Site Office

Honolulu, Hawaii 
BIOLOGICAL WASTE-TO-ENERGY OPTIONS FOR AMERICAN SAMOA

TABLE OF CONTENTS

1.0 INTRODUCTION $\ldots \ldots \ldots \ldots \ldots \ldots \ldots \ldots \ldots \ldots \ldots \ldots \ldots \ldots$

2.0 WASTE STREAMS ON TUTUILA ISLAND $\ldots \ldots \ldots \ldots \ldots \ldots \ldots \ldots \ldots$

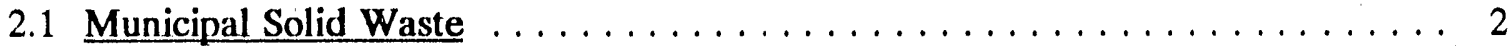

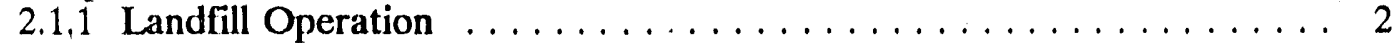

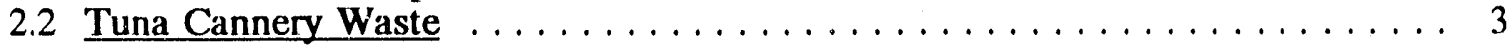

2.2 .1 Ocean Dumping of Tuna Slurge $\ldots \ldots \ldots \ldots \ldots \ldots \ldots \ldots \ldots$

3.0 APPLICATION OF HIGH SOLIDS ANAEROBIC DIGESTION $\ldots \ldots \ldots \ldots \ldots$

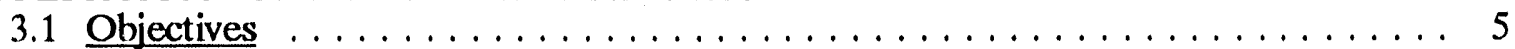

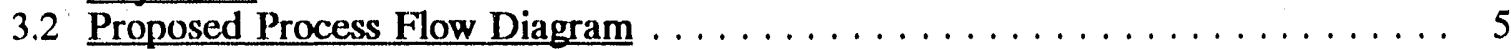

3.3 Biogas Production an $\mathbb{1}$ End Use $\ldots \ldots \ldots \ldots \ldots \ldots \ldots \ldots \ldots \ldots \ldots$

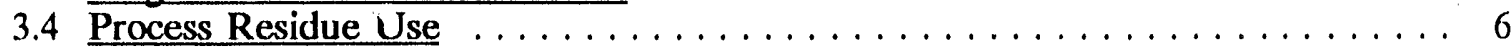

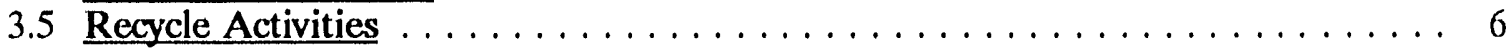

4.0 LOCAL CONSIDERATIONS FOR HIGH SOLIDS APPLICATION . . . . . . . . . 7

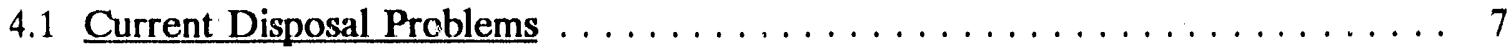

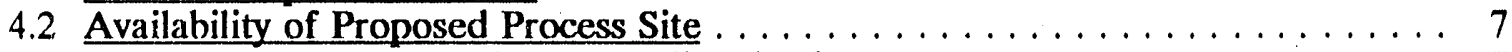

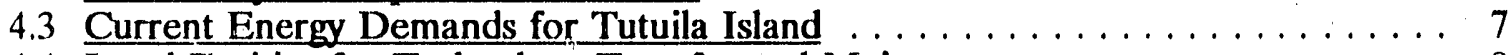

4.4 Local Entities for Technology Transfer and Maintenance $\ldots \ldots \ldots \ldots \ldots \ldots$

5.0 ECONOMIC PROCESS EVALUATION $\ldots \ldots \ldots \ldots \ldots \ldots \ldots \ldots \ldots \ldots$

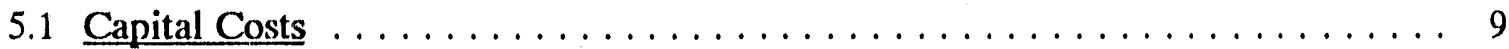

5.2 Revenue Generation . . . . . . . . . . . . . . . . . . . . . . 9

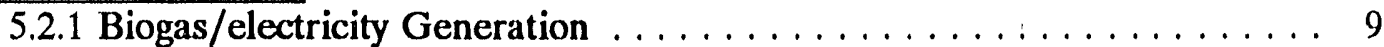

5.2 .2 Process Residue $\ldots \ldots \ldots \ldots \ldots \ldots \ldots \ldots \ldots$

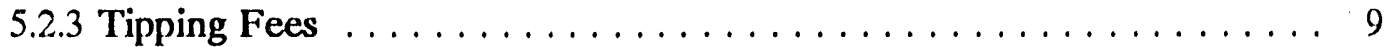

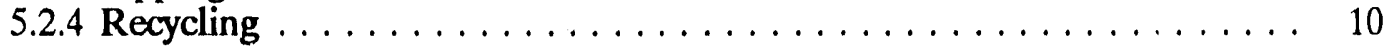

6.0 ADDITIONAL STUDIES REQUIRED $\ldots \ldots \ldots \ldots \ldots \ldots \ldots \ldots \ldots \ldots \ldots \ldots$

6.1 Anaerobic High Solids Digestion Studies $\ldots \ldots \ldots \ldots \ldots \ldots \ldots \ldots \ldots \ldots$

6.2 Process Engineering and Economics $\ldots \ldots \ldots \ldots \ldots \ldots \ldots \ldots \ldots$

6.3 Costs for Proposed Research $\ldots \ldots \ldots \ldots \ldots \ldots \ldots \ldots \ldots$

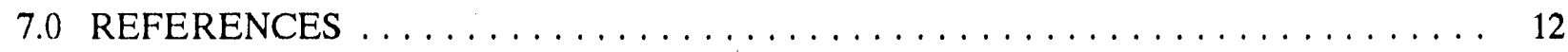

8.0 AMERICAN SAMOA PROJECT CONTACTS $\ldots \ldots \ldots \ldots \ldots \ldots \ldots$ 


\subsection{INTRODUCTION}

Various wastes generated on Tutuila Island, American Samoa, represent both an ongoing problem and an emerging opportunity. Current disposal practices for municipal solid wastes (MSW) involve standard landfill operation. A severe shortage of available land limits this disposal option. The landfill is also not operated under sanitary conditions, due in part to the lack of cover materials, and presents both a health risk and fire hazard. Finally, the landfill is operated without effective compaction, and is therefore dangerous to the operators.

The tuna canneries on Tutuila Island produce the second major waste stream -- tuna sludge from processing operations. The current mode of disposal involves ocean dumping under permit from the U.S. Environmental Protection Agency. However, the current disposal site will be changed from a site 2.5 miles off the coast of Tutuila Island to one 5.0 miles from the island. The change in ocean dumping sites significantly increases the cost of disposal for the canneries. Additionally, ocean dumping of tuna sludge is currently the only approved method of disposal. Without a backup disposal route the canneries and workers face the possibility of lost profit and wages from cannery shutdown due to sludge buildup.

Currently all energy (diesel fuel for generation of electricity) is imported for residential and commercial energy use. No major sources of energy or natural fuel reserves exist in American Samoa.

The combined disposal of MSW and tuna sludge in a process that produces energy and useful byproducts in a cost effective method would therefore be highly beneficial.

Although previous technologies have been proposed for using waste materials to produce energy, these technologies are able to utilize only one of the waste streams and often result in residue materials with uncertain disposal options. The technology developed by the Biotechnology Research Branch of the Solar Energy Research Institute (SERI) represents a possible solution to the combined disposal of MSW and tuna sludges with the production of energy and a useful residue. The application of this technology to Tutuila Island wouli reduce or eliminate the

disposal of MSW in landfill operations and the ocean dumping of tuna sludge, while providing a substantial source of continuous renewable energy. 


\subsection{WASTE STREAMS ON TUTUILA ISLAND}

\subsection{Municipal Solid Waste}

MSW, with the exception of that produced by the tuna canneries, is collected from curbside drums by an independent hauler, $T$ \& $T$ Recycle and Salvage, contracted by the American Samoa Government (Department of Public Works). the contractor has responsibility to haul wastes and manage the landfill. Although the quantity and composition of MSW is known to vary greatly with season and location and although there are no scales appropriate for weighing vehicles to accurately determine the total amount of MSW disposed of on Tutuila Island, the total quantity of wastes was estimated in three different studies and is shown in Table 1, below.

Table 1. Municipal Solid Waste Estimates for Tutuila Island

\begin{tabular}{ccc}
\hline MSW (tons/day) & Reference & Date \\
\hline 87.0 & 1 & 1984 \\
37.4 & 2 & 1988 \\
60.0 & 3 & 1988 \\
\hline
\end{tabular}

Although the estimates for the quantity of MSW wastes generated on Tutuila Island differ, the average value of 60 tons per day is consistent with internal estimates for MSW production per capita ( 4 pounds per person per day times approximately 30,000 people).

The most recent information obtained during the 1990 census places the current population of Tutuila Island at approximately 47,000 people. Therefore, the current estimate for MSW generated and to be processed in the proposed technology is 94 tons/day.

MSW composition varies, although the MSW generated on Tutuila Island is expected to be similar to most U.S. MSW. Therefore, it is estimated to contain $80 \%$ combustibles in the form of paper products and food and yard wastes, and $20 \%$ non-combustibles including glass, aluminum and ferrous metals. One possibly noteworthy difference may be the higher percentage of metal packaging of food and beverages over glass packaging because most food materials are imported.

\subsubsection{Landfill Operation}

MSW disposal has presented a problem to the government of American Samoa for some time. Several studies were conducted to evaluate the practices for MSW disposal, improvements in the operation of the landfill, and alternative technologies to recover energy and reduce loading to the landfill (1-3).

In an independent study funded by the American Samoa Government, Department of Public Works, in June 1988, the lack of landfill capacity was identified as a major concern on the island. Due in part to land ownership rights, the landfill has not been expanded to date. Additional 
problems noted in the study included inappropriate landfill operation methods. The containment of new wastes to sections of the landfill followed by appropriate compaction and application of cover materials would allow for "sanitary" operation. However, on two recent site visits (January and July 1990) the practice of spreading the waste over the entire landfill without proper compaction and cover materials continues. This landfill practice encourages flies and rodents, increases the possibility of fires, and creates uristable footing for vehicles dumping wastes in the landfill. During a site visit to the Star-Kist Cannery, it was reported that the lack of compaction caused a recent accident, in which a company vehicle that hauls solid wastes to the landfill overturned. Severe vehicular damage and driver injury could have occurred.

\subsection{Tuna Cannery Waste}

The tuna canneries, whicn include Star-Kist S: moa Inc. and VCS Samoa Packing Co., have been in operation for some time. During the $1980 \mathrm{~s}$, production outputs have increased for both canneries. Additionally, improvements in recovering of cannery fish byproducts to market them for fish meal have affected the quantity of waste nuaterials generated. Estimates for combined tuna wastes for tuna sludge (generated as a result of dissolved air-floatation [DAF] processing) are shown in Table 2 , below.

Table 2. Combired Tuna Sludge Wastes for Tutuila Island

\begin{tabular}{cccc}
\hline Gallons/year & $\begin{array}{c}\text { Tuna Sludge } \\
\text { Gallons/day }\end{array}$ & Reference & Date \\
$10,003,000$ & 32,258 & 3 & 1988 \\
$12,400,000$ & 40,000 & 4 & 1989 \\
$4,650,000$ & 15,000 & 5 & 1980 \\
\hline
\end{tabular}

* Gallons/day were calculated from the values for gallons/year using a 310 working day estimate.

** Yearly estimates were based on daily averages.

An average tuna slucige production of 40,000 gallons/day is reasonable from the studies reported above ( 4 provides the besi information). The tuna sludge is reported to contain approximately $7 \%$ solids. The tuna sludge nay be further dewatered using belt presses or continuous centrifugation similar to those equipment employed in the dewatering of sewage sludges, to obtain a tuna sludge of $30.35 \%$ solids. Recent discussions with plant managers from both canneries (see American Samoa Project (cntacts), have indicated that the interruption of tuna sludge disposal can be a serious problem. Each cannery has the storage capacity of approximately 1.2 days per volume of tuna sludge. Beyond this capacity, the canneries must shut down as waste effluent exceeds the capacity to store or remove it. A reces example as described in the Honolulu Advertizer, August 4. 1990, has resulted in a third of Tuldila Jslands labor force out of work for more than a week.

BWTEOASCR/jK 


\subsubsection{Ocean Dumping of Tuna Sludge}

The disposal of tuna sludge has an extensive and controversial history $(4,5)$. Up to 1980, tuna sludge disposal involved land dumping at two locations on Tutuila Island. Environmental pollution because of the rupture of an earthen dam, and the loss of life by asphyxiation at the other dumping site discouraged land disposal. Reports of public discontent over odors emanating from transport vehicles used to transfer the tuna sludge from the canneries to the land disposal site using the only roadway on the island were instrumental in developing alternatives to land disposal. The U.S. EPA, after conducting environmental impact studies, permitted the canneries to dispose of the tuna sludge in ucean waters approximately 2.5 miles off the coast of Tutuila Island. However, significant controversy persists over contamination of the reefs surrounding Tutuila Island. Possible violations of the dumping vessel in the sludge dumping location has continued.

A second waste stream produced in tuna cannery operations is referred to as high strength waste waters and are a result of the current DAF dewatering of tuna sludges and process wash waters. Much of the high strength nature of this waste stream is due to the poor separation of solids during the rather antiquated DAF process. Utilizing modern dewatering technology for removal of solids such as belt presses or continuous cent ifugation will serve a dual purpose of greatly improving the solids content of the tuna sludge (important for the economics of the proposed conversion process) while reducing the strength of the remaining waste waters (and subsequent environmental pollution lcad). Although these waste waters are also presently disposed of by ocean dumping, future disposal is planned through the construction of an ocean outfall.

Although actual costs for ocean dumping of tuna sludges are not available it is reported that both canneries use a single vessel which makes two trips to the ocean disposal site per working day. Costs for ocean dumping are estimated to escalate with recent changes in the ocean disposal site from 2.5 miles off the coast of Tutuila Island to 5.0 miles as required in the Final Environmental Impact Statement (4) released in February 1989. 


\subsection{APPLICATION OF HIGH SOLIDS ANAEROBIC DIGESTION}

\subsection{Objectives}

Waste conversion technology for American Samoa should include processes that encompass both waste steams (MSW and tuna sludge), product a useful fuel to reduce reliance upon imported fuel, produce byproducts that are useful or do not pose disposal problems themselves, and are simplistic and stable to operate and maintain. The high solids anaerobic digestion process may be the best overall solution to American Samoa's waste problems.

The piocess of anaerobic digestion has been proven to be effective in red.ucing odors, organic content, and further biological activity of many organic waste streams. Its primary use is in municipal sewage treatment. However, because these waste streams are low in solids content (5\%$8 \%$ ), the reactor design most often employed is the continuously stirred tank reactor (CSTR). Economic evaluation: indicate that the high level of water (which acts as a carrier for the solids) drives tha process costs prohibitively high due in part to the large reactor vessels required, high heating requirements for large vessels, and high stirring or mixing costs. Research at SERI has developed an improved reactor design that has specific applications for feedstocks or wastes that are initially low in water content such as MSW. Laboratory scale reactor systems have been successfully tested on MSW, sewage sludges, and various forms of biomass. The reactor design and process performance is described in references $6-8$.

\subsection{Proposed Process Flow Diagram}

The proposed high solids process would incorporate a standardized sorting and processing section for the raw MSW, followed by a blending section in which the tuna sludge is introduced and mixed with the MSW. The total solids for the blended material are estimated from Figure 1 to be approximately $64 \%$. This material would enter the high solids anaerobic reactor system with a residence time of approximately 14 days. A preliminary mass balance for the process shown in Figure 1 is representative for U.S. MSW. Variation in MSW composition, which may apply to MSW from American Samoa, and digestion of tuna sludge is predicted to be similar, and must be experimentally eximined to derive actual mass flows for the process. Additionally, we have not accounted for minor losses in water vapor content of the biogas in this preliminary process flow diagram.

Upon initial inspection of the size of high solids reactor required (Figure 2), it becomes evident that a sizable volume is necessary for the process flows treated. This reactor volume must be viewed as a starting point from which improvements to the process can be addressed. The tuna sludge wast $\epsilon s$ are presented at solids levels which may be obtained through the use of continuous centrifugation or belt presses for dewatering.

\subsection{Biogas Production and End Use}

The composition of biogas from the anaerobic digestion of MSW is in general $60 \%$ methane and $40 \%$ carbon dioxide. End use of biogas in the United States involves upgrading this medium BTU biogas to $98 \%$ methane using gas selective membrane technology. This high BTU gas is known as synthetic natural gas and is appropriate for use in the natural gas distribution pipeline. However, a system for distribution and use of natural gas is not in place in American Samoa. Electricity is the major utility in place for residential use. Therefore, the conversion of medium BTU gas (biogas) in internal combustion engines with electrical generating sets has the greatest application. 
The electricity may be used in the electrical utility power grid. Preliminary estimates for revenue generated from the production of electricity are shown below. These estimates use values for biogas production from Figure 1, an efficiency estimation of 35\% for the internal combustion engine electrical generating sets, and a value of $\$ 0.08$ per kilowatt hour $(\mathrm{kWh})$.

$$
\begin{gathered}
1,152,705 \mathrm{ft}^{3} \mathrm{biogas} / \text { day }=707,166,212 \mathrm{BTU} / \text { day }=207,200 \mathrm{kWh} / \text { day } \\
207,200 \mathrm{kWh} / \text { day } \cdot 0.35 \text { (efficiency) }=72,520 \mathrm{kWh} / \text { day } \\
72,520 \mathrm{kWh} / \text { day } \cdot 365 \mathrm{day} / \mathrm{yr}=26,469,800 \mathrm{kWh} / \mathrm{yr} \\
26,469,800 \mathrm{kWh} / \mathrm{yr} \cdot \$ 0.08 / \mathrm{kWh}=\$ 2,117,584 / \mathrm{yr}
\end{gathered}
$$

The yearly value for the electricity produced from the high solids anaerobic digestion process is estimated to be approximately $\$ 2.1$ million. This value may change as the price of electricity per $\mathrm{kWh}$ must be negotiated with the American Samoa Power Authority.

\subsection{Process Residue Use}

The residue from the anaerobic digestion process results in approximately $63 \%$ of the loading mass. However, during the process greater than $57 \%$ of the solids are converted to the biogas endproduct. Of the remaining solids, the majority are inert or non-biodegradable. Because of the near complete conversion of biodegradable materials and low moisture content, the residue materials are stable and relatively odor free. The high solids digestion process also results in a residue with a $\mathrm{pH}$ of $7.8-8.4$. This $\mathrm{pH}$ reduces the risk of any odors due to residual volatile fatty acids present in the residue. As native soils in American Samoa are characteristically within a pH range of 5.5 - 6.5 (personal communication, American Samoa Land Grant) the addition of residue may serve to neutralize the soils $\mathrm{pH}$. A preliminary assessment of the use of this residue material at the Land Grant experimental agricultural test site is suggested.

Although agriculture is not a major industry in American Samoa, a demand still exists for fertilizers and ground cover materials for residential use (personal communication, Land Grant). Residents of American Samoa currently obtain partially digested municipal sewage solids, which are made available free to the public by the waste water treatment works for residential landscaping purposes. Additionally, on the nearby islands, which include Western Samoa, substantial agricultural industries do exist. These industries may represent a market for this fertilizer residue as a ground cover material.

\subsection{Recycle Activities}

Recycling of waste metals from cannery operations, the shipyard, and from large residential discards has not been economic on Tutuila Island because of the relatively low volume produced in relation to shipping costs for transportation to recycling centers off the island. The landfill designated for metal disposal has been closed with few avenues of disposal available. Through the sorting and separation of non-biodegradable materials from the MSW waste stream, the total arnount of recycled metals may be sufficient to warrant aggressive recycling of metals. 


\subsection{LOCAL CONSIDERATIONS FOR HIGH SOLIDS APPLICATION}

\subsection{Current i isposal Problems}

At present, both the MSW and tuna cannery wastes constitute a major disposal problem for American Samoa. As discussed above, the current disposal method for the MSW generated on Tutuila Island is by landfilling. However, with the capacity of the current landfill decreasing rapidly and unsafe landfill operation practices, an alternative disposal method is required. It is not envisioned that there will be public opposition to the use of anaerobic digestion technology. In fact, effectively converting the MSW to energy and soil amendment products, increasing the viability of recycling programs, and creating new jobs as a result of this technology will cause favorable public attitudes.

The change in disposal of Tuna cannery wastes from ocean dumping to araerobic digestion conversion technology should also result in positive public attitudes. With concern over the pollution of the e ivironment, and contamination and destruction of the delicate reef system that borders the island, the change in disposal practices may invoke positive public attitudes. The canneries may also benefit because this land-based technology may reduce costs for disposal (which are to increase because of a change in dumping site from 2.5 miles to 5.0 miles off shore). Additionally, utilizing the proposed conversion technology provides for a backup system for tuna sludge disposal (ocean dumping) which is currently not available. The existence of a backup disposal system will reduce the chances of discontinuous cannery operations due to tuna sludge disposal.

\subsection{Availability of Proposed Process Site}

Availability of land for developing the proposed technology is a primary concern. In past technology project proposals, two sites have been examined. The proposal that considered the combustion of MSW to produce electricity proposed a site located near the power plant at Tafuna near the airport (1). This site is appropriate for the Anaerobic Digestion technology considered here if the tuna sludge can be transported without public awareness and concern. The second site takes into account the problems with tuna sludge transportation and suggests a location close to the canneries (5).

In discussions within the American Samoa Project contacts, the only legitimate site is one close to the canneries with consideration for the odorous nature of the tuna sludge and the current state of congestion of the main roadway to be traveled. Although this location is essentially fully utilized, several sites have been proposed subject to approval in which 1.2 and greater acres may be available.

Additional concepts such as locating the technology on a floating platform/station in the harbor may not be practical with the significant harbor traffic and occasional ocean storms prevalent in American Samoa.

Although selecting the site is of prime importance to the development of any waste-to-energy facility, it is anticipated that a suitable solution may be reached if the interested parties meet to discuss the issues and options.

\subsection{Current Energy Demands for Tutuila Island}

BWTEOAS.CR/JK 
The electrical energy demands for Tutuila Island are supplied by the American Samoa Power Autl ority (ASPA), using diesel powered electrical generating systems. The current power demand for Tituila island is approximately 10-12 MW with a peak demand of $16 \mathrm{MW}$. The diesel fuel used is imported as American Samoa has no natural fuel reserves. This dependence on foreign fuel supplies weakens the American Samoa economy through the unfavorable balance of trade. Renewabie energy technology may therefore serve to strengthen the American Samoa economy and reduce the dependence on foreign fuel supplies.

\subsection{Local Entities for Technology Transfer and Maintenance}

The transfer of technology from off-island interests to native operations on American Samoa has proved to be problematic in the past. However, several local entities both governmental and private industry may be appropriate to assume the operation and maintenance of this technology past the installation and performance testing stages. Significant expertise and professionalism in the management of electrical power generation and distribution and water and wastewater services has been demonstrated by the American Samoa Power Authority (ASPA). Alternatively, VCS Samoa Packing Co. may also provide effective operation ability as this tuna cannery currently has extensive experience in energy production through the operation of their own private electrical generators for power. Finally, a private firm with past experience in waste-to-energy technology may be found within the pacific rim region to manage the ongoing operation. 


\subsection{ECONOMIC PROCESS EVALUATION}

It is premature to develop a meaningful econonic evaluation for the anaerobic digestion technology for Tutuila Island before the biological performance studies have been conducted and the site selected. However, projected costs and revenues are discussed.

\subsection{Capital Costs}

Although in-depth process engineering is required to accurately determine the cost of the technology application to American Samoa, a preliminary cost estimate for the overall process may be in the neighborhood of $\$ 16$ million. However, cost estimates are also directly affected by the location of installation, process performance evaluation with actual wastes and site availability and preparation.

\subsection{Revenue Generation}

The following areas of revenut generation using the technology may be appropriate for consideration as briefly discussed below.

\subsubsection{Biogas/electricity Generation}

As discussed in an earlier sect...n, the biogas product may be most easily utilized through the immediate production of electricity in internal combustion engine electrical generating set using the biogas as-is as a medium BTU gas. The value of the electricity generated was estimated as approximately $\$ 2.1$ million with the purchase rate determined from discussions with ASPA. The actual revenue is subject to changes reflected as a function of the negotiated fixed price for continuous power with ASPA during the time of technology implementation. Additionally, a substantial amount of waste heat is generated which may not be completely utilized in maintaining the fermentation reactor systems at a constant optimum temperature. This heat may therefore be available to the canneries and have an as yet unknown value.

\subsubsection{Process Residue}

In the United States the residue derived fiom the anaerobic digestion of organic materials (anaerobic composting) depending upon the location, may have a significant value. Often this material is packaged and marketed to the landscaping industry. Alternatively, the fertilizer value (yet to be determined for the combination of tuna sludge and MSW) may be significant in agricultural areas or in regions which lack adequate topsoil (as is the case in American Samoa).

\subsubsection{Tipping Fees}

Tuna Sludges. It is estimated that the combined costs for oce : d dumping of tuna sludges is on the order of $\$ 500,000$ per year. As the tuna sludge is converted in the proposed technology and an ocean outfall is constructed for the high strength waste waters, the need for ocean dumping will be eliminated. Additionally, the proposed technology will establish a continuous disposal route for the tuna sludge with the ocean dumping option still available as a backup disposal option. Currently, no backup system is available for tuna sludge disposal and when ocean dumping is temporarily unavailable, the canneries must shut down with severe effects upon both cannery profits and island workers incomes. A tipping fee will be assessed of both canneries based upon the quantities of sludge disposed. The combined yearly fee for cannery tuna sludges may approach $\$ 400,000$. 
MSW. In the mainland US a tipping fee (US average $\$ 40 /$ ton) is assessed MSW entering landfills or waste-to-energy operations for disposal. This tipping can be significant (US Northeast $\$ 80$ $\$ 250 /$ ton) where the availability of landfills or disposal options are limited. This revenue is ultimately derived from the residential consumer in the form of refuse collection fees. However, in American Samoa, costs for collection, hauling, and operation of the landfill are paid by the government. The current yearly estimate for MSW costs are approximately $\$ 320,000$ through a contract with private industry (T \& T Salvage). Costs for operation of the landfill will be reduced as the MSW is rerouted to the proposed conversion technology site. The avoided costs for operating the current landfill may be considered as a tipping fee for operation of the waste-toenergy technology.

5.2.4 Recycling. As mentioned previously, the recycle of less valuable scrap metals (iron) may be economically advantageous in light of the higher recovery from the MSW waste stream through the sorting and separation processing involved in the proposed technology. Enough scrap metal may be produced that a modest income may be produced. Much of the aluminum is currently recycled by the residential sector with the remainder physically removed during landfill operation by the private hauling contractor. In the proposed technology the sorting and separation phase of MSW handling will more efficiently remove aluminum and therefore derive additional income and more complete recycling efforts. 


\subsection{ADDITIONAL STUDIES REQUIRED}

To thoroughly develop effective cost and mass flow balances for the anaerobic digestion technology as it is applied to MSW and tuna sludge wastes on Tutuila Island, several key studies must be undertaken.

\subsection{Anaerobic High Solids Digestion Studies}

Several anaerobic digestion studies are required with the actual waste materials to determine the parameters for accurate process engineering plans and economic evaluation. The current preliminary values for the proposed process in this report are derived from SERI studies conducted with actual MSW from the mainland United States. The composition of MSW on Tutuila Island may be different, and tuna sludge is being introduced as a feedstock for the digestion process. Several important studies are required.

- Compositional analysis of representative samples of American Samoa MSW and tuna sludges.

- Biological methane potential (BMP) studies are used to determine the maximum level of degradation that is possible for a particular feedstock. The values for biogas production and extent of degradation are used as an ultimate value to assess the effectiveness of the real time process.

- High solids digestion studies using our laboratory scale reactors and the actual waste materials from American Samoa will allow the process dynamics to be examined. Adcitionally, representative residue will be produced for evaluation in American Samoa by the Land Grant Institution as a soil amendment on their experimental test garden.

\subsection{Process Engineering and Economics}

Evaluation of the site and site preparation costs, ability to further dewater the tuna sludges, analysis of digestion rates for the actual waste materials (MSW and tuna sludge), and identification of markets and revenues for electricity, process residue, recycling, and tipping fee charges for MSW and tuna sludges will allow an accurate process engineering design and economic evaluation to be conducted.

\subsection{Costs for Proposed Research}

Costs for anaerobic digestion studies are projected at $\$ 70,000$ with completion in $6-8$ months. Process engineering and economic evaluation costs are projected at $\$ 30,000$ with completion three months past the digestion studies. 


\subsection{REFERENCES}

1. "Municipal Solid Waste Energy Conversion Study," March 1984. Burret, Harris, and Assoc., DOE Contract No. DE-AC03-83SF11958.

2. "Review of Solid Waste Management in American Samoa," June 1988. Stearns, Conrad, and Schmidt Consulting Engineers, Inc., American Samoa Government, Dept. of Publis: Works, Contract No. 28734.

3. "Industrial and Household Waste Treatment for American Samoa," 1988. SEDEP Report.

4. "Final Envirunmental Impact Statement for the Designation of an Ocean Disposal Site off Tutuila Island, American Samoa for Fish Processing Wastes," February 1989, U.S. EPA, Region 9, San Francisco, CA.

5. "Final Report on the Economic Feasibility of Producing Methane Gas From Bioconversion of Tuna Cannery Waste," Sept. 1980, Action Resources Inc., DOE/American Samoa Government Contract No. CM-273-79.

6. Rivard, C.J., M.E. Himmel, T.B. Vinzant, W.S. Adney, C.E. Wyman, and K. Grohmarn, 1989, "Development of a Novel Laboratory Scale High Solids Reactor for Anaerobic Digestion of Processed Municipal Solid Wastes for the Production of Methane," Appl. Biochem. Biotech. 20/21, 461-478.

7. Rivard, C.J., M.E. Himmel, T.B. Vinzant, W.S. Adney, C.E. Wyman, and K. Grohmann, 1990, "Anaerobic Digestion of Processed Municipal Solid Waste Using a Novel High Solids Reactor: Maximum Solids Levels and Mixing Requirements," Biotech. Lett. (submitted).

8. Rivard, C.J., T.B. Vinzant, W.S. Adney, and K. Grohmann, 1990, "Anaerobic High Solids Fermentation of Feedstocks from the Western Regional States for the Production of Methane," Final Report for Western Area Power Administration, Biomass Program Office. 


\subsection{AMERICAN SAMOA PROIECT CONTACTS}

Mr. Matt T. Le'i

Territorial Energy Office

Samoa Energy House, Tafuna

American Samoa Government

Pago Pago, American Samoa 96799

Ms. Sheila Wiegman

Office of the Governor

Environmental Protection Agency

American Samoa Government

Pago Pago, American Samoa 96799

Mr. Ross Fleming

Plant Engineering/Maintenance

Star-Kist Samoa Inc.

P.O. Box 368

Pago Pago, American Samoa 96799

Mr. John E. Perry

Plant Engineering Manager

VCS Samoa Packing Co.

P.O. Box 957

Pago Pago, American Samoa 96799

Mr. Perelini S. Perelini

Chief Engineer

American Samoa Power Authority

P.O. Box PPB

Pago Pago, American Samoa 96799

Mr. Richard Volk

Office of the Governor

Development Planning Office

American Samoa Government

Pago Pago, American Samoa 96799

Mr. Larry Hirata

Land Grant

American Samoa Community College

P.O. Box 2609

Pago Pago, American Samoa 96799 


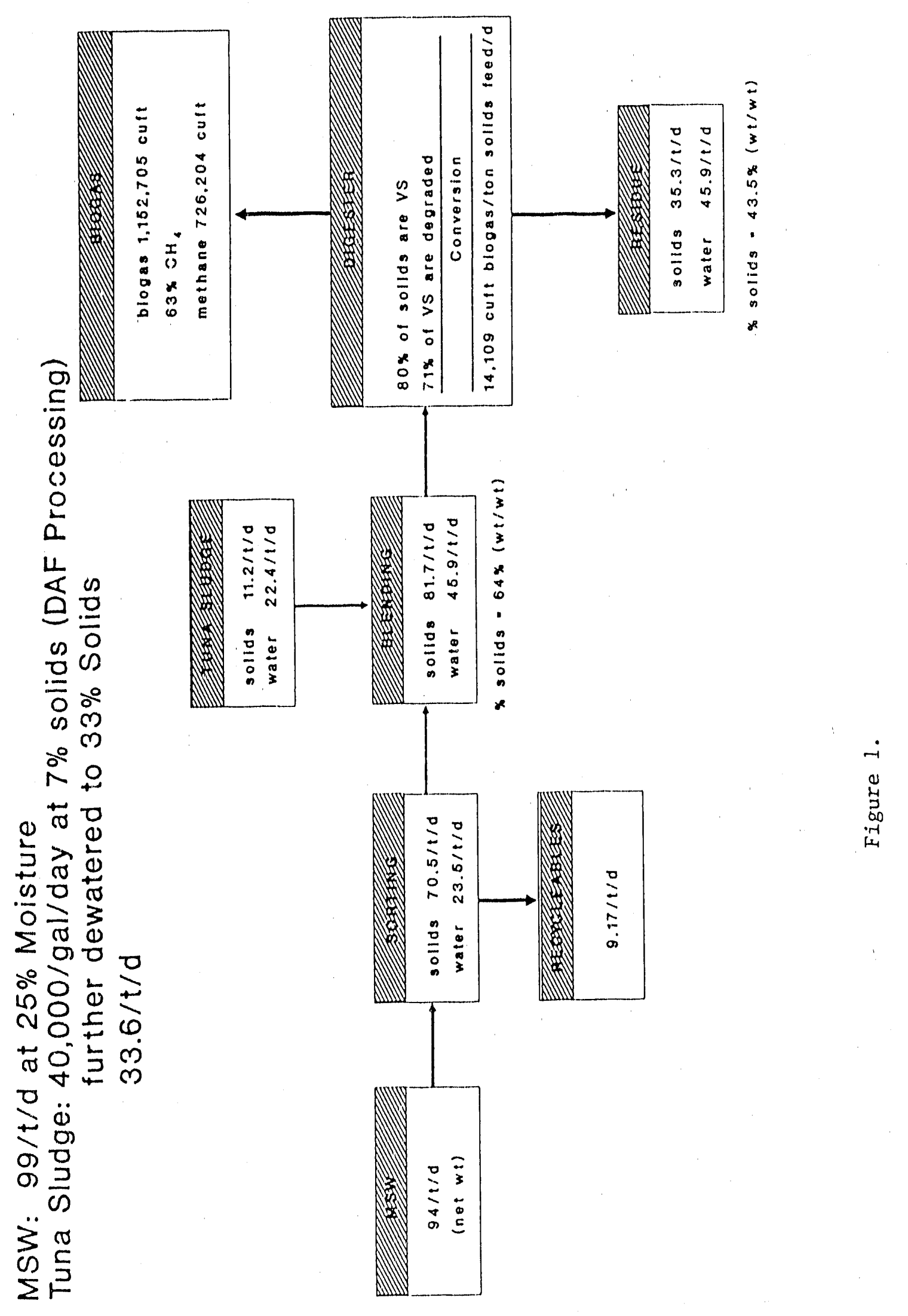




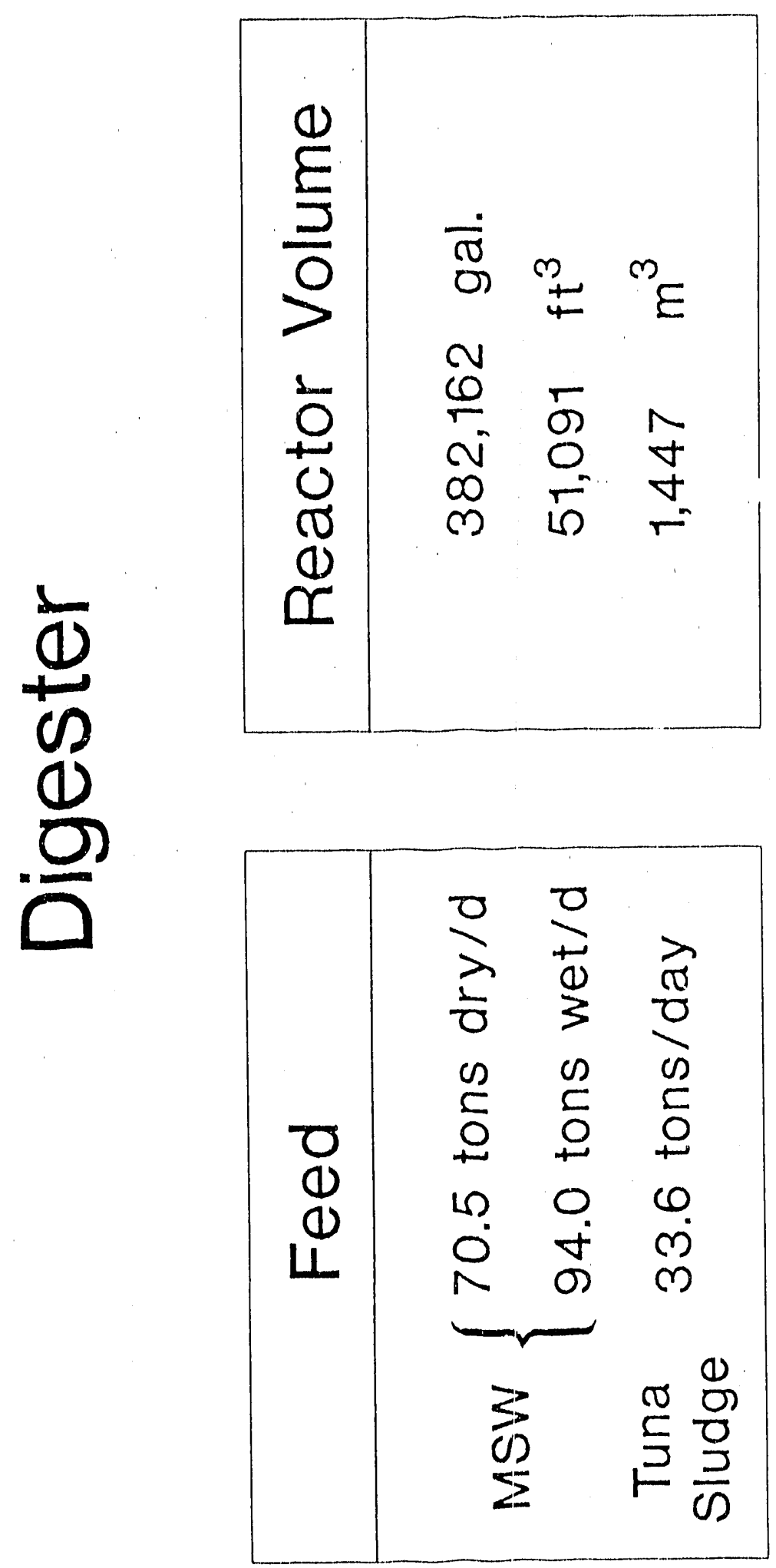




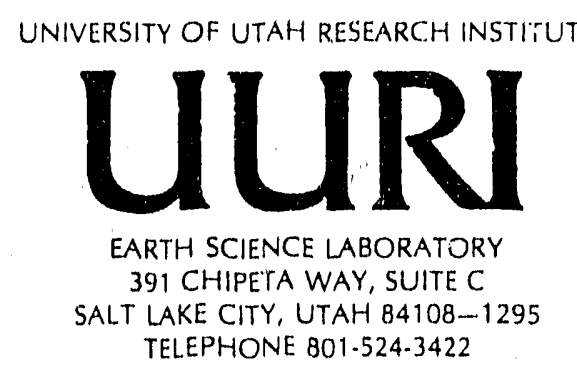

February 7,1990

Dr. John W. Shupe, Director

Pacific Site Office

U. S. Department of Energy

PO Box 50168

Honolulu, HAWAII 96850

Dear John:

I appreciate the opporiunity to comment on the possibility of geothermal development on American Samoa. I believe that there is significant potential for the occurrence of a geothermal resource there, and I recommend that we proceed with means to include a geothermal option in the REPOA. I have commented on the programs recommended by others for your benefit, and have suggested a program for your consideration. I will be happy to work further with you on this interesting project.

Sincerely.

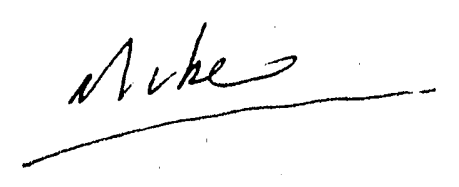

Phillip M. Wright Technical Vice President 


\section{RECOMMENDED EXPLORATION PROGRAM \\ GEOTHERMAL ENERGY DEVELOPMENT \\ ON AMERICAN SAMOA}

\section{INTRODUCTION}

That American Samoa has significant, but unquantified, potential for the occurrence of geothermal resources is essentially beyond question. Documentation of historic eruptions on these volcanic islands means that shallow crustal heat sources exist. Water to provide fluid for a hydrothermal system occurs in abundance in the ocean. The other essential ingredient is fracturing to form a plumbing system for the circulating hydrothermal water. This is the ingredient whose existence and nature are unknown on American Samoa.

It is typical in volcanic terranes in areas of high rainfall for surface manifestations of underlying hydrothermal convection systems to be suppressed by the downward flow of meteoric water. We know that volcanic piles usually have significant vertical permeability. This is especially true in basaltic piles such as those that characterize oceanic islands because the eruptions are usually quiescent in nature and comprised of flows and ash falls. Explosive eruptions, such as the one at Mt. St. Helens in Washington in 1982, deposit hot ash that consolidates into welded tuffs that can limit vertical permeability. However, these explosive eruptions are not characteristic of basaltic oceanic volcanism. Thus, we can expect to have to drill to depths of 3,000 or maybe more in order to test the underlying thermal regirne.

COMMENTS ON EXPLORATION PROGRAMS PREVIOUSLY RECOMMENDED BY OTHERS

I have reviewed the following exploration programs previously recommended to PSO:

1. Keller and Grose, 1980;

2. KRTA, 1986 with an update in 1989; and,

3. Olson, 1989.

I would like to make a few candid comments on each of these programs.

1. Keller and Grose recognized the need for more detailed geologic mapping. which is critical to any exploration program. I do not agree that a minimuin program of exploration should include self-potential and gravity surve' ing, however. The self-potential (SP) method has indeed yielded anomalies due to subsurface flow of water in some geothermal areas. However, in the majority of cases, no clear interpretation of the results in terms of the existence or nature of any 
underlying geothermal system is possible. SP surveys will almost invariably show anomalies, $r$ ut due to the many possible causes, not all of $w$ hich have anything to do with hydrothermal convection, geologic and hydrologic interpretations will be highly nonunique. I would rarely spot a test drill hole on an SP anomaly.

Gravity surveys can also be helpful in certain circumstances, but they lack the ability to detect hydrothermal activity in anything but the most indirect way. Gravity may detect underlying basaltic dikes, as Keller and Grose suggest, but I believe the problem is more in detecting subsurface permeability than in finding heat sources. In addition. gravity surveys would be quite expensive in this environment of steep, vegetated terrain. For precise work, gravity surveys require leveling surveys to deternine the elevations of the stations to within about 0.1 foot. Station density would have to be high to decrease the risk of misinterpretation of the results.

Soil mercury surveys may be useful, as Keller and Grose suggest. This could best be judged after reconnaissance and detailed geologic mapping. Keller and Grose also mention the possibility of microseismic studies and airborne infrared imaging. Microseismic studies are very expensive, but can yield information of active subsurface faulting, needed to keep permeable pathways open. However, microseismicity if highly episodic. One should count on operating a net of six to ten stations on Tutuila for six months minimum to obtain results useful in locating faults with enough definition to form a drilling target. Airborne infrared imaging may be useful as Keller and Grose suggest to identify suboceanic flows of hot water exiting laterally from a hydrothermal convection system. This may be advisable at a late stage in the program.

2. My main criticism of the KRTA program is that they apparently recommend drilling of large, production-sized wells immediately after the surface exploration program. We at UURi would rarely recommend this course of action, and probably would never recommend it in the absence of surface manifestations of hydrothermal activity such as fumaroles, geysers and hot springs. Large-diameter wells are very expensive, especially in this remote location. The program recommended by KRTA has three chances of locating a resource, one at each well. I believe for the same amount of money, the odds of success can be essentially doubled by drilling slim core test holes to gather information for siting a production well. This is the course of action that the U.S. industry is taking in its exploration of such volcanic areas as the Cascade range in the northwestern United States, which also lacks surface manifestations around most knuwn heat sources. 
3. The program recommended by Olson is close to the one that I recommend. My main criticism of Olson's program is that it could be shortened to 3 years or maybe less. We could do the surface exploration during the first year, the heat-flow/thermal-gradient drilling the second year and a production test well the third year.

\section{RECOMMENDED EXPLORATION PROGRAM}

We recommend a four-stage program to discover a geothermal resource on the island of Tutuila.

Stage 1 -- Geologic Mapping. This stage would consist of geologic mapping and reconnaissance geochemical sampling. The main objectives of geologic mapping would be (1) to identify and determine the configuration of the various rock types, (2) to determine the relative ages among them and (3) to determine the nature and location of geologic structures. Geologic structures such as rift zones and calderas control hydrothermal systems in known ways, and their mapping is essential to any further exploration. It would be accomplished by two geologists with the part-time assistance of a geochemist, and would take about three months to complete. The product would be a geologic map of the $50 \mathrm{mi}^{2}$ island at a scale of 1:50,000 (or other scale depending o.n available maps) suitable for planning subsequent surface exploration and drilling.

Stage 2 -- Surface Exploration. Following the geologic mapping, and guided by the results, a program of surface exploration would be carried out. The primary survey for this stage would probably be some form of electrical geophysical survey. Hydrothermal convection systems affect the electrical properties of rocks in a number of ways. Electrical conductivity is increased by hot, saline fluids circulation in a permeable area and by the clay and zeolite minerals that form when hydrothrrmal fluids react chemically with the reservoir rocks. The objective of the surface electrical survey would be to locate areas of high subsurface conductivity. The survey would be carried out by a crew of two geophysicists and two technicians, who could be local labor. We anticipate that electrical surveying would take about 2 months to complete and one more month to interpret completely, although preliminary interpretations could be made more quickly.

During the second stage, any soil geochemical work would also be carried out. Depending on the resultsi of the geologic mapping, we may recommend a soil mercury survey to help determine the locations of open faults and fractures. Work done by UURI on several geothermal systems, including the volcanic-hosted system at Zunil in Guatemala, indicates that mercury often marks the location of open faults. It is these open faults that would be the targets for drilling. 
During the second stage, it may also be advisable to perform a detailed aeromagnetic survey. UURI performed such surveys in the volcanic-hosted geothermal system at Los Azufres in Mexico and on Ascension Island in the South Atlantic Ocean, and we found that these surveys are of material assistance in locating and mapping geologic structures. This may be of help on Tutuila, where vegetation could obscure structures and make geologic mapping difficult.

Stage 3 -- Gradient Well Drilling. The problem identified by others of the possibility of down-flowing meteoric water obscuring heat anomalies coming from depth is a real problem in the volcanic environment. The objective of this stage is to locate an area of high subsurface geothermal gradient in order to site a production-sized well.

In the Cascades province, UURI has been associated as technical advisors to DOE for a program of cost-shared drilling with geothermal developers. Four core holes were drilled under the DOE program, and at least three developers (California Energy Company, Santa Fe Geothermal and GEO Operator Corporation) have drilled at least 10 other coreholes on their own. All of this drilling has been with core rigs to depths of 3,000 to 5,000 feet to obtain core samples of the subsurface and measure geothermal gradients. We have found that holes to at least 3,000 feet are often required to get beneath the zone of down-flowing meteoric water and measure a temperature gradient representative of deeper levels.

An Ascension Island, UURI drilled 7 thermal gradient coreholes and used the results to locate a deep, 10,000-foot production-sized test well that intercepted temperatures of $470 \circ \mathrm{F}\left(240{ }^{\circ} \mathrm{C}\right)$. The meteoric downflow problem was not so severe on Ascension, but was still significant in a number of areas.

The main reason for drilling slim coreholes for thermal gradient measurement in advance of spotting production-sized wells is to decrease the costs and risks of the exploration program. If the gradient drilling does not succeed in locating anomalous subsurface temperatures and hydrothermal minerals indicative of a hydrothermal system, one has spent significantly less money than if one had proceeded directly to large-diameter holes, and the program can be stopped. If an area of high thermal gradient is located, a deep, production-sized hole can be spotted with much less risk of failure.

Stage 4 -- Production Well Test. At this stage, a large drill rig is mobilized and a production-sized test well is drilled. The objective of this stage is to test the temperature-gradient anomaly found in Stage 3 and to encounter production of geothermal fluids. Drilling could be 
accomplished in one year, including mobilization of a drill rig, if all goes well. Frequently, however, projects of the magnitude of a largediameter well take longer than hoped.

The well diameter at the bottom of the hole will typically be 9 $5 / 8$ inches. A full oil-well rig is needed for this kind of drilling and the costs are high. Costs at the time of drilling would depend on the availability of rigs and the world oil drilling activity -- the drillers charge whatever the traffic will bear. An additional important consideration is the port facilities. On Ascension, for example, the dock cranes were not capable of lifting the components of a drill rig as one is ordinarily broken down. UURI had either to locate a rig that could be broken down into smaller components or locate a landing craft that could take large components up the beach. We settled for a helicopter-transportable rig that we located 1,000 miles up the Amazon river.

If the drilling is successful, a production test of the well would be necessary. This would be accomplished by a consulting reservoir engineering firm, who may have some of the equipment needed.

\section{ESTIMATED COSTS FOR RECOMMENDED EXPLORATION PROGRAM}

Stage 1 -- Geologic Mapping.

Stage 2 -- Surface Exploration.

Resistivity survey

Soil-mercury survey

Aeromagnetic survey

Stage 3 -- Gradient Drilling

6 Coreholes -- 24,000 ft total at $\$ 125 / \mathrm{ft}$

Mobilization/demobilization

Stage 4 -- Production Test Drilling

1 ea $6,000 \mathrm{ft}$ well

Mobilization/demobilization

TOTAL
$\$ \quad 40,000$

50,000

20,000

40,000

$3,000,000$
100,000

$1,100,000$

650,000

$\$ 5,000,000$ 


\title{
PROSPECTS FOR WIND ENERGY IN AMERICAN SAMOA
}

\author{
Dennis L. Elliott \\ Pacific Northwest Laboratory \\ January 30,1990
}

\section{WIND RESOURCE}

A preliminary wind energy resource assessment of American Samoa was prepared by PNL. The wind resource maps, which are shown in Figures 1 through 3 , provide estimates of annual average wind power classes. The wind power classes are defined in Table 1, in relation to the mean wind power density at a height of $10 \mathrm{~m}$ above ground. Qualitative descriptors of the wind power classes are also given. Wind power class 4 is generally considered good for most applications, and class 3 is useful for many applications. Class 2 is marginal but may be suitable for some specific applications such as water pumping.

The annual average wind speed distribution is approximated using a Weibull $k$ (shape factor) value in the range of 2.2 to 2.4 . For this range, wind power class 4 corresponds to mean wind speeds from 5.8 to $6.3 \mathrm{~m} / \mathrm{s}$ at a height of $10 \mathrm{~m}$ above ground, and class 3 to mean speeds from 5.3 to $5.8 \mathrm{~m} / \mathrm{s}$.

Areas estimated to have class 4 or greater annual average wind resource occur in scattered locations on Tutuila Island and the Manua Islands. These areas are mostly ridge crests and coastal points that are well exposed to the prevailing strong trade winds from the east. The maximum wind resource occurs June through October; this period has about 20 to $30 \%$ higher average wind power density than the annual average.

Prevailing winds are from the east, with the most frequent directions being east and east-southeast, respectively. Easterly winds are most persistent and strongest during the windy season from June to October, during which winds are from the easterly sector (southeast to northeast) almost $90 \%$ of the time. On an annual basis, winds are from the easterly sector almost $70 \%$ of the time.

Surface wind data are available for three locations in American Samoa Pago Pago Airport and Cape Matatula on Tutuila Island, ana near the village of Ofu on Ofu Island. NOAA operates the data collection systems at all these locations. The mean annual wind speed at the Pago Pago Airport, for the period 1972-78, was $4.8 \mathrm{~m} / \mathrm{s}$ at a height of $8.5 \mathrm{~m}$ (date from PNL's U.S. Wind Resource Atlas). For the site on Cape Matatula, the mean wind speed for 1987 was $5.9 \mathrm{~m} / \mathrm{s}$ at a height of $14 \mathrm{~m}$ (data from NOAA report). The data from the anemometer site on ofu have not been summarized. We anticipate the mean wind speed is relatively low at this site, because it is located on the leeward (sheltered) sicie of the island. In addition to these three sites, summaries of ship-based wind observations are available for offshore areas in the vicinity of American Samoa. The mean annual wind speed for the offshore areas was $5.7 \mathrm{~m} / \mathrm{s}$. 
Upper-air wind data from the Pago Pago Airport are useful in estimating the free-flow wind resource at elevated terrain features such as ridge crests. Mean annual wind speed at the 950-mb pressure level, which corresponds to a height of about $450 \mathrm{~m}$, is $6.7 \mathrm{~m} / \mathrm{s}$. Monthly mean wind speeds at this height during the windy season of June through October range from 7.3 to $8.1 \mathrm{~m} / \mathrm{s}$.

\section{STATUS OF WIND TURBINES IN AMERICAN SAMOA}

Three small-sized wind turbines have been installed in Americari Samoa. One was an Enertech $3.5-\mathrm{kW}$ model installed in the early $1980 \mathrm{~s}$ as a demonstration unit on the grounds of the Territoria? Energy office (TEO) located in the Tafuna industrial park near the airport. The turbine has since quit operating and replacement parts are not available, since Enertech is no longer in business. The TEO would like to replace the Enertech with another small-sized wind turbine (about $1 \mathrm{~kW}$ ) to be used as a demonstration unit. The turbine could be munted on the existing 60-ft tower, which appears to be in good condition.

A North Wind HR2 wind turbine, manufactured by Northern Power Systems (NPS), was installed in September 1986 at the KVZK TV translator station located on Tumu Mountain on the island of ofu. In addition to the wind turbine, which was rated at $3 \mathrm{~kW}$, a $400-W$ PV system was also installed. Five months after the station was operational, in January 1987, a devastating cyclone with winds estimated at over $200 \mathrm{mph} \mathrm{hit} \mathrm{the} \mathrm{island} \mathrm{and} \mathrm{destroyed} \mathrm{the} \mathrm{system} \mathrm{-}$ tower, PV's, and electronics were "totalled". The HR2 alternator was salvaged and eventually repaired.

A North Wind HR3 wind turbine was ordered to replace the HR2 (the HR3 model is essentially the updated version of the HR2 model). The HR3 was placed in service in May 1988. Four problems were noted with the operation of the HR3.

1) A field brush failure occurred after 9 to 10 months, but replacement of brushes was covered by the warranty. NPS comments that typical field brush wear is over two years now, and it is possible they had a bad brush.

2) Blade tip erosion was noticed after 9 to 10 months. NPS colnments that blade tip erosion can be overcome with stainless steel leading edge tape, which they offer.

3) The front main bearing went bad after 1 year of operation. NPS comments that the bearings do go bad if not greased.

4) The VARCS shaft rusted after 1 year of operation. NPS comments that the rusty VARCs did not cause a problem other than the way it looks and is a cosmetic problem only. Stainless steel shafts are available from NPS.

After the HR3 bearing failure, the TV station attempted to install the previous HR2 alternator (which had been repaired) but the HR2 alternator would not fit or. the HR3 saddle. New alternator bearings and stainless steel VARCs shafts were ordered for the HR3, and the it was scheduled to be placed back in service 
in January 1990. NPS recently supplied (December 1989), at no charge, new spring hubs for interchangeability of the HR2/3 alternators.

The wind turbine was the primary power source for the TV station, and winds were sufficient enough that the wind turbine and PV system provided adequate power for the batteries to keep the three translators operating at full power. Without the wind turbine, the TV station's operation has been quite limited. The TV station requires 200 amp-hours (Ah) per day to operate at full power under the current program. The existing PV system delivers a maximum of 123 Ah on a bright sunny day. In cloudy weather, it will deliver only $30 \%$ to $50 \%$ of this, or about 40 to 60 Ah per day. Cloudy conditions (sunrise to sunset) are prevalent about $75 \%$ of the time on an annual basis in American Samoa (NOAA Climatological Data for Pago Pago Airport). The TV station would like to install additional PV sufficient to operate at full power using PV. They estimate an additional $1200 \mathrm{~W}$ of PV may be needed, considering the prevalent cloudy conditions. They plan to re-install the HR3 wind generator for backup power or for additional capacity if they decide to change the current program. Plans for use of the HR2 alternator were not revealed.

NPS notes that their wind turbines have successfully operated for years without problems in other areas of the world with similar atmospheric conditions. In their product literature, NPS states that the North Wind HR series wind turbines have logged more than 2.5 million hours of operation--many at sites in harsh environments--with system availability exceeding $99 \%$. Due to the design of the wind turbine, the installation environment appears to have little or no effect on availability. In regard to other similar sites in tropical, salt-water environments, NPS provided as an example an HR2 on Hawaii installed by Hawaiian Electric. The wind turbine operated with no problems for two years running a beacon light. After two years, the electric company brought in a utility line and took the wind turbine out of service.

\section{PROSPECTS FOR FUTURE APPLICATIONS}

Many prospective areas have been identified throughout the islands of American Samoa where the wind resource is estimated to be sufficient for various types of potential applications using wind energy. Such applications might include use of medium- to large-size wind turbines for utility gridconnected power or use of small-size wind turbines at remote sites that require relatively small loads and are not connected to the utility power. For many remote applications where power is required on an everyday basis, use of hybrid systems (such as wind/PV) may be more advantageous and economical than use of a single type of power system. For example, the wind resource at many prospective sites in American Samoa is estimated to be good during the nighttime as well as during the daytime, whereas PV is strictly a daytime resource. During prolonged periods of cloudy weather, which occur quite frequently in American Samoa, PV output is quite low but wind energy is not dependent on the cloud cover. However, luils of several days may occur occasionally in the wind resource, when it may be necessary to depend on PV or some other power source to get through the duration of the lull. Of course, the size and characteristics of the battery storage system become very important in this regard. 
As medium- and large-size wind turbine designs are increasingly becoming more efficient and reliable, wind energy costs for utility-scale applications are decreasing and are projected to continue to decrease over the next 5 to 10 years. On the other hand, costs of diesel-generated power will most likely increase over the next 5 to 10 years. A recent DOE report has estimated wind energy costs at a site with an average wind speed of $5.8 \mathrm{~m} / \mathrm{s}(13 \mathrm{mph})$ in the range of 6.1-9.3 cents/kWh, which is lower than today's energy costs in American Samoa. It is estimated that American Samoa has sufficient land area with an average wind speed of at least $5.8 \mathrm{~m} / \mathrm{s}$ to provide many megawatts of wind power. Moreover, the advanced wind turbines being developed could be almost ideal for small-grid networks because their design is to produce highquality power and circumvent power-factor control problems. Therefore, utility grid-connected wind power should be given serious consideration as an alternative energy source in the near future. Wind energy can be placed in service relatively quickly; if the price of diesel fuel were to escalate considerably in the near future, relative speed of installation could be important.

The electric utility power in American Samoa is completely supplied by diesel power plants. The peak power load on Tutuila Island was about $15 \mathrm{MW}$ in 1983 and is projected to be $20 \mathrm{MW}$ by 1996 and $25 \mathrm{MW}$ by 2003. New generating equipment and upgrading or replacing present facilities will be required to meet the increased power needs. Fuel consumption averaged about $700,000 \mathrm{gal} /$ month in 1988, and fuel consumption efficiency averaged $11.5 \mathrm{kWh} / \mathrm{gal}$. Fuel costs in 1988 varied by $26 \%$ over a low-to-high range. Such extreme price movements translate into fluctuations in the fuel adjustment charge on customers' monthly bills. The fuel adjustment charge is calculated, in part, with reference to the prevailing fuel costs. American Samoa's remote location and its complete dependence on imported fossil fuels greatly complicates the electric utility's financial planning since fuel price instability on world markets is strongly felt in the territory. Base rates assessed by the utility in 1988 ranged from $\$ 0.07 / \mathrm{kWh}$ to $\$ 0.09 / \mathrm{kWh}$. Fuel adjustment charges in 1988 varied from $\$ 0.05 / \mathrm{kWh}$ to $\$ 0.08 / \mathrm{kWh}$. With fuel adjustment charges added, the actual power rates in 1988 varied from about $\$ 0.12 / \mathrm{kWh}$ to $\$ 0.17 / \mathrm{kWh}$. Essentially all populated areas of American Samoa are served by utility feeder lines.

Suitable wind sites exist that should enable a large fraction of the power needs to be supplied by wind energy. Some prospective sites are located near existing utility lines. One of the most suitable areas on Tutuila Island is in the southwestern part of the island, where ridge crests and elevated areas between Aoloaufau and Futiga are estimated to have good wind resource potential and are not far from existing roads and utility lines. Ridges between Futiga and Steps Points also appear quite suitable. Of course, site measurement data would be required to verify the resource estimates and to optimize the site selection.

The most immediate need for an alternative power source is on the island of Tau. An 8-mile feeder line on Tau connects the Faleasao power plant in the northwest part of the island to the village of Fitiuta in the northeast part of the island. The 8-mile feeder line experiences large line losses and frequent outages of considerable duration due to high winds. The peak load for the entire island of Tau is in the range of $250 \mathrm{~kW}$, and it is estimated that 
the peak load for Fitiuta is about $60 \mathrm{~kW}$. However, a new airport for Tau is under construction near Fitiuta, which will result in substantially increased loads. Because of the large line losses on the 8-mile feeder line, the power plant has problems supplying the peak loads at Fitiuta, which will be compounded after the airport is opened for service. It is estimated that the airport load will be around 10 to $20 \mathrm{~kW}$. An alternative power supply is needed to keep the airport operational during power outages and to supplement the line power during peak loads. PNL's wind resource assessment indicates that this part of the island (the northeast corner) is estimated to have good wind resource potential (power class 4 to 5), although site data should be collected to verify these estimates. Wind energy could be a viable, economical alternative if the wind resource is found to be sufficient. 


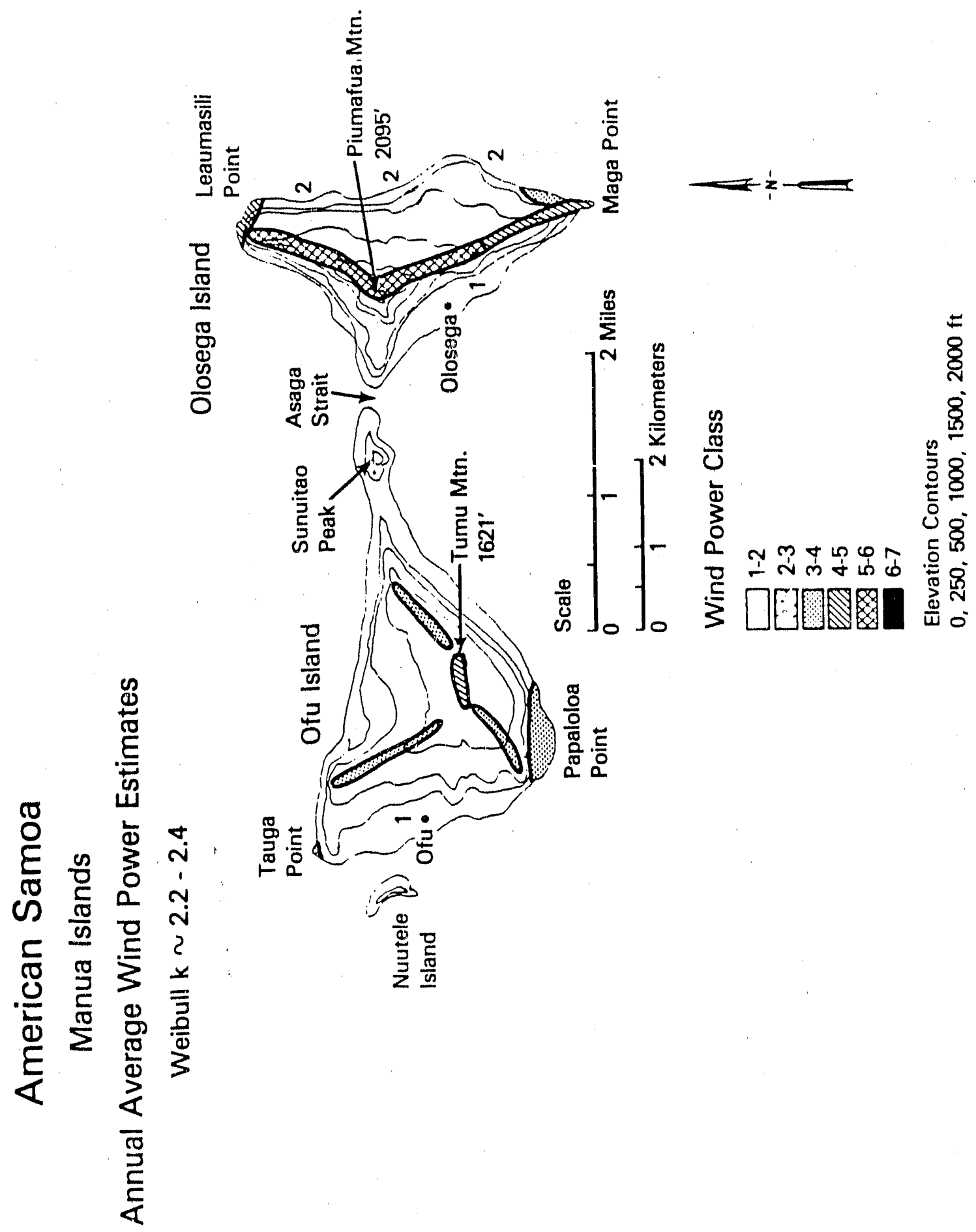

D-6 

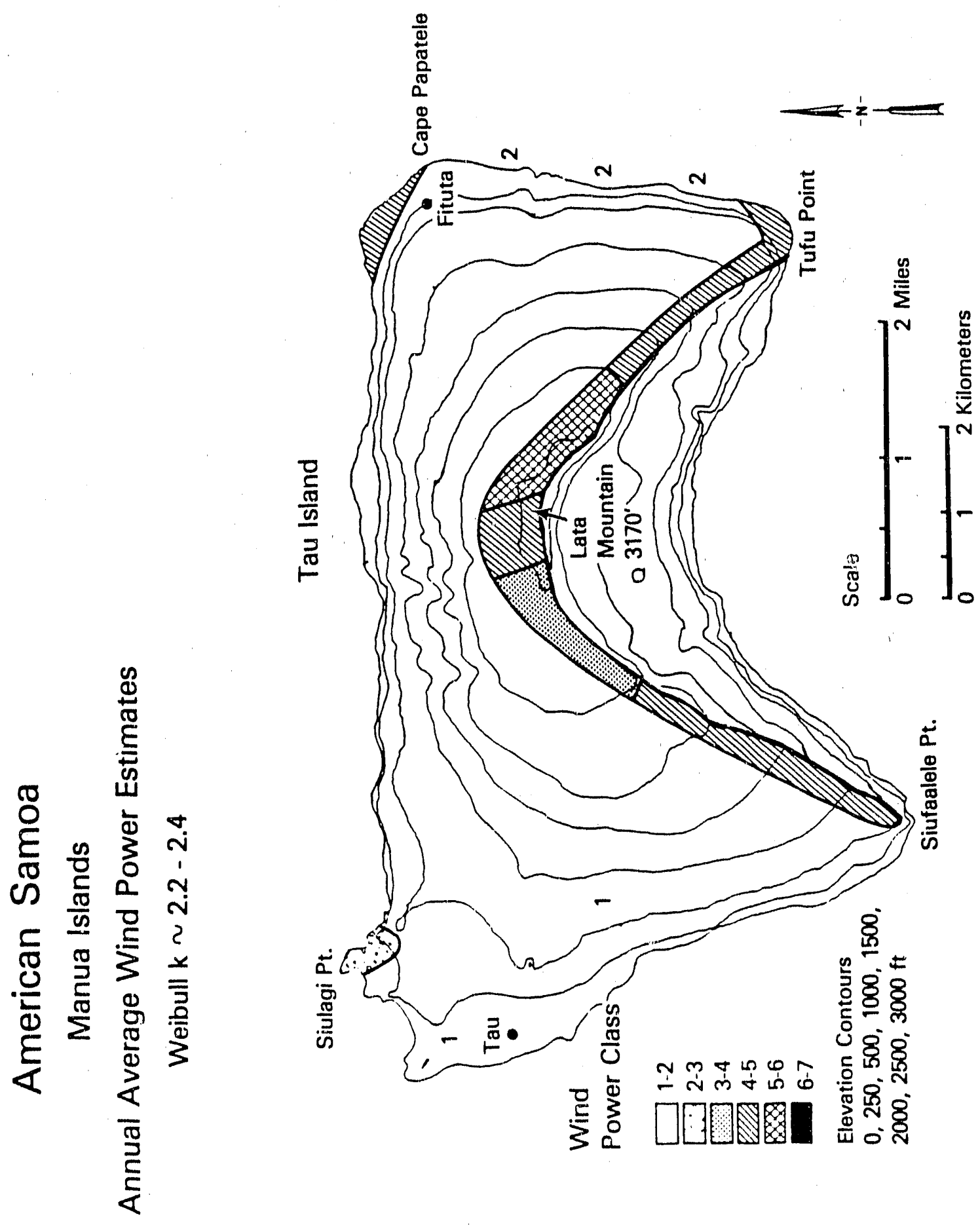


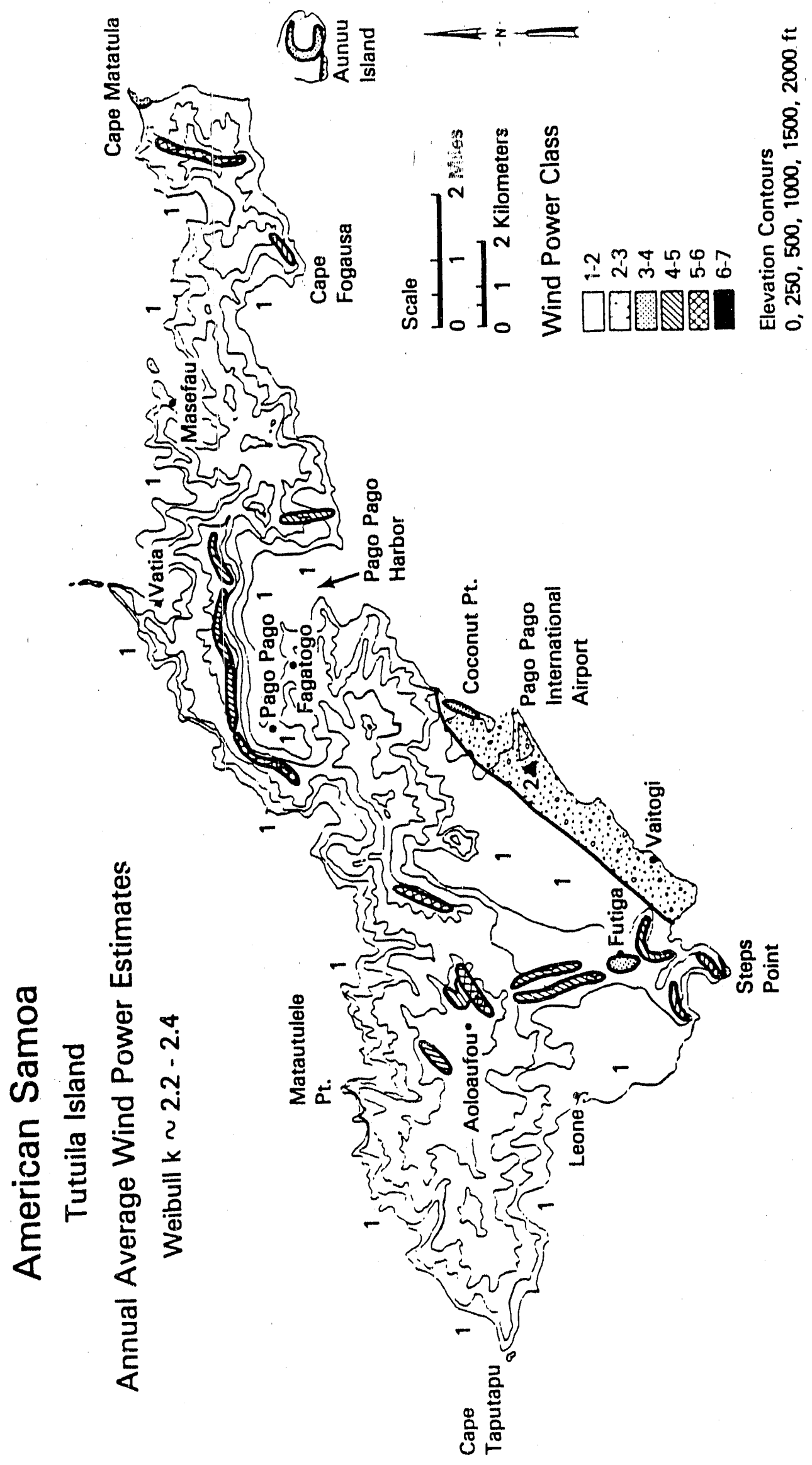




\title{
PRELIMINARY EVALUATION OF POTENTIAL OTEC SITES
}

Prepared by
A. Trenka
E. Udui

\begin{abstract}
APRIL 1990
Pacific International Center FOR

HIGH TECHNOLOGY RESEARCH (PICHTR)

HONOLULU, HAKAII
\end{abstract}


The report, "Preliminary Evaluation of Potential OTEC Sites: Bathymetry and Feasibility 1 , " and accompanying technical report ${ }^{2}$ provide data and analysis to assist the Commonwealth of the Northern Mariana Islands and the Territories of Guam and American Samoa to determine the technical and economic feasibility of proceeding with further establishment of Ocean Thermal Energy Conversion Technology as part of their renewable energy programs.

In 1981, the Northern Marianas, Guam and American Samoa Governments were interested in the potential of Closed-Cycle OTEC for their islands and carried out extensive work in preparing a Solicitation ( Solicitation \# DEPN01-80CS80000) to the U.S. Departmeni of Energy for the design, construction and operation of an OTEC plant. The Northern Marianas Government included a generic description of the OTEC technology and a summary of the data available for Puntan Hagman, but pointed out the lack of bathymetric data (ocean depth as a function of distance from the shoreline) necessary as a first step for determining the length required for the pipe to draw the cold water from the deep ocean. This pipe is referred to as the cold water pipe (CWP). Similar proposals were developed for American Samoa and Guam.

This analysis represents an essential step in evaluating the feasibility of OTEC for these three islands. It provides the detailed bathymetric information required before any further technical and economic evaluation of installing a land-based OTEC plant can be performed and estimates the capital investment necessary for a land-based site in each of the islands. It should be noted that the economic analysis performed by PICHTR is conservative based on a

\footnotetext{
1Nihous, G., Uoui, E, Vega, L. "Preliminary Evaluation of Potential OTEC Sites: Bathymetry and Feasibility." Prepared for the Commonwealth of the Northern Mariana Islands under Contract C549994-01 with the U.S. Department of Energy Territorial Assistance Program. Honolulu: PICHTR. December 1989.
}

2Noda, Edward K. and Associates. "Bathymetry Surveys of Potenial OTEC Sites in American Samoa, Guam and the Commonwealth of the Northern Mariana Islands." Prepared for the Pacific International Center for High Technology Research. Honolulu: PICHTR. August 1989. 
realistic assessment of the cost of installing the first OTEC plant of its kind. As with any new technology, once it has been proven and established, costs are expected to decrease.

\section{THE OTEC CONCEPT}

Ocean thermal energy conversion (OTEC) technology is based on the principle that energy can be extracted from two reservoirs at different temperatures. A temperature difference as low as $20^{\circ} \mathrm{C}\left({ }^{36} \mathrm{~F}\right)$ can be exploited effectively to produce usable energy. Temperature differences of this magnitude prevail between ocean waters at the surface and at depths up to 1,000 meters $(3,300$ feet) in many areas of the world, particularly in tropical latitudes between 24 degrees north and south of the equator. Here, surface water temperatures typically range from $22^{\circ} \mathrm{C}$ to $29^{\circ} \mathrm{C}\left(71.6^{\circ} \mathrm{F}\right.$ to $\left.84.2^{\circ} \mathrm{F}\right)$ while temperatures at a depth of 1,000 meters $\left(3,300\right.$ feet) typically range from $4^{\circ} \mathrm{C}$ to $6^{\circ} \mathrm{C}\left(39.2^{\circ} \mathrm{F}\right.$ to $42.8^{\circ} \mathrm{F}$ ). This constitutes a vast, renewable resource for baseload power generation. PICHTR has concentrated on two OTEC power cycles for converting this thermal energy to electrical energy, namely, closed cycle (CC-) OTEC and open-cycle (OC-) OTEC.

In a closed-cycle system warm seawater is used to vaporize a working fluid such as ammonia flowing through a heat exchanger (evaporator). The vapor expands at moderate pressures, and turns a turbine. The vapor is condensed in another heat exchanger (condenser) using cold seawater pumped from the ocean's depth through a cold water pipe. The condensed working fluid is pumped back to the evaporator to repeat the cycle. The working fluid remains in a closed system and is continuously circulated.

In an open-cycle system, warm seawater is the working fluid. The warm seawater is "flash" evaporated in a vacuum chamber at an absolute pressure of about 2.4 kilopascals $(\mathrm{kPa})$, after which it expands through a low-pressure turbine coupled to a generator to produce electricity. The vapor exiting the turbine is condensed by using cold seawater pumped from the ocear's depths through a cold water pipe. If a heat exchanger (surface condenser) is used, the condensed steam remains separated from the cold seawater and provides a supply of desalinated water. 
Effluents from either a closed-cycle or open-cycle system can be further processed to enhance production of desalinated water through a flash evaporator/condenser system in a second stage.

The evolution of OTEC has paralleled that of many innovative technology development programs. Initial efforts defined the potential feasibility and markets for numerous options. This was followed by baseline designs, computer simulation, laboratory-scale tests, and engineering-scale experimental verification. PICHTR's current work in OTEC includes site identification and analysis as well. The major remaining constraint is the confirmation of research data in the actual operation of a prototypical plant. Until that time, the Pacific Island Governments are advised to continue to monitor the development of OTEC.

\section{FEASIBILITY OF OTEC}

In evaluating the feasibility of a land-based OTEC plant for the Pacific Islands, one major cost is the construction and deployment of the cold water pipe. Furthermore, this cost is directly linked to the length of the pipe, which in turn is determined by offshore bathymetry characteristics and the temperature of the deep, ocean waters. Depending on the length of the pipe, its cost could represent approximately $30 \%$ to $40 \%$ of the total cost of the OTEC plant. This makes an offshore bathymetric survey, such as the ones conducted for Puntan Hagman, Saipan, Commonwealth of the Northern Mariana Islands; Cabras Island, Guam; and Fatuasina Point, Tutuila, American Samoa, one of the most important input data in evaluating the feasibility of the site and the cost of OTEC power. Figure 1 shows the bathymetric profiles for the three islands.

Using data from the bathymetric surveys, the total length of the piping system needed to bring the cold deep ocean water to the plant from various depths was determined, Costs for the various pipe configurations were assessed and incorporated into a capital cost estimate for various jizes of land-based OTEC plants. One, ten, and forty MWe net power outputs were selected for comparison as these sizes correspond, respectively, to the smallest commercial size plant for island communities, the size previously proposed 
by the Northern Marianas in its 1981 Solicitation, and, the size which could be competitive with existing oil-fired technologies considering the current price of fossil fuels.

For example, a 1 MWe Open Cycle OTEC plant would cost around $\$ 25$ to $\$ 28$ million. Current capital costs for a diesel fired plant of the same size would be about $\$ 750,000$ to $\$ 1$ million. However, capital costs are misleading for comparisons of OTEC with conventional power technologies, such as diesel. OTEC requires a large initial capital investment and no subsequent fuel expenses, as seawater is "free." Conventional power plants require relatively low capital investment, but the cost of fossil fuel is significant, and more importantly, its price is not controlled by Pacific Island Governments. The operational costs for both technologies (excluding fuel) are similar.

A technique, called "levelized cost", which spreads costs and revenues over a plant's operational life is commonly used by the power industry to compare the costs of new technologies.

For the example given above of a 1 MWe Open Cycle OTEC plant with an 850 $\mathrm{m}$ long pipe, "levelized cost" would be 41 cents per $\mathrm{kWh}$ for Guam; 34 cents per kWh for American Samoa and 39 cents per kWh for Saipan. These costs can be reduced, if the revenue from the sale of OTEC desalinated water ${ }^{3}$ is included, and will range from: 27 cents to 35 cents per kWh for Guam; 19 cents to 27 cents per $\mathrm{kWh}$ for American Samoa and 24 cents to 32 cents per kWh for Saipan.

In 1990, these costs compare unfavorably with the costs of production of power in the three islands which range from 3.5 cents per $\mathrm{kWh}$ to 6 cents per $\mathrm{kWh} .4$

Nevertheless, when the "levelized costs" for the larger 40 MWe Closed Cycle OTEC plant are calculated, we show the following values for the $850 \mathrm{~m}$ depth:

\footnotetext{
${ }^{3}$ Fresh water credit is based on a production of 160,000 kilogallons per year at unit prices ranging from $6 \$ / \mathrm{kgal}$. to $1.5 \$ / \mathrm{kgal}$.

4 Integrated Electric Utiity Workshop, Saipan, May 1989.
} 
Guam, 12 cents per kWh; American Samoa 11 cents per kWh; Saipan 12 cents per $\mathrm{kWh}$. When fresh water revenue is produced by addition of a desalination unit, the price for electricity production (deducting fresh water revenue), drops to 4 cents per $\mathrm{kWh}$.

OTEC has not yet been implemented by industry or government because the present low price of petroleum allows conventional power plants to produce electricity at lower costs.

\section{CONCLUSION}

The PICHTR study provides information on the bathymetry at selected locations: Puntan Hagman, Saipan, Northern Mariana Islands; Cairas Island, Guam; Fatuasina Point, Tutuila, American Samoa. This data can be used to assist Pacific Island Governments to determine if they should proceed further with the establishment of Ocean Thermal Energy Conversion Plants in their islands.

The study indicates that OTEC does not appear to be immediately applicable in these islands because of high capital costs of OTEC and low fuel costs for conventional technologies. Government Energy Officers are advised to continue monitoring advances in the field as well as projected fuel costs for current power plants and the cost and availability of fresh water. Because the Pacific Islands are most likely to be the initial market entry point for OTEC, this technology should not be overlooked by Governments planning their energy future because of its major benefits--energy self-sufficiency and minimal environmental impact. 

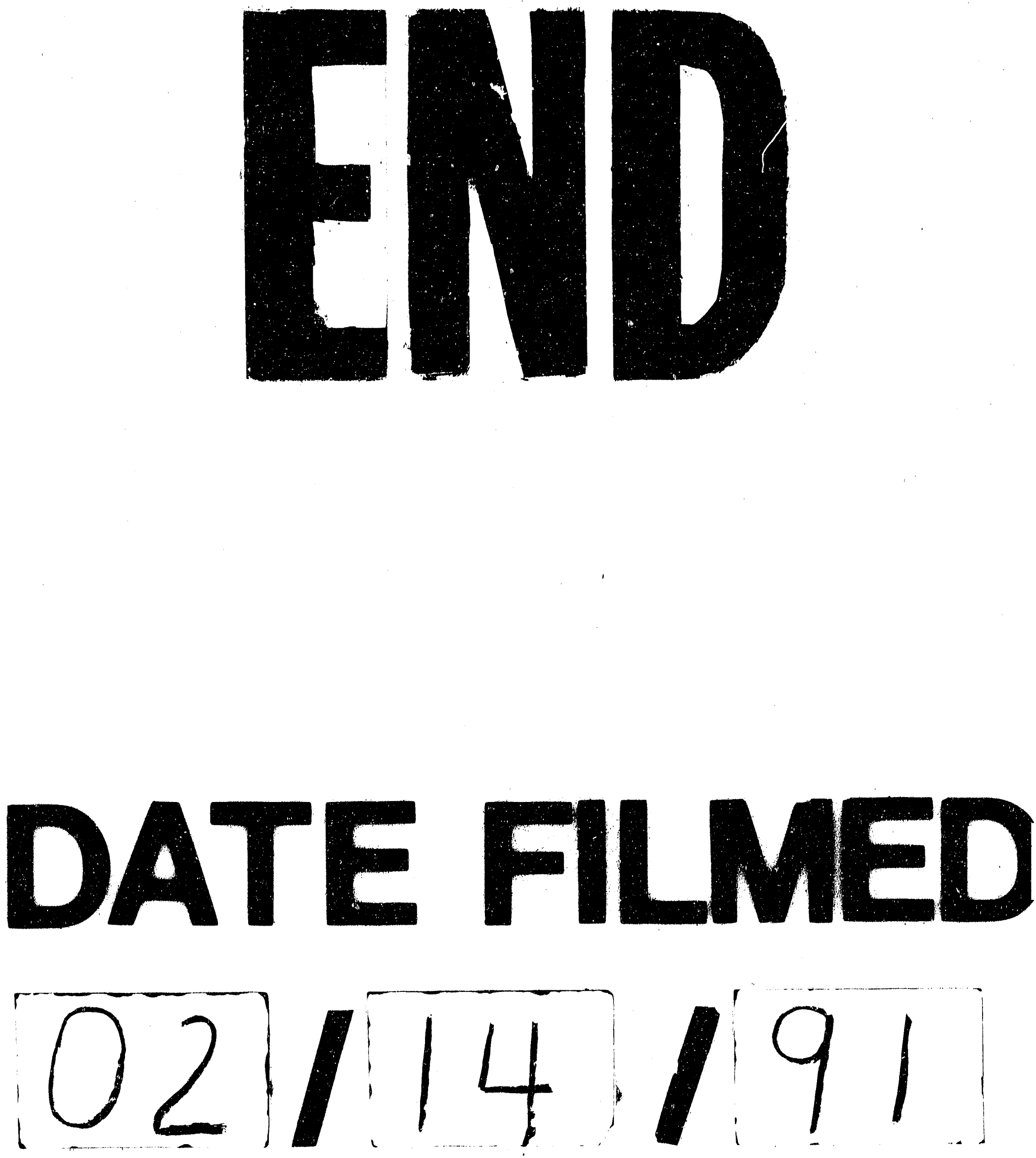
